\title{
Desenvolvimento e avaliação psicométrica da Escala de Seguimento de Jogadores: uma medida de evolução para jogadores patológicos em tratamento
}


Aos meus pais 


\section{Agradecimentos}

Agradeço às seguintes pessoas que contribuíram para a realização deste projeto:

Meu orientador, Hermano Tavares, pela dedicação e paciência inigualáveis ao orientar e transmitir seus conhecimentos e pelo seu imprescindível esforço para a fundação e o crescimento do AMJO, que hoje realiza belíssimo trabalho.

Arthur Guerra de Andrade, Mônica Levit Zilberman e Jorge Henna pelas valiosas contribuições e críticas feitas no exame de qualificação, levando ao aprimoramento do trabalho e acréscimo em meus conhecimentos.

Meus pais, Diógenes e Geni, pelo incentivo constante, pelo apoio em todos os momentos e pelas incontáveis revisões deste texto.

Minha irmã, Cecília, pelas imensas disponibilidade e generosidade em doar seu tempo para me auxiliar nas tarefas mais cansativas deste trabalho.

Toda a equipe do AMJO que com dedicação presta assistência aos pacientes e dá vida ao ambulatório, sem o qual este trabalho seria impossível, e que participou diretamente nas entrevistas.

A Pós-graduação do Departamento de Psiquiatria que acreditou neste projeto e permitiu que ele fosse realizado, e seus prestativos funcionários que deram todo o suporte necessário. 
A CAPES pelo apoio através da concessão de verba de auxílio à pesquisa destinada a este projeto.

Aos pacientes e seus familiares que, dispondo-se a prestar informações íntimas e valiosíssimas, participaram da realização deste trabalho. Agradeço a oportunidade de poder contribuir com os resultados desse esforço para ampliar o conhecimento e auxiliá-los no difícil processo de adoecimento.

Aos amigos que compreenderam minhas ausências durante o período de realização deste projeto e continuaram a me apoiar. 
Esta dissertação está de acordo com as seguintes normas, em vigor no momento desta publicação:

Referências: adaptado de International Committee of Medical Journals Editors (Vancouver)

Universidade de São Paulo. Faculdade de Medicina. Serviço de Biblioteca e Documentação. Guia de apresentação de dissertações, teses e monografias. Elaborado por Anneliese Carneiro da Cunha, Maria Julia de A. L. Freddi, Maria F. Crestana, Marinalva de Souza Aragão, Suely Campos Cardoso, Valéria Vilhena. $2^{\mathrm{a}}$ ed. São Paulo: Seviço de Biblioteca e Documentação; 2005.

Abreviatura dos títulos dos periódicos de acordo com Lists of Journals Indexed in Index Medicus. 


\section{SUMÁRIO}

\section{Dedicatória}

\section{Agradecimentos}

\section{Lista de tabelas}

\section{Lista de siglas}

\section{Resumo}

\section{Summary}

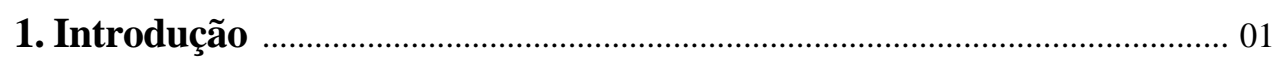

$1.1 \quad$ Jogo Patológico e impacto funcional ................................................................... 01

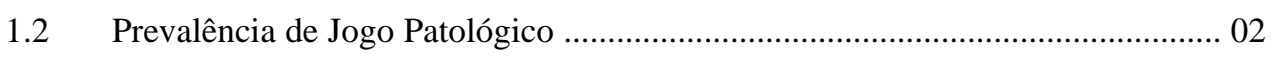

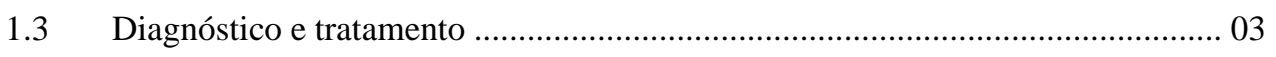

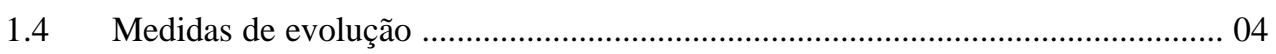

1.4.1 Validade e confiabilidade de uma escala .................................................. 05

1.4.2 Medidas de evolução em Jogo Patológico ………………………........... 07

1.5 A Escala de Seguimento de Jogadores (ESJ) ………………………................ 09

1.5.1 Escala de Seguimento de Jogadores $-1^{\text {a }}$ versão ....................................... 09

1.5.2 Escala de Seguimento de Jogadores - 2 ${ }^{\mathrm{a}}$ versão ........................................ 13 


\section{FASE 1}

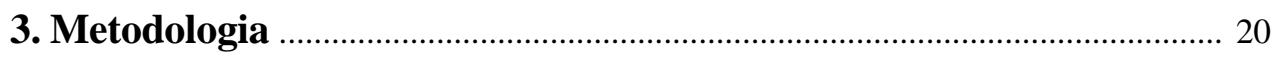

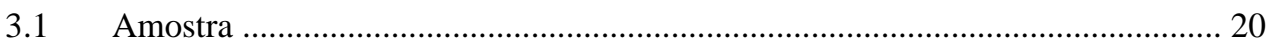

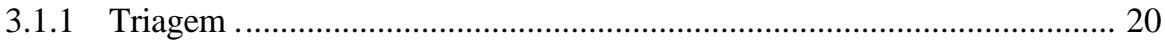

3.1.1.1 Critérios de inclusão .................................................................. 20

3.1.1.2 Critérios de exclusão .................................................................. 21

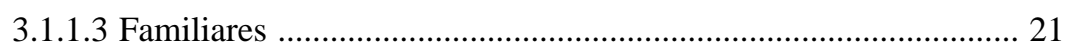

3.1.2 Intervenção terapêutica ........................................................................ 22

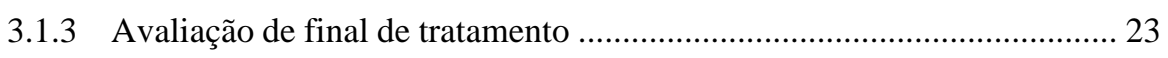

3.2 Entrevistas e aplicação das escalas ................................................................... 24

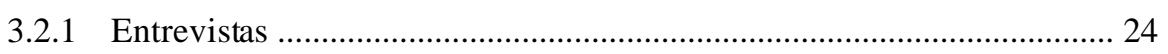

3.2.1.1 Questionário de dados sócio-demográficos ................................. 24

3.2.1.2 Critérios diagnósticos para Jogo Patológico segundo o DSM-IV 25

3.2.1.3 Addiction Severity Index - Gambling (ASI-jogo) ........................ 27

3.2.1.4 Timeline follow-back method (TFB) .......................... 28

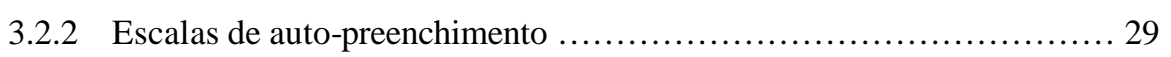

3.2.2.1 South Oaks Gambling Screen (SOGS) .......................... 29

3.2.2.2 Escala de Seguimento de Jogadores .............................................. 30

3.2.2.3 Gambling Symptom Assessment Scale (G-SAS) ........................ 30

3.2.2.4 Escala de Adequação (EAS) ...................................................... 31

3.2.2.5 Escala de Seguimento de Jogadores adaptada para informante

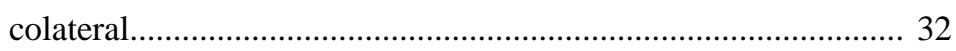




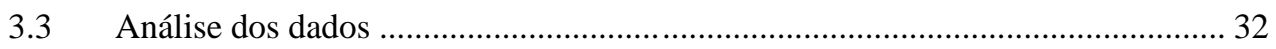

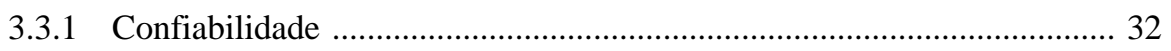

3.3.2 Validação cruzada .................................................................................. 33

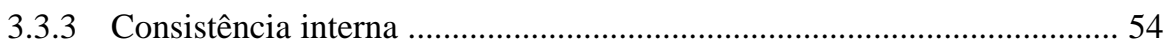

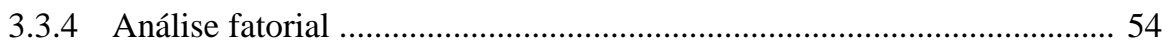

3.3.5 Sensibilidade à mudança no tempo .......................................................... 54

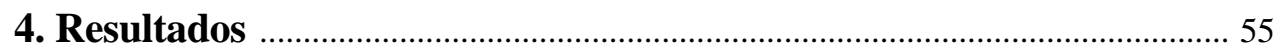

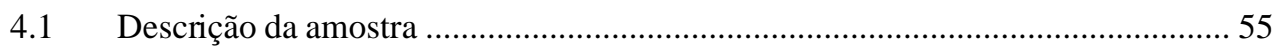

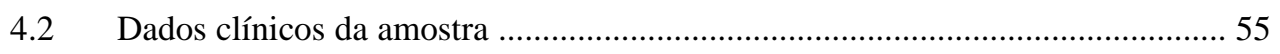

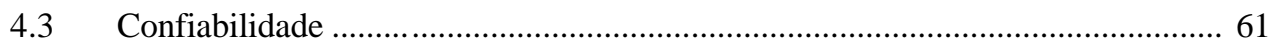

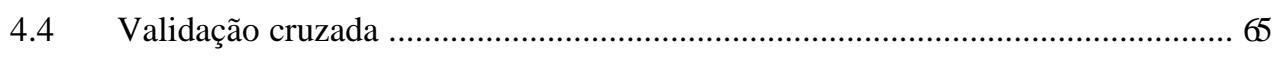

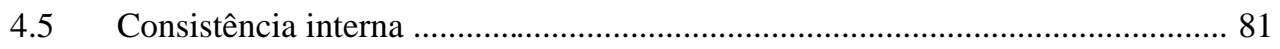

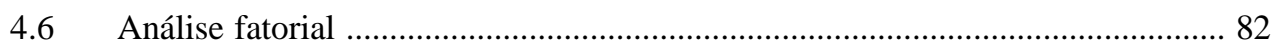

4.7 Sensibilidade à mudança no tempo ................................................................... 83 


\section{FASE 2}

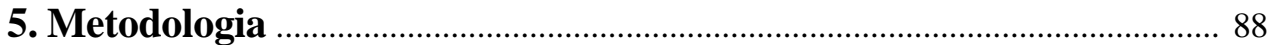

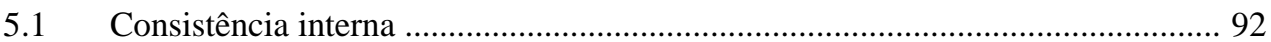

5.2 Análise fatorial .......................................................................................... 92

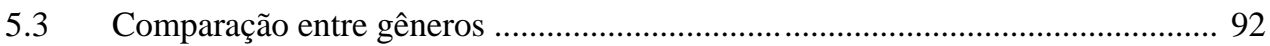

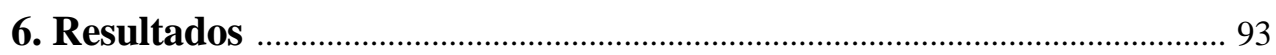

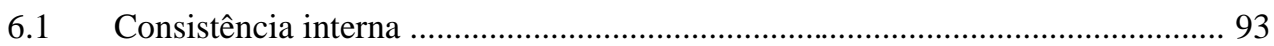

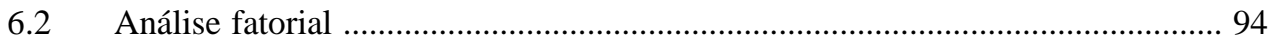

6.3 Comparação entre gêneros …………………………………………………... 95

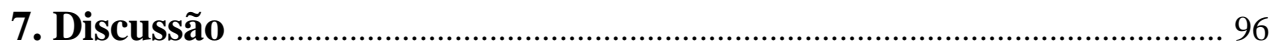

7.1 Perfil sócio-demográfico, características clinicas e comparação entre

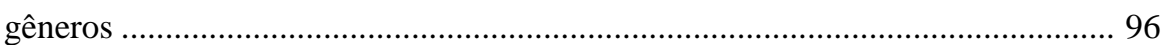

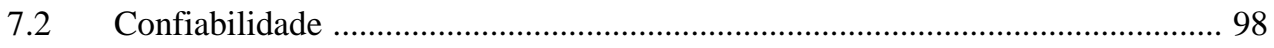

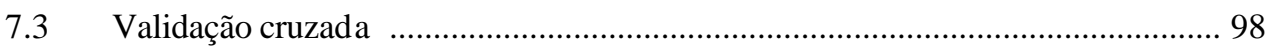

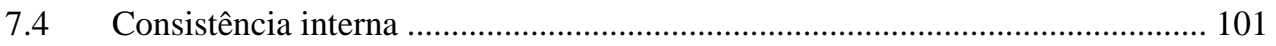

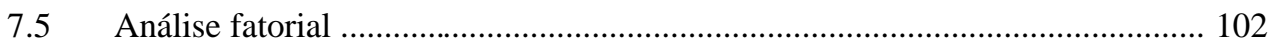

7.6 Sensibilidade à mudança no tempo ………………………………………….... 103

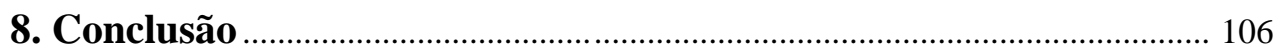

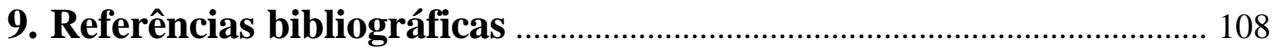




\section{LISTA DE TABELAS}

Tabela 1 Questões da Escala de Seguimento de Jogadores e questões correspondentes para validação cruzada.

Tabela 2 Características sócio-demográficas de jogadoras e jogadores patológicos em início de tratamento.

Tabela 3 Características clínicas de jogadoras e jogadores patológicos em início de tratamento......

Tabela 4 Contagem dos escores sobre freqüência de jogo para medida de concordância inter-juízes.....

Tabela 5 Contagem dos escores sobre tempo gasto em jogo para medida de concordância inter-juízes ....

Tabela 6 Contagem dos escores para dinheiro gasto em jogo para medida de concordância inter-juízes.

Tabela 7 Contagem dos escores sobre relacionamentos familiares para medida de concordância inter-juízes.

Tabela 8 Contagem dos escores sobre autonomia para medida de concordância inter-juízes.

Tabela 9 Contagem dos escores sobre freqüência de lazer para medida de concordância inter-juízes

Tabela 10 Coeficientes de correlação de Spearman para os escores de freqüência de apostas no início do tratamento.

Tabela 11 Coeficientes de correlação de Spearman para os escores de tempo gasto em jogo no início do tratamento.

Tabela 12 Coeficientes de correlação de Spearman para os escores de dinheiro gasto em jogo no início do tratamento

Tabela 13 Coeficientes de correlação de Spearman para os escores de vontade de jogar no início de tratamento.

Tabela 14 Coeficientes de correlação de Spearman para os escores de sofrimento emocional no início do tratamento. 
Tabela 15 Coeficientes de correlação de Spearman para os escores de autonomia no início do tratamento.

Tabela 16 Coeficientes de correlação de Spearman para os escores de lazer no início do tratamento

Tabela 17 Coeficientes de correlação de Spearman para os escores de freqüência de jogo no final de tratamento.

Tabela 18 Coeficientes de correlação de Spearman para os escores de tempo gasto em jogo no final de tratamento.

Tabela 19 Coeficientes de correlação de Spearman para os escores de dinheiro gasto em jogo no final do tratamento.

Tabela 20 Coeficientes de correlação de Spearman para os escores de vontade de jogar no final do tratamento.

Tabela 21 Coeficientes de correlação de Spearman para os escores de sofrimento emocional no final do tratamento.

Tabela 22 Coeficientes de correlação de Spearman para os escores de autonomia no final do tratamento.

Tabela 23 Coeficientes de correlação de Spearman para os escores de lazer no final do tratamento.

Tabela 24 Análise de confiabilidade das questões da Escala de Seguimento de Jogadores.

Tabela 25 Análise fatorial das questões da Escala de Seguimento de Jogadores.......

Tabela 26 Teste de Wilcoxon para as questões de 1 a 10 da ESJ comparando-se os escores iniciais e finais..

Tabela 27 Teste de Wilcoxon para as questões da ASI e TFB comparando-se os escores iniciais e finais.

Tabela 28 Teste de Wilcoxon para os critérios do DSM-IV e escore da GSAS comparando-se os momentos inicial e final

Tabela 29 Teste de Wilcoxon para os escores da EAS comparando-se os momentos inicial e final. 
Tabela 30 Análise de confiabilidade das questões da Escala de Seguimento de Jogadores após reestruturação...

Tabela 31 Análise fatorial das questões da Escala de Seguimento de Jogadores após reestruturação. 


\section{LISTA DE SIGLAS}

\begin{tabular}{|c|c|}
\hline AMJO & $\begin{array}{l}\text { Ambulatório do Jogo Patológico e Outros Transtornos do } \\
\text { Impulso }\end{array}$ \\
\hline ASI & Addiction Severity Index \\
\hline CID - 10 & C lassificação Internacional de Doenças, $10^{\mathrm{a}}$ edição \\
\hline$\overline{\mathrm{DSM}}-\mathrm{III}$ & $\begin{array}{l}\text { Manual Diagnóstico e Estatístico de Transtornos Mentais, } 3^{\mathrm{a}} \\
\text { edição }\end{array}$ \\
\hline DSM - IV & $\begin{array}{l}\text { Manual Diagnóstico e Estatístico de Transtornos Mentais, } 4^{\mathrm{a}} \\
\text { edição }\end{array}$ \\
\hline EAS & Escala de Adequação Social \\
\hline$\overline{\mathrm{ESA}}$ & Escala de Seguimento de Alcoolistas \\
\hline$\overline{\mathrm{ESJ}}$ & Escala de Seguimento de Jogadores \\
\hline FMUSP & Faculdade de Medicina da Universidade de São Paulo \\
\hline$\overline{\text { GREA }}$ & Grupo de Estudos de Álcool e Drogas \\
\hline G-SAS & Gambling Symptom Assessment Scale \\
\hline $\mathrm{HC}$ & Hospital das Clínicas \\
\hline IBGE & Instituto Brasileiro de Geografia e Estatística \\
\hline$\overline{\mathrm{IPq}}$ & Instituto de Psiquiatria \\
\hline JA & Jogadores Anônimos \\
\hline
\end{tabular}




\begin{tabular}{|ll|}
\hline OCDS-PG & Obsessive Compulsive Drinking Scale adapted for \\
& Pathological Gambling \\
\hline PG-YBOCS & Yale Brown Obsessive Compulsive Scale adapted for \\
& Pathological Gambling \\
& \\
\hline QDSD & Questionário de Dados Sócio-Demográficos \\
\hline SOGS & South Oaks Gambling Screen \\
\hline TCC & Terapia Cognitivo Comportamental \\
\hline TFB & Timeline Follow Back \\
\end{tabular}




\section{Resumo}

Galetti AM. Desenvolvimento e avaliação psicométrica da Escala de Seguimento de Jogadores: uma medida de evolução para jogadores patológicos em tratamento [Dissertação]. São Paulo: Departamento de Psiquiatria, Instituto de Psiquiatria, Faculdade de Medicina da Universidade de São Paulo; 2006. 126 p.

Esta dissertação teve por objetivo desenvolver e realizar a testagem psicométrica da Escala de Seguimento de Jogadores (ESJ), uma escala criada para avaliação de jogadores patológicos em tratamento. Este trabalho mostra os resultados da avaliação da primeira versão da ESJ, o aprimoramento com a correção das falhas apontadas e a transformação no formato de auto-preenchimento que resultou em uma escala com dez itens que avaliam, nas últimas quatro semanas, frequiência de jogo, tempo gasto em jogo, dinheiro gasto em jogo, vontade de jogar, dívidas, sofrimento emocional, relacionamentos familiares, autonomia e freqüência e satisfação com atividades de lazer. Esta segunda versão foi testada quanto a sua confiabilidade, validade cruzada, consistência interna, análise fatorial e sensibilidade à mudança no tempo. Para isto, foram avaliados 120 jogadores patológicos que procuraram tratamento no Ambulatório do Jogo Patológico e Outros Transtornos do Impulso (AMJO) do Hospital das Clínicas da Faculdade de Medicina da Universidade de São Paulo (IPq-HC-FMUSP) através de entrevistas e escalas de auto-preenchimento. Destes 120 pacientes, 50 foram reavaliados após seis meses de tratamento e 52 trouxeram familiares que preencheram escala desenvolvida para informante colateral. Numa primeira fase do estudo, a ESJ mostrou boa confiabilidade com bons índices de concordância inter-juízes (Kappa variando entre 0,170 e 0,486, com p entre 0,039 e < 0,001). A validade cruzada foi feita através de correlação com escalas de referência validadas e em uso na área de jogo patológico e status funcional: a sessão de jogo da 
Addiction Severity Index (ASI-Gambling), entrevista com o método Timeline followback, a Gambling Symptom Assessment Scale (G-SAS), a Escala de Adequação Social (EAS) e a escala de seguimento de jogadores desenvolvida para informante colateral. As questões da ESJ mostraram excelente validade cruzada com as escalas de referência (índices de correlação de Spearman variando entre 0,291 e 0,775, com p entre 0,043 e $<0,001$ ), à exceção da questão sobre relacionamento familiar, que foi parcialmente comprovada $(\mathrm{p}=0,001$ no início do tratamento e $\mathrm{p}=0,73$ no final do tratamento). Quanto à consistência interna, o Alfa de Cronbach calculado foi igual a 0,83 , porém a questão sobre autonomia mostrou baixa correlação com as demais questões da escala e sua exclusão aumentava o Alfa total. A análise fatorial mostrou composição em três fatores. A escala também se mostrou sensível à mudança no tempo ( $\mathrm{p}$ variando entre $0,036 \mathrm{e}<0,001$ ), com exceção da questão sobre autonomia (p $=0,986)$. Numa segunda fase do estudo, a questão sobre autonomia foi substituída e nova testagem foi realizada. A consistência interna melhorou (Alfa de Cronbach igual a 0,86$)$ e todos os itens tiveram boa correlação com o total da escala. A análise fatorial manteve a estrutura em três fatores, com a modificação de algumas questões entre eles, sendo o primeiro fator formado pelas questões sobre comportamentos específicos de jogo, o segundo formado pelas questões sobre dívidas, sofrimento emocional e autonomia, e o terceiro formado pelas questões sobre relacionamento familiar e lazer. A ESJ apresentou boas medidas de confiabilidade, consistência interna e validade cruzada, mostrou-se estruturada em três fatores bem definidos e coerentes com os conceitos abordados e sensível à mudança no tempo. Encontra-se pronta para uso clínico e o aprimoramento da questão sobre relacionamentos familiares está em andamento. 
Descritores: 1. JOGO DE AZAR/psicologia 2. ESCALAS

3. EVOLUÇÃO CLÍNICA 4. QUESTIONÁRIOS 5. RESULTADO DE TRATAMENTO 


\section{Summary}

Galetti AM. Development and psychometric testing of the Gambling Follow-up Scale: an outcome measure for pathological gamblers in treatment [dissertation]. São Paulo: "Departamento de Psiquiatria, Instituto de Psiquiatria, Faculdade de Medicina da Universidade de São Paulo"; 2006. 126 p.

This dissertation concerns the development and the psychometric testing of the Gambling Follow-up Scale (GFS), a scale created to evaluate pathological gamblers in treatment. This study shows the testing results of the first version of the GFS, its improvement with the correction of the pointed failures and its transformation in a self-report format which resulted in a ten-item scale that assesses, in the past four weeks, frequency of gambling, time spent on gambling, money spent on gambling, craving for gambling, debts, emotional distress, family relationship, autonomy and frequency and satisfaction with leisure. This second version was tested concerning its reliability, convergent validity, internal consistency, factor analysis and sensibility to change over time. To this end, 120 pathological gamblers that sought treatment in the Pathological Gambling and Other Impulse Control Disorders Outpatient Unit (AMJO) of the Institute of Psychiatry of the Clinical Hospital of the São Paulo Medical School (IPq-HC-FMUSP) were assessed with interviews and self-report scales. From these 120 patients, 50 were reassessed after a six-month treatment and 52 brought relatives that responded a scale developed for collateral informant. In a first phase of this study, the GFS showed good reliability with good inter-judges agreement measures (Kappa ranging between 0,170 and 0,486 , and $\mathrm{p}$ between 0,039 and $<0,001$ ). The convergent validity was tested through the correlation with valid reference scales used in the field of pathological gambling and functional status: the gambling section of the Addiction Severity Index (ASI-Gambling), interview with the Timeline follow-back method, the 
Gambling Symptom Assessment Scale (G-SAS), the Social Adjustment Scale (SAS) and the gambling follow-up scale developed for collateral informant. The GFS questions showed good convergent validity with the reference scales (Spearman's correlation ranging between 0,291 and 0,775, with p between 0,291 and 0,775), except the question concerning family relationship, which was partially confirmed ( $\mathrm{p}$ $=0,001$ in the beginning of treatment and $p=0,73$ in the end of treatment). Regarding internal consistency, the Cronbach's Alpha calculated was 0,83 , however the question about autonomy showed low correlation with the others and its exclusion increased the total Alpha. The factor analysis presented a composition in three factors. The scale also showed sensibility to change over time ( $\mathrm{p}$ ranging between 0,036 and $<0,001$ ), except the question about autonomy $(\mathrm{p}=0,986)$. In a second phase, the question concerning autonomy was changed and new testing was made. The internal consistency improved (Cronbach's Alpha equal to 0,86) and all items had good correlation with the total scale. The factor analysis kept a three factor structure, with some questions changing among them, with the first factor formed by the questions about specific gambling behaviors, the second formed by the questions about debts, emotional distress and autonomy, and the third formed by questions concerning family relationship and leisure. The GFS presented good reliability, internal consistency and convergent validity measures, showed a well defined three factor structure and coherent with the concepts approached and sensibility to change over time. It is ready for clinical use and the improvement of the question about family relationship is in progress.

Keywords: 1. GAMBLINGpsychology 


\section{INTRODUÇÃO}

\subsection{Jogo Patológico e impacto funcional}

O Jogo Patológico ganhou notoriedade e chamou a atenção de autores e profissionais da área de saúde mental nos últimos anos, chegou à mídia e informações a seu respeito têm sido divulgadas para a população. Mas esse transtorno não é exclusividade das últimas décadas do século $\mathrm{XX}$. O comportamento de jogo excessivo, com descontrole sobre o hábito de apostar e acarretando prejuízos ao indivíduo, já havia sido descrito anteriormente por diferentes autores. Dentre obras conhecidas, podemos encontrar uma descrição psicopatológica marcante das alterações desses indivíduos no romance de Dostoievski chamado "O jogador", escrito em 1866, onde o autor narra a história de um jogador patológico. Este livro foi escrito às pressas para cobrir uma situação financeira desesperadora causada por dívidas de jogo e o autor se baseou em suas próprias experiências (Dostoievski, 1866).

Contudo, Jogo Patológico só foi reconhecido oficialmente como transtorno psiquiátrico e teve seus critérios diagnósticos definidos em 1980, quando passou a fazer parte do Manual Diagnóstico e Estatístico de Transtornos Mentais $3^{\mathrm{a}}$ Edição DSM-III (American Psychiatric Association, 1980), sendo classificado entre os transtornos de controle do impulso.

A Classificação de Transtornos Mentais e de Comportamento $10^{\mathrm{a}}$ Edição (CID-10) o descreve como "episódios freqüentes e repetidos de jogo que dominam a vida do indivíduo restringindo gradativamente seus compromissos sociais, materiais e 
familiares" (CID-10, Organização Mundial da Saúde, 1993). O Jogo Patológico é caracterizado pela perda do controle sobre apostas, aumento progressivo do envolvimento com o jogo, prejuízos no trabalho e no relacionamento familiar, comprometimento financeiro, envolvimento em atos ilegais para financiar o jogo, e retorno ao jogo para recuperar as perdas. Nota-se que, desde as descrições feitas ao longo da história até às definições atuais, o Jogo Patológico tem como características o sofrimento emocional desses sujeitos e o prejuízo funcional por afetar diversas áreas da vida do jogador, principalmente relacionamentos familiares, trabalho, lazer e atividades sociais (American Psychiatric Association, 1994).

Além disso, o comportamento disfuncional do jogo parece também estar relacionado com um amplo espectro de comportamentos de risco (Westphal et al, 2000). Esses comportamentos estão associados com a impulsividade aumentada desses pacientes (Petry, 2001; Martins et al, 2004), apresentando importante comorbidade com uso de substâncias (Proimos et al, 1998; Blanco et al, 2001; Petry, 2001; Martins et al, 2004), tentativas de suicídio (DeCaria et al, 1996; Martins et al 2004), comportamento sexual de risco (Petry, 2000; Martins et al, 2004) e envolvimento com atividades ilegais (Potenza et al, 2000).

\subsection{Prevalência de Jogo Patológico}

As taxas de prevalência variam de $1 \%$ a $2 \%$ nos Estados Unidos (Volberg, 1996), em diferentes partes do Canadá (Ladouceur, 1996) e Europa (Beconia, 1996). Sabe-se que a prevalência de Jogo Patológico está relacionada com a disponibilidade e oferta de oportunidades de jogos, sejam legais ou ilegais (Jacques et al, 2000; 
Ladouceur \& Walker, 1996; Volberg, 1994). Em diversos países, o número de indivíduos expostos tem aumentado nos últimos anos, assim como as taxas de prevalência de Jogo Patológico (Shaffer, 2002).

Em nosso país ainda não há dados epidemiológicos sobre Jogo Patológico. A partir da década de 90, com a legalização e a abertura de casas de bingo no Brasil e o conseqüente aumento da oferta de jogos, principalmente jogos eletrônicos, é esperado que a expressão deste transtorno aumente em nossa população.

\subsection{Diagnóstico e tratamento}

Apesar de classificado como um transtorno do impulso, os critérios operacionais adotados para o diagnóstico de Jogo Patológico, bem como a maioria dos modelos terapêuticos, são inspirados nos critérios utilizados para diagnóstico de dependência de substâncias psicoativas (McElroy et al, 1992; Tavares et al, 2003). O diagnóstico baseia-se na identificação da perda de controle sobre as apostas; adaptações psicobiológicas ao comportamento crônico repetitivo, tais como escalada progressiva do valor das apostas e desconforto subjetivo ao tentar cessar ou reduzir o jogo, à semelhança dos fenômenos clínicos de tolerância e abstinência; e persistência do comportamento mesmo em face de conseqüências negativas, por vezes devastadoras.

O tratamento para jogadores patológicos é relativamente novo. Há poucos programas desenvolvidos e geralmente utilizam abordagens psicossociais, terapias cognitivas e cognitivo-comportamentais. Os estudos controlados são escassos e heterogêneos quanto aos métodos, intervenções e, principalmente, quanto às medidas 
de evolução, revelando uma pobreza de evidências quanto a tratamentos efetivos para Jogo Patológico (Oakley-Browne et al, 2000; Petry \& Armentano, 1999).

\subsection{Medidas de evolução}

Com o crescimento da prevalência de Jogo Patológico, a demanda por tratamentos mais eficientes e mais acessíveis tem aumentado. Surge o desafio de desenvolver esses tratamentos e avaliar e identificar seus efeitos. É interesse crescente dos pacientes, médicos e serviços de saúde que a eficácia terapêutica seja avaliada. O maior esforço na área de mensuração é realizado na direção de ser capaz de associar o que é feito com o paciente e o impacto dessa intervenção (associar o processo com a evolução). O melhor meio para isto seria conduzir uma pesquisa que mostre quais intervenções funcionam para uma doença particular em populações específicas. Para isso, as escolha das medidas a serem usadas é de importância vital. Além das medidas de redução sintomática, medidas de evolução funcional são importantes porque avaliam um conceito que concentra o objetivo último de qualquer intervenção: melhora do status funcional (Grayson, 2002).

Em transtornos psiquiátricos e especificamente em Jogo Patológico, a avaliação do impacto do tratamento é particularmente difícil devido ao fato de estarmos lidando com estados e comportamento subjetivos (Peck \& Dean, 1983). O exame clínico realizado pelo terapeuta depende de suas impressões pessoais e isto pode desviá-lo de uma avaliação objetiva do paciente. O uso de escalas de avaliação em pesquisas e na prática clínica visa diminuir erros de coleta e a subjetividade do 
examinador, garantir a padronização e assim possibilitar a reprodutibilidade do estudo, criando uma linguagem comum para permitir a comparação de resultados.

\subsubsection{Validade e confiabilidade de uma escala}

A validade de um instrumento pode ser definida como a capacidade de realmente medir aquilo que se propõe a medir (Kelsey et al, 1996). A validade apresenta: (1) um aspecto conceitual, que depende do julgamento subjetivo do pesquisador sobre se o instrumento mede o que deveria e é influenciado pelo panorama de conceitos e teorias aceitos na época; (2) um aspecto operacional, que pode ser avaliado com métodos estatísticos (Almeida Filho et al, 1989). Esta última é geralmente medida comparando-se o instrumento com outra medida externa já existente considerada "padrão-ouro" (Menezes \& Nascimento, 2000), e denomina-se validade convergente ou validade cruzada.

Dentro do aspecto conceitual deve-se considerar a validade aparente e a validade de construto. A validade aparente (face validity) é o grau com que uma medida intuitivamente parece avaliar o que se propõe (Bush, 2002). Diz respeito a um critério de credibilidade na formulação dos itens. O item deve ser formulado de modo que não pareça ridículo, despropositado ou infantil (Pasquali, 2000). A formulação do item pode contribuir para uma atitude desfavorável para com o teste e assim aumentar os erros de resposta (Nevo, 1985), indiretamente afetando a própria validade psicométrica do instrumento. A validade de construto é a presença de uma correlação positiva entre um grupo de características ou variáveis e a entidade principal que está sendo medida (Bush, 2000). Diz respeito à construção dos itens, sob embasamento teórico, a partir das características do que se pretende medir. 
A confiabilidade refere-se à capacidade do instrumento de reproduzir uma mesma medida, isto é, ao grau de concordância entre múltiplas medidas de um mesmo objeto (Armstrong et al, 1994). A consistência interna (Alfa de Cronbach) é um escore sumário de confiabilidade geral de um instrumento. O escore pode variar de zero a um. Por convenção, o escore mínimo aceitável para a consistência interna é 0,70 (Nunnally \& Bernstein, 1994). Um escore bom para a consistência interna gira em torno de 0,80 e um escore em torno de 0,90 é considerado excelente. Contudo, um alfa muito próximo de 1 indica alta co-variância, sugerindo que possivelmente o conjunto de itens em questão poderia ser substituído por apenas um, aquele que for mais representativo. Assim sendo, é desejável que os itens de uma escala apresentem boa consistência interna, porém que não seja demasiada elevada para garantir uma complementaridade entre os mesmos e uma avaliação abrangente.

Os tipos de confiabilidade mais comumente avaliados são: a confiabilidade entre diferentes avaliadores, onde os mesmos sujeitos são avaliados por dois ou mais avaliadores, e a confiabilidade teste-reteste, onde um grupo de sujeitos é avaliado em dois momentos diferentes (Menezes \& Nascimento, 2000).

O grau de concordância entre as avaliações é quantificado por meio de coeficientes de confiabilidade. Os considerados mais adequados para esse fim, por considerarem a probabilidade de concordância devido ao acaso, são: (1) o Kappa (Cohen, 1960), utilizado quando o instrumento produz medidas categóricas ou binárias; (2) o Kappa ponderado (Cohen, 1968), utilizado quando o instrumento produz medidas categóricas ordenadas; e (3) o coeficiente de correlação intraclasse (Bartko, 1966), quando o instrumento mede uma variável contínua. Valores do coeficiente Kappa entre 0 e 0,20 são considerados como concordância superficial, entre 0,20 e 0,40 concordância moderada, entre 0,40 e 0,60 concordância 
considerável, entre 0,60 e 0,80 concordância boa e entre 0,80 e 1 concordância quase perfeita.

\subsubsection{Medidas de evolução em Jogo Patológico}

Não há, até o momento, uma medida de evolução considerada "padrão ouro" para avaliação de jogadores patológicos em tratamento. As medidas de evolução usadas em estudos para tratamento de jogadores patológicos são muito heterogêneas. Esses trabalhos concentram a avaliação da evolução em medidas do número e freqüência de sintomas de jogo, baseando-se no número de critérios do DSM-IV para Jogo Patológico, ou de itens positivos em escalas rastreio como a South Oaks Gambling Screen (SOGS - Lesieur \& Blume, 1987; vide item 3.2.2.1 para uma descrição mais detalhada da escala). Entretanto, o uso de um instrumento de rastreio ou diagnóstico para outro propósito, tal como avaliação de gravidade clínica ou impacto terapêutico, que não seja sua finalidade original é metodologicamente questionável.

Uma revisão de intervenções psicossociais para Jogo Patológico identificou somente quatro estudos randomizados controlados: dois estudos canadenses (Ladouceur et al, 2001; Sylvain et al, 1997), um estudo espanhol (Echeburúa et al, 1996) e um estudo australiano (McConaghy et al, 1991). Os critérios para avaliar o sucesso do tratamento variaram entre os estudos. As medidas de evolução adotadas pelos estudos canadenses foram freqüência de jogo, percepção de controle sobre o ato de jogar, estimativa de auto-eficácia frente a situações de risco, desejo de jogar, e número de critérios do DSM-III-R (American Psychiatry Association, 1987). As 
medidas de evolução dos estudos espanhol e australiano foram frequiência e quantia de dinheiro gasto em jogo.

Até o momento, foram desenvolvidas algumas escalas para avaliar a eficácia de tratamentos farmacológicos para Jogo Patológico. Essas novas escalas têm sido utilizadas em conjunto com medidas gerais de melhora, como a Impressão Clínica Global (Clinical Global Impression - Guy, 1976), e suas características variam de acordo com o objetivo do estudo para a qual foram desenvolvidas.

DeCaria e colaboradores desenvolveram uma versão modificada para Jogo Patológico da Yale-Brown Obsessive Compulsive Scale (PG-YBOCS - DeCaria et al, 1998). Esta escala foi baseada em similaridades entre Jogo Patológico e Transtorno Obsessivo Compulsivo, sendo focada nesses aspectos. Dados definitivos de confiabilidade e validade da PG-YBOCS ainda não foram publicados. Kim e colaboradores desenvolveram a Gambling Symptom Assessment Scale (G-SAS - Kim et al, 2001), um instrumento de 12 itens para avaliar evolução de jogadores em tratamento. A Obsessive-Compulsive Drinking Scale modificada para Jogo Patológico foi usada em um estudo controlado com citalopram (OCDS-PG - Zimmerman et al, 2002). A PG-YBOCS, G-SAS e OCDS-PG são focadas em sintomas de avidez por jogo (do inglês "craving" ou "urge"). A G-SAS é a única com dados de confiabilidade e validade publicados (Kim et al, 2001).

Petry, recentemente, validou uma seção de Jogo Patológico da Addiction Severity Index (ASI), a ASI-Jogo (Petry, 2003). A ASI é um instrumento amplamente utilizado na área de dependências. É uma entrevista semi -estruturada que avalia sete variáveis consideradas cruciais para o tratamento: condição médica, trabalho ou autonomia, uso de álcool, uso de drogas, atividades ilegais, relações familiares e sociais e condição psiquiátrica (McLellan et al, 1992). A ASI, com sua seção para 
Jogo Patológico, é a entrevista mais completa até o momento para avaliar jogadores, pois possui medidas sintomáticas de jogo e medidas de funcionamento em outras áreas. Contudo, a ASI possui características que podem ser um obstáculo para seu uso em grandes serviços clínicos que demandam medidas rápidas e freqüentes. Primeiramente, ela requer um avaliador com treinamento específico, o que exige um investimento e disponibilidade maior de pessoal para executá-la. Além disso, a avaliação extensa de várias áreas acarreta um prolongamento da entrevista que pode consumir muito tempo e desgastar tanto o avaliador quanto o paciente.

\subsection{A Escala de Seguimento de Jogadores (ESJ)}

\subsubsection{Escala de Seguimento de Jogadores $-1^{\mathrm{a}}$ versão}

Com intuito de avaliar jogadores patológicos em tratamento, o Ambulatório do Jogo Patológico e Outros Transtornos do Impulso (AMJO) do Instituto de Psiquiatria do Hospital das Clínicas da Faculdade de Medicina da Universidade de São Paulo (IPq-HC-FMUSP) desenvolveu um instrumento destinado a este fim: a Escala de Seguimento de Jogadores (ESJ). A ESJ é uma versão adaptada de Escala de Seguimento de Alcoolistas (ESA - Andrade et al, 1988) desenvolvida no Grupo de Estudos de Álcool e Drogas (GREA) do IPq -HC-FMUSP.

Seguindo o intuito de seu modelo original, a ESA, a ESJ foi projetada para ser um instrumento confiável, simples, de rápida aplicação e capaz de prover informação relevante na avaliação do status clínico do jogador em tratamento. 
A opção por um formato simplificado, em oposição a uma entrevista mais alongada como a ASI, visa:

- enfoque estrito nos elementos primordiais do tratamento de Jogo Patológico, ou seja, redução ou supressão do comportamento de jogo e sintomas associados, redução do estresse na relação com indivíduos em contato direto com o paciente (família) e incremento de autonomia e socialização;

- flexibilidade de aplicação (uso à distância, auto-aplicação e necessidade mínima de treinamento);

- e, finalmente, fácil conjugação com medidas mais específicas de resultado que podem ser selecionadas de acordo com a modalidade de tratamento utilizada (por exemplo escalas de avaliação de distorção cognitiva em tratamentos cognitivocomportamentais, ou escalas de fortalecimento egóico em tratamentos psicodinâmicos).

Essa primeira versão, mostrada em anexo, foi construída em forma de entrevista semi-estruturada, com cinco itens pontuados em escala de um a cinco e que são avaliados nas últimas quatro semanas, a saber:

1. Freqüência e tempo gasto em jogo

2. Ocupação (trabalho)

3. Relações Familiares

4. Lazer

5. Participação em Jogadores Anônimos

Essa versão da ESJ foi avaliada em estudo onde três entrevistadores independentes avaliaram 47 jogadores patológicos, sendo 13 deles entrevistados duas vezes, com intervalo mínimo de seis meses. A amostra foi coletada em dois centros 
universitários de São Paulo. Os pacientes freqüentavam psicoterapia com acompanhamento psiquiátrico concomitante, Jogadores Anônimos, ou ambos.

A ESJ mostrou-se de rápida aplicação com tempo médio de entrevista de 6,0 minutos (desvio padrão de 2,7 minutos). À semelhança da ESA, a ESJ demonstrou excelente confiabilidade com índices de concordância inter-juízes entre $82 \%$ e $95 \%$ e coeficientes de correlação intraclasses entre 0,85 e 0,99 ( $\mathrm{p}<0,001)$. Mostrou boa consistência interna com boa correlação entre seus itens (índices de correlação de Pearson com p < 0,05), à exceção do item Ocupação, que teve correlação significativa somente com o Lazer.

A análise fatorial dos cinco itens da ESJ resultou em um único fator que explicava 47,6\% da variância das respostas. A análise dos fatores mostrou maior contribuição dos itens Lazer, Freqüência e Tempo de Jogo e Relações Familiares $(0,84 ; 0,71$; e 0,71 , respectivamente), e contribuição moderada dos itens Participação em Jogadores Anônimos e Ocupação (0,59 e 0,56, respectivamente). Uma segunda análise fatorial foi feita acrescentando-se a variável duração do tratamento. Esta resultou em dois fatores, sendo um englobando todos os cinco itens da ESJ e o segundo formado somente pela duração do tratamento, isto é, a estrutura da escala mostrou-se independente do tempo de tratamento.

Foi feito um modelo de regressão linear tendo o item Freqüência e Tempo de Jogo como variável dependente, e Lazer, Duração do tratamento, Relações familiares e Participação em Jogadores Anônimos como variáveis independentes, que adentraram o modelo nesta ordem. O modelo correlacionou significativamente Freqüência e tempo de jogo $\left(\mathrm{R}^{2}=0,356 ; \mathrm{F}_{2,44]}=12,2 ; \mathrm{p}<0,001\right)$ com o item Lazer $(\mathrm{R}=0.495 ; \mathrm{p}=0,001)$ e Duração do tratamento $(\mathrm{R}=0,054 ; \mathrm{p}=0,016)$. 
Com relação às diferentes modalidades de tratamento, encontrou-se impacto significativo somente com o item Lazer $\left(\mathrm{F}_{[2,43]}=5,00 ; \mathrm{p}=0,011\right)$. A análise Bonferroni post hoc mostrou diferença no grupo recebendo somente tratamento psiquiátrico, com seus escores em Lazer sendo significativamente menores do que no grupo que freqüentava somente Jogadores Anônimos $(p=0,008)$ e no grupo que recebia tratamento psiquiátrico com Jogadores Anônimos ( $\mathrm{p}=0,017)$.

Esses dados, recentemente publicados (Castro, Fuentes \& Tavares, 2005), apontam que em sua primeira versão a ESJ mostrou-se rápida, com altas taxas de concordância entre entrevistadores, com uma estrutura unifatorial coerente. Contudo, alguns problemas foram identificados nesta versão da ESJ. Durante seu desenvolvimento, foram consultados nove especialistas nas áreas de dependência ou psicometria, psicólogos ou psiquiatras, com experiência clínica e de pesquisa. Os textos de cada item foram misturados e foi pedido que eles os reordenassem. $\mathrm{O}$ indicador Relações Familiares apresentou problemas relativos à ordenação das opções de repostas, mas a estrutura original foi mantida para a realização desse estudo sobre a primeira versão. Outro problema foi que os indicadores Ocupação, Lazer e Participação em Jogadores Anônimos correlacionaram mais entre si do que om outros indicadores da escala original. Os indicadores específicos para comportamento de jogo avaliados foram somente frequiência de jogo e tempo gasto em jogo, ambos conjugados em um único item. Além disso, havia a exigência de um entrevistador. 
1.5.2 Escala de Seguimento de Jogadores $-2^{\mathrm{a}}$ versão

A fim de aprimorar o instrumento, uma segunda versão da ESJ foi desenvolvida com base nas observações acima.

O indicador Frequiência de Jogo e tempo gasto em jogo, antes conjugado em um mesmo item, foi desmembrado em duas questões distintas. Visando ampliar a avaliação do nível de envolvimento com jogo, um novo indicador denominado Perdas Financeiras foi criado, baseado em conceitos atuais que consideram frequiência, tempo e dinheiro gasto em jogo como indicadores de gravidade, além de já serem utilizados em instrumentos desenvolvidos para identificar o grau de comprometimento do jogador (ASI-jogo). Este indicador foi estruturado para avaliar dinheiro gasto em jogo em relação à renda do paciente. Outros dois indicadores diretamente relacionados a jogo foram acrescentados, Avidez por jogo e Dívidas, uma vez que estes fatores podem determinar recaídas e dificultar o compromisso com a abstinência (Hodgins et al, 2001). O indicador Dívidas não encontra similar em escalas na literatura e foi incluído pelos pesquisadores baseado também em experiência clínica. Além da presença de dívidas devido a jogo ser indicador de impacto na vida financeira do indivíduo, notou-se que os jogadores, sentindo-se pressionados por suas dívidas, tendem a recorrer ao jogo como forma de solucionar seus problemas, perpetuando o comportamento. Clinicamente observa-se que problemas financeiros estão entre os principais fatores que predispõem a recaídas (Hodgins \& el-Guebaly, 2004).

Baseado em observação clínica e na presença deste indicador em outras escalas, foi acrescentado um novo item sobre Sofrimento Emocional causado por jogo para avaliar nível subjetivo de estresse. 
O indicador Relações Familiares foi parcialmente reformulado para refletir melhor o nível de suporte e críticas proveniente do relacionamento familiar de acordo com a percepção do jogador.

O indicador Ocupação foi renomeado para Autonomia e parcialmente reformulado para refletir melhor a capacidade e satisfação do avaliado em promover seu auto-sustento.

O indicador Lazer foi inteiramente reformulado para avaliar a freqüência de qualquer atividade não profissional orientada para entretenimento ou socialização, desenvolvida regularmente pelo paciente. O indicador Participação em Jogadores Anônimos da primeira versão foi incluído como sub-item no indicador Lazer da segunda versão por sua forte correlação com este item mostrado no estudo anterior. Para sua inclusão no item Lazer, o envolvimento em atividades de Jogadores Anônimos foi vis to como promotora de socialização, não sendo considerada como entretenimento. A participação nessas atividades promove maior contato com outras pessoas, diminuindo a vergonha e o isolamento. Uma nova questão abordando a satisfação com as atividades de lazer realizadas foi acrescentada para melhor avaliar o indicador Lazer.

A ESJ foi convertida para o formato de auto-preenchimento, aumentando sua praticidade por dispensar entrevistador e treinamento para seu uso. Resultou, então, em uma escala com 10 questões:

1. Frequiência de jogo

2. Tempo gasto em jogo

3. Perdas Financeiras

4. Avidez por jogo

5. Dívidas 

6. Sofrimento emocional
7. Relações Familiares
8. Autonomia
9. Freqüência de atividades de lazer
10. Satisfação com lazer

A avaliação das qualidades psicométricas desta segunda versão da ESJ (mostrada a seguir) quanto a sua confiabilidade, validade comparativa, consistência interna e sensibilidade à mudança no tempo é o objetivo principal do presente estudo. 


\section{Escala de Seguimento de Jogadores}

As questões abaixo se referem ao jogo, ou outras áreas de sua vida que tenham sido afetadas por ele:

1. Com que freqüência você jogounas últimas 4 semanas?

1) joguei diariamente

2) joguei em média mais de uma vez por semana

3) joguei em média uma vez por semana

4) joguei ocasionalmente, em média menos de uma vez por semana

5) não joguei

2. Nas últimas 4 semanas, da vez em que jogou por mais tempo, quanto tempo jogou?

1) joguei mais de 12 horas seguidas

2) joguei entre 8 e 12 horas seguidas

3) joguei entre 4 e 8 horas seguidas

4) joguei menos de 4 horas seguidas

5) não joguei

3. Nas últimas 4 semanas, quanto dinheiro você perdeu no jogo em relação à sua renda?

1) joguei sem ter renda própria, OU fiz empréstimos, desfiz-me de bem pessoal, economias, OU roubei (passei cheques sem fundos, falsifiquei cheques) para jogar ou pagar dívidas de jogo

2) possuo renda própria e perdi mais que o equivalente a minha renda

3) possuo renda própria e perdi o equivalente a minha renda ou mais que a metade desse valor

4) possuo renda própria e perdi menos que a metade desse valor

5) não tive perdas

4. Nas últimas 4 semanas, como esteve a sua vontade de jogar?
1) senti uma vontade irresistível de jogar
2) senti uma forte vontade de jogar, algumas vezes resistível, outras não
3) senti uma forte vontade de jogar, porém resistível na maior parte do tempo
4) senti uma leve vontade de jogar
5) não tive vontade de jogar

5. Como você tem se sentido em relação a suas dívidas nas últimas 4 semanas?

1) sinto-me extremamente pressionado, tenho jogado como forma de tentar obter dinheiro para saldar dívidas ou para aliviar as preocupações com elas

2) sinto-me extremamente pressionado, porém não joguei, ou se joguei não foi motivado pelas dívidas

3) tenho dívidas, mas elas não me preocupam no momento

4) não tenho dívidas 
6. Nas últimas 4 semanas, quanto problema emocional o jogo lhe causou (sofrimento, angústia, culpa, vergonha, constrangimento)?
1) extremo
2) muito
3) moderado
4) leve
5) nenhum

7. Nas últimas 4 semanas, como esteve o seu relacionamento familiar (com as pessoas com quem mora ou, se mora sozinho, com familiares com quem tem contato próximo)?

1) não tive contato com minha família

2) minha família me culpa e me critica muito OU estive isolado a maior parte do tempo

3) minha família ainda desconfia de mim, mas às vezes sinto afeto e encorajamento por parte deles

4) sinto afeto e encorajamento por parte de minha família, mas às vezes eles anda me criticam

5) sinto muito encorajamento por parte de minha família, eles agora confiam em mim e passamos bons momentos juntos

8. Nas últimas 4 semanas você trabalhou ou teve renda própria para manutenção de suas necessidades básicas: asseio, saúde, alimentação e moradia?Você está satisfeito com seu trabalho?

1) estou desempregado, inativo ou sem renda própria no momento, $\mathrm{OU}$ a manutenção das minhas necessidades básicas passaram para a responsabilidade de outra pessoa

2) estou desempregado, sem renda no momento, mas desempenhando atividades úteis para a manutenção das minhas necessidades básicas (inclui atividades não remuneradas como dona de casa)

3) estou empregado ou com outra fonte de renda própria, porém insuficiente para a manutenção de todas as minhas necessidades básicas

4) estou empregado ou com outra fonte de renda própria suficiente para a manutenção das minhas necessidades básicas

5) estou empregado ou com outra fonte de renda própria que excede minhas necessidades básicas, OU estou prosperando, OU sinto muita satisfação no meu trabalho 
9. Como você tem ocupado seu tempo livre nas últimas 4 semanas? Utilize os números abaixo para marcar o número de vezes que realizou cada uma das atividades descritas. número

de

\begin{tabular}{|c|c|c|c|c|c|}
\hline \multicolumn{6}{|l|}{$\frac{\text { vezes }}{\text { Atividades esportivas }}$} \\
\hline em academias ou clubes & 0 & 1 & 2 & 3 & $4 \mathrm{ou}+$ \\
\hline $\begin{array}{l}\text { em ambiente externo, como corridळ ou } \\
\text { caminhadas }\end{array}$ & 0 & 1 & 2 & 3 & $4 \mathrm{ou}+$ \\
\hline joguei futebol ou outros esportes coletivos & 0 & 1 & 2 & 3 & $4 \mathrm{ou}+$ \\
\hline outras._Especifique: & 0 & 1 & 2 & 3 & $4 \mathrm{ou}$ \\
\hline 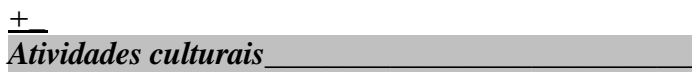 & & & & & \\
\hline fui ao cinema, teatro, museu ou exposição de arte & 0 & 1 & 2 & 3 & $4 \mathrm{ou}+$ \\
\hline ouvi música & 0 & 1 & 2 & 3 & $4 \mathrm{ou}+$ \\
\hline leitura individual, em grupo ou participei de um curso & 0 & 1 & 2 & 3 & $4 \mathrm{ou}+$ \\
\hline outras. Especifique: & 0 & 1 & 2 & 3 & $4 \mathrm{ou}+$ \\
\hline Atividades de grupo & & & & & \\
\hline $\begin{array}{l}\text { fui ao JA ou outro grupo de anônimos, grupos } \\
\text { religiosos ou de reflexão, grupos de atividade voluntária }\end{array}$ & 0 & 1 & 2 & 3 & $4 \mathrm{ou}+$ \\
\hline fui à igreja & 0 & 1 & 2 & 3 & $4 \mathrm{ou}+$ \\
\hline passei meu tempo com amigos & 0 & 1 & 2 & 3 & $4 \mathrm{ou}+$ \\
\hline outras. Especifique: & 0 & 1 & 2 & 3 & 4 \\
\hline
\end{tabular}

10. Q ual foi a sua satisfação em realizar as atividades acima?

1) Nenhuma, ou não fiz nada

2) Muito pouca satisfação

3) Pouca satisfação

4) Razoável satisfação

5) Muita satisfação 


\section{OBJETIVOS}

Com base nos dados expostos anteriormente, podemos definir os seguintes objetivos para esta dissertação:

Verificar a confiabilidade, validade, consistência interna e sensibilidade à mudança no tempo da ESJ em sua segunda versão, através de:

a) cálculo de medida de confiabilidade;

b) comparação dos escores da ESJ com escores de escalas de referência, em dois tempos distintos, para validação cruzada;

c) cálculo de medidas de consistência interna.

d) comparação dos escores da ESJ e de escalas de referência antes e depois de tratamento. 


\section{FASE 1}

\section{METODOLOGIA}

\subsection{Amostra}

\subsubsection{Triagem}

Os sujeitos dessa pesquisa são pacientes que procuraram tratamento no AMJO, no período de 21/11/2002 a 08/09/2004, e familiares desses pacientes.

Esses indivíduos procuraram o AMJO fazendo suas inscrições por telefone, comparecendo pessoalmente, ou foram encaminhados por outros profissionais médicos diretamente para o ambulatório.

Foi solicitado ao paciente que comparecesse com um familiar, que residisse no mesmo domicílio, de preferência o cônjuge, para participar de reuniões psico-educacionais realizadas pelo AMJO para os familiares dos jogadores.

\subsubsection{Critérios de inclusão}

Os pacientes inscritos passaram por triagem realizada por pessoal treinado da equipe do AMJO (psicólogos e psiquiatras). Foram selecionados os indivíduos que numa avaliação inicial pontuaram cinco ou mais na SOGS (Lesieur \& Blume, 1987) e cujo diagnóstico de Jogo Patológico foi confirmado em entrevista com psiquiatra pelos critérios diagnósticos para Jogo Patológico especificados no DSM-IV (American Psychiatric Association, 1994). 
No período de realização desta pesquisa, 121 sujeitos procuraram tratamento no AMJO. Um único sujeito não preenchia critérios para diagnóstico de Jogo Patológico pelo DSM-IV.

\subsubsection{Critérios de exclusão}

Foram considerados os seguintes critérios para exclusão no momento da triagem: (1) pacientes que apresentassem patologia clínica que demandasse tratamento emergencial em caráter de internação em outro serviço; (2) pacientes portadores de oligofrenia ou outra afecção do sistema nervoso central com prejuízo grave das funções cognitivas; (3) pacientes portadores de transtorno psicótico que poderia comprometer as respostas às escalas em uso; (4) pacientes que se recusassem a participar do protocolo de pesquisa pela não assinatura do termo de consentimento. Os critérios (2) e (3) foram verificados na avaliação psiquiátrica de cada paciente. Nenhum paciente foi excluído desta amostra por esses critérios.

\subsubsection{Familiares}

Os familiares passaram por entrevista com equipe do AMJO responsável pelas reuniões psico-educacionais específicas para familiares. Para o preenchimento da escala usada nesse estudo, foram inclusos os familiares que residiam com os pacientes, preferencialmente o cônjuge, e com escolaridade mínima de cinco anos do ensino básico. 


\subsubsection{Intervenção terapêutica}

$\mathrm{O}$ atendimento segue o modelo padrão ambulatorial do IPq-HC-FMUSP, com avaliação psiquiátrica inicial e orientações gerais quanto à natureza do Jogo Patológico. A abstinência absoluta de qualquer forma de jogo envolvendo apostas é a principal orientação e a meta do tratamento. Comorbidades psiquiátricas identificadas são abordadas com o tratamento clínico habitual.

Pela grande demanda e fila de espera, o AMJO ofereceu duas modalidades de tratamento: Terapia cognitivo-comportamental (TCC) em grupo e reuniões psicoeducacionais. Esses tratamentos foram programados para ocorrer concomitantemente e com duração aproximada de seis meses. Os pacientes foram encaminhados de acordo com a ordem de inscrição. Os primeiros pacientes foram encaminhados para os grupos de TCC até completar o número máximo de participantes, e freqüentaram também as reuniões psicoeducacionais. Os pacientes seguintes da lista de espera foram encaminhados para freqüentar somente as reuniões psico-educacionais, que, por sua estrutura, não limitavam o número de participantes. Dessa forma, reduziu-se consideravelmente o tempo de espera por tratamento. Todos os pacientes receberam seguimento psiquiátrico concomitante.

Os jogadores que freqüentaram somente as reuniões psico-educacionais e que, ao final desta modalidade, ainda demandavam continuidade de tratamento específico para Jogo Patológico foram encaminhados para os próximos grupos de TCC que se formavam. Assim, os grupos de TCC subseqüentes foram formados por pacientes vindos diretamente da triagem e pacientes que já haviam concluído o psico-educacional.

Dos 120 pacientes triados, 35 foram encaminhados para participarem do grupo de TCC $(30 \%)$ e 75 pacientes para participarem somente das reuniões psico-educacionais $(70 \%)$. 
I. Reuniões psico-educacionais: baseadas em teoria cognitivocomportamental, especificamente desenvolvidas para jogadores patológicos e adaptadas de modelo canadense de manual para jogadores (Hodgins, 2005) pela aluna e pelo Dr. Hermano Tavares. O programa é de quatro reuniões que ocorrem num período de seis meses, com intervalo de cerca de um mês e meio entre elas.

II. TCC em grupo: o programa foi desenvolvido pela equipe do AMJO especificamente para jogadores patológicos, com freqüência de uma vez por semana, e programação de 18 sessões (duração aproximada de seis meses).

\subsubsection{Avaliação de final de tratamento}

Ao término de cada tratamento, os pacientes que finalizaram o programa foram convocados para reavaliação. Esta reavaliação foi feita por avaliador cego para a modalidade de tratamento.

Dos 120 iniciais, somente 50 finalizaram o tratamento $(41,6 \%)$.

Dos 35 pacientes do grupo de TCC, 18 pacientes chegaram ao final do tratamento (51\%), e, dos 85 pacientes das reuniões psico-educacionais, 32 chegaram ao final do tratamento $(37,6 \%)$.

Dos 120 pacientes, 52 vieram com familiares ao início do tratamento. 


\subsection{Entrevistas e aplicação das escalas}

A aplicação das escalas e entrevistas foi feita em dois momentos: na triagem do AMJO e em reavaliação ao final de tratamento (seis meses após).

\subsubsection{Entrevistas}

As entrevistas foram realizadas pela equipe do AMJO e foram feitos o Questionário de Dados Sócio-Demográficos (QDSD), a avaliação da presença dos critérios para Jo go Patológico do DSM -IV, as questões da Addiction Severity Index - Gambling (ASI-Jogo) e a Timeline Follow-back (TFB), descritas a seguir.

\subsubsection{Questionário de Dados Sócio-Demográficos}

Foi utilizado o Questionário de avaliação sócio-demográfica para a lcoolistas (QDSD), desenvolvido no GREA e adaptada para jogadores (Tavares et al, 2003) para descrição da amostra e comparação entre gêneros.

As seguintes variáveis foram avaliadas:

- Gênero

- Idade

- Etnia

- Estado civil

- Procedência remota

- Religião e freqüência da prática religiosa 
- Anos de educação formal

- Situação profissional

- Indicador de classe econômica

- Idade de início da atividade de jogo

- Idade de início de problemas devidos a jogo

- Idade de procura do primeiro tratamento para jogo

- Intervalo de jogo social (entre o início da atividade de jogo e o surgimento de problemas devido a jogo)

- Intervalo de jogo problema (entre o início de problemas devidos a jogo e procura de tratamento)

- Intervalo total (entre início da atividade de jogo e procura de tratamento)

- Total de horas gastas em episódio típico de jogo

- Período máximo de abstinência voluntária

- Tipo de jogo apostado

- Envolvimento em atividades ilegais

- Tentativas de suicídio

- Comportamento de risco para doenças sexualmente transmissíveis

3.2. 1.2 Critérios diagnósticos para Jogo Patológico segundo o DSM-IV

Foram utilizados os critérios diagnósticos para Jogo Patológico segundo o DSM-IV mostrados a seguir: 


\section{CRITÉRIOS DIAGNÓSTICOS PARA JOGO PATOLÓGICO (DSM-IV)}

A. Comportamento de jogo mal-adaptativo, persistente e recorrente, indicado por cinco (ou mais) dos seguintes quesitos :

1. preocupação com o jogo (por ex., preocupase com reviver experiências de jogo passadas, avalia possibilidades ou planeja a próxima parada, ou pensa em modos de obter dinheiro para jogar)

2. necessidade de apostar quantias de dinheiro cada vez maiores, a fim de obter a excitação desejada

3. esforços repetidos e fracassados no sentido de controlar, reduzir ou cessar com o jogo

4. inquietude ou irritabilidade, quando tenta reduzir ou cessar com o jogo

5. joga como forma de fugir de problemas ou de aliviar humor disfórico (por ex., sentimentos de impotência, culpa, ansiedade, depressão)

6. após perder dinheiro no jogo, freqüentemente volta outro dia para ficar quite ("recuperar o prejuízo")

7. mente para familiares, para o terapeuta ou outras pessoas, para encobrir a extensão do seu envolvimento com o jogo

8. cometeu atos ilegais, tais como falsificação, fraude, furto ou estelionato, para financiar o jogo

9. colocou em perigo ou perdeu um relacionamento significativo, o emprego ou uma oportunidade educacional ou profissional por causa do jogo

10. recorre a outras pessoas com o fim de obter dinheiro para aliviar uma situação financeira desesperadora causada pelo jogo

\section{B. O comportamento de jogar não é melhor explicado por um Episódio Maníaco}

Fonte: Manual Diagnóstico e Estatístico de Transtornos Mentais - 4ª Edição - DSM-IV (1995). Tradução: Dayse Batista e Alceu Fillmann. 


\subsubsection{Addiction Severity Index - Gambling (ASI-Jogo)}

A Addiction Severity Index (ASI) é um instrumento reconhecido e sensível para avaliação de dependências (McLellan et al, 1985). Lesieur e Blume desenvolveram uma seção para Jogo Patológico, a ASI-Gambling, que foi avaliada em 119 jogadores patológicos mostrando boa validade cruzada com escores da SOGS $(r=0,57, p<0,001)$, boa consistência interna (Alfa de Cronbach $=0,73$ ) e sensibilidade a mudanças notadas em pacientes sob tratamento para Jogo Patológico (Lesieur \& Blume, 1991, 1992).

Petry ampliou a validação da ASI-Jogo em uma amostra de 597 sujeitos de quatro populações diferentes (jogadores patológicos envolvidos em estudo sobre tratamento, jogadores patológicos iniciando tratamento ambulatorial, jogadores recrutados por anúncio e dependentes químicos - Petry, 2003). A ASI-Jogo manteve boa consistência interna (Alfa de Cronbach $=0,90)$ e uma análise fatorial mostrou um único fator que explicava $73 \%$ das respostas. Os escores mostraram excelente validade convergente com outras medidas de jogo (escores da SOGS, número de critérios do DSM-IV para Jogo Patológico e dados do Timeline Follow-back) e com fontes externas (informantes colaterais e equipe de tratamento). A ASI-Jogo mostrou-se capaz de discriminar os grupos participantes desse estudo e mantevese estável no período de um mês no grupo de pacientes dependentes químicos que não receberam intervenção para Jogo Patológico.

Os cinco itens da ASI-Jogo foram traduzidos para o português pela aluna e revisados pelo Dr. Hermano Tavares com atenção especial para equivalência cultural dos termos traduzidos (Flaherty et al., 1988; Ellis et al., 1989). ASI-Jogo avalia, nos últimos 30 dias, número de dias de jogo, quantidade de dinheiro gasto em jogo, dias de problemas com jogo, preocupação com jogo e importância atual de tratamento para jogo. 
A TFB é uma técnica de entrevista retroativa desenvolvida para avaliar consumo de álcool (Sobell \& Sobell, 1992). Vem sendo utilizada de forma semelhante para abordar atividade de jogo na área de estudos sobre Jogo Patológico (Petry, 2005; Hodgins et al, 2004; Petry, 2003).

Com esta técnica, o entrevistador determina os dias de jogo e a quantidade de dinheiro apostado, diariamente, em determinado período de tempo. Inicialmente, o entrevistador identifica datas relevantes para o paciente neste período e as utiliza como marcadores que facilitam a recordação das informações. Auxilia e estimula o paciente a se recordar, retrospectivamente, de informações sobre os episódios de jogo e as anota em folha de calendário. Obtém-se, assim, um diário da atividade de jogo no período desejado.

Hodgins e Makarchuk (2003) avaliaram esta técnica para o uso em jogadores patológicos, cobrindo um período de até seis meses prévios, o número de dias de jogo e a quantia de dinheiro gasto em jogo. A TFB mostrou confiabilidade de boa a excelente com teste-reteste (Coeficientes de Correlação Intraclasse variando de 0,61 a 0,98, p < 0,01) e boa concordância com informantes colaterais dos jogadores (Coeficientes de Correlação Intraclasse entre 0,46 a $0,65, \mathrm{p}<0,01)$.

Weinstock e colaboradores ampliaram os estudos psicométricos da TFB que manteve excelente confiabilidade (coeficiente de correlação de Pearson para teste-reteste variando entre 0,74 a $0,96, p<0,01$ ) para freqüência de jogo, duração, saldo do dinheiro gasto em jogo e consumo de álcool durante episódio de jogo. A TFB também mostrou boa correlação com dados obtidos por monitorização diária dos pacientes (coeficientes de correlação de Pearson variando de 0,59 a 0,87 - Weinstock, Whelan \& Meyers, 2004). 
Neste estudo, a TFB cobriu os últimos 30 dias, avaliando dias de jogo, quantidade de dinheiro apostado, quantidade de dinheiro na saída do episódio de jogo e o tempo, em horas, do episódio.

3.2.2 Escalas de auto-preenchimento

Os pacientes preencheram a SOGS, ESJ, G-SAS e a Escala de Adequação Social (EAS). Os familiares preencheram a ESJ adaptada para informante colateral.

\subsubsection{South Oaks Gambling Screen (SOGS)}

A SOGS (Lesieur \& Blume, 1987) é um instrumento utilizado para rastreio em populações clínicas. Pode ser utilizada na forma de entrevista ou auto-preenchimento. O escore máximo da SOGS é 20. Escore maior ou igual a cinco indica provável jogo patológico, enquanto que escores de um a quatro indicam algum problema com jogo. Pacientes que pontuam cinco ou mais na SOGS devem ser avaliados usando os critérios diagnósticos do DSM-IV para Jogo Patológico.

A SOGS foi traduzida para várias línguas, incluindo espanhol, italiano, alemão, japonês, hebreu, entre outras (Lesieur \& Blume, 1992). A SOGS conta com uma versão traduzida e validada para o português no Brasil desenvolvida em dissertação de mestrado apresentada ao Instituto de Psicologia da Universidade de São Paulo (Oliveira, 1997). A versão brasileira da SOGS já foi utilizada em trabalhos envolvendo rastreio e avaliação de indivíduos em ambientes de jogo no Brasil (Oliveira, 2001; Oliveira, 2000). 
A SOGS demonstrou especificidade e confiabilidade adequadas em populações clínicas (Stinchfield, 2002).

Foi usada nesse estudo como instrumento de rastreio e diagnóstico.

3.2.2.2 Escala de Seguimento de Jogadores

A ESJ foi discutida na seção 1.5 .

3.2.2.3 Gambling Symptom Assessment Scale (G-SAS)

A G-SAS (Kim et al, 2001) é uma escala de 12 itens desenvolvida para avaliar intensidade de sintomas de avidez por jogo. As questões abrangem vontade de jogar, pensamentos sobre jogo, atividade de jogo, estresse emocional e problemas causados por jogo. Possui boa confiabilidade (teste-reteste mostrou índice de correlação = 0,704, p < 0,01), boa consistência interna (Alfa de Cronbach $=0,89$ ) e alta correlação com escores da Impressão Clínica Global de gravidade ( $\mathrm{r}=0,812, \mathrm{p}<0,01-$ Guy, 1976).

Já foi utilizada em estudos para avaliar evolução de jogadores em tratamento farmacológico com naltrexone e paroxetina (Grant et al, 2003; Kim et al, 2001).

A G-SAS foi traduzida pela aluna. A primeira versão foi revisada e comparada ao original em inglês pelo Dr. Hermano Tavares com atenção específica para equivalência cultural dos termos relacionados a jogo, produzindo-se a versão definitiva utilizada neste estudo (Flaherty et al., 1988; Ellis et al., 1989). 


\subsubsection{Escala de Adequação Social (EAS)}

A Escala de Adequação Social (EAS) foi traduzida da original Social Adjustment Scale - Self Report (Weissman \& Bothwell, 1976) e validada por Gorenstein e colaboradores (2002). A EAS é a escala de ajuste social que mostra os maiores índices de confiabilidade e validade McDowell \& Newell, 1996). É uma escala de auto-preenchimento com 54 itens que avalia sete áreas específicas: (1) trabalho (externo, doméstico e como estudante); (2) vida social e lazer; (3) relação com a família (incluindo pais, irmãos, cunhados e outros membros da família), (4) relação marital; (5) relação com os filhos; (6) vida doméstica; (7) situação financeira. Fornece, além de um escore total, escores individuais para cada área que são calculados pela média aritmética dos itens respondidos, permitindo uma avaliação específica. Os itens consideram aspectos do desempenho, a qualidade das relações interpessoais e os sentimentos e satisfações pessoais, em relação às duas últimas semanas.

A forma de auto-avaliação da EAS mostrou-se confiável pela alta correlação dos seus resultados com o formato entrevista (Weissman \& Bothwell, 1976). A EAS mostrou sensibilidade para diferenciar grupos de indivíduos, como alcoolistas, deprimidos, esquizofrênicos e normais (Weissman et al, 1978). Mostrou-se sensível também para detectar mudança dos pacientes em função do tratamento, medicamentoso ou psicoterápico (Weissman et al, 1971; Weissman \& Bothwell, 1976; Cooper et al, 1982). 
3.2.2.5 Escala de Seguimento de Jogadores adaptada para informante colateral

Para obter dados de informante externo, as questões da ESJ sobre freqüência de jogo, tempo gasto em jogo, dinheiro gasto em jogo, autonomia, relacionamentos familiares e freqüência de lazer, foram adaptadas para informante colateral (questões 1, 2, 3, 7, 8 e 9). As questões sobre avidez por jogo, posição do paciente frente a dívidas, sofrimento emocional, e satisfação com atividades de lazer (questões 4, 5, 6 e 10) não foram adaptadas por serem subjetivas e de difícil avaliação por observador externo.

\subsection{Análise dos dados}

As análises estatísticas foram feitas com o SPSS 11.0 for Windows.

\subsubsection{Confiabilidade}

Foi feita a concordância inter-juízes utilizado-se os dados obtidos com os 52 pacientes e seus respectivos familiares que compareceram na triagem do AMJO, considerando a avaliação do jogador sobre si mesmo e a do familiar sobre o jogador. Os itens avaliados foram frequiência de jogo, tempo gasto em jogo, dinheiro gasto em jogo, relações familiares, autonomia e frequiência de lazer, que possuem informação do colateral. Foi utilizado o teste de Kappa ponderado (Cohen, 1968). Este cálculo só é possível para matrizes simétricas, isto é, com número idêntico de linhas e colunas, o que não ocorreu com as questões sobre tempo gasto em jogo (nenhum colateral marcou o escore 1) e relacionamentos familiares (nenhum jogador marcou o escore 1, eliminando esta linha da tabela e impossibilitando o cálculo do 
Kappa). Para a realização do cálculo essas tabelas foram ajustadas em um formato $4 \mathrm{X} 4$, onde os escores da linha excluída foram transportados para a linha imediatamente seguinte. $\mathrm{O}$ escore da questão sobre freqüência de lazer foi ajustado e dividido em cinco intervalos simétricos para possibilitar a comparação com os cinco itens da questão do colateral.

\subsubsection{Validação cruzada}

Foram utilizados os dados obtidos com as entrevistas e escalas dos 50 pacientes que iniciaram e finalizaram tratamento para a validação cruzada dos itens da ESJ.

Os escores obtidos em cada questão da ESJ foram correlacionados, através do coeficiente de correlação de Spearman (teste não-paramétrico), com escores de questões específicas de outras escalas e entrevistas, de acordo com o item a ser avaliado. O coeficiente de correlação de Spearman foi utilizado por se tratarem de variáveis ordinais. As correlações foram feitas nos dois tempos: início e final de tratamento.

Para a comparação dos escores sobre relacionamentos familiares, foi calculado um escore Família Total para a EAS, não fornecido originalmente por essa escala, a partir dos escores específicos sobre família: vida familiar expandida, vida marital, relação com filhos e vida doméstica. O escore Família Total foi calculado pela média dos escores específicos. A condensação dos escores específicos da EAS em um único escore justifica-se pelos seguintes motivos: (1) a ESJ avalia relacionamentos familiares em uma única questão que considera o relacionamento com familiares que residem junto com o jogador, sem especificar qual, ou com familiar próximo mas que não reside junto; esta forma de avaliação abrange mais de um escore fornecido pela EAS; (2) alguns sujeitos não têm vida conjugal ou não possuem filhos, e nesses casos os respectivos escores da EAS não são produzidos, reduzindo o tamanho da amostra para comparação e acarretando perda de poder para a comparação. 
As escalas e entrevistas para a validação cruzada neste estudo foram escolhidas por serem as existentes na literatura internacional com dados de validade e confiabilidade disponíveis, serem reconhecidas e terem seu uso difundido. Nos casos em que uma questão da ESJ apresentou correspondência com mais de uma questão da mesma escala ou questões em escalas diferentes, não houve seleção para o cruzamento, sendo feitas todas as correlações possíveis. A tabela 1 mostra cada item da ESJ com as questões correspondentes nas escalas e entrevistas de referência. Os quadros de 1 a 9 mostram os conteúdos das questões relacionadas para validade cruzada. 
Tabela 1 Questões da Escala de Seguimento de Jogadores e questões correspondentes para validação cruzada.

\begin{tabular}{|c|c|}
\hline Item da ESJ & Questões e escores correlacionados \\
\hline $\begin{array}{l}\text { ESJ } 1 \\
\text { (freqüêência de jogo) }\end{array}$ & $\begin{array}{l}\text { ASI - dias de jogo } \\
\text { TFB - dias de jogo } \\
\text { Questionário do colateral, questão } 1\end{array}$ \\
\hline $\begin{array}{l}\text { ESJ } 2 \\
\text { (tempo de jogo) }\end{array}$ & $\begin{array}{l}\text { TFB - horas de jogo } \\
\text { G-SAS } 8 \\
\text { Questionário do colateral, questão } 2\end{array}$ \\
\hline $\begin{array}{l}\text { ESJ } 3 \\
\text { (dinheiro gasto em jogo) }\end{array}$ & $\begin{array}{l}\text { ASI - dinheiro gasto } \\
\text { TFB - dinheiro gasto } \\
\text { TFB - saldo } \\
\text { EAS } 54 \text { - situação financeira } \\
\text { Questionário do colateral, questão } 3\end{array}$ \\
\hline $\begin{array}{l}\text { ESJ } 4 \\
\text { (avidez por jogo) } \\
\text { ESJ } 5 \\
\text { (dívidas) }\end{array}$ & $\begin{array}{l}\text { G-SAS questões } 1 \text { a } 12 \\
\text { G-SAS Total } \\
\text { EAS } 54 \text { - situação financeira }\end{array}$ \\
\hline $\begin{array}{l}\text { ESJ } 6 \\
\text { (sofrimento emocional) } \\
\text { ESJ } 7 \\
\text { (família) }\end{array}$ & $\begin{array}{l}\text { ASI - dias de preocupação } \\
\text { G-SAS } 11 \\
\text { EAS - família total } \\
\text { Questionário do colateral, questão } 4\end{array}$ \\
\hline $\begin{array}{l}\text { ESJ } 9 \text { e } 10 \\
\text { (lazer) }\end{array}$ & $\begin{array}{l}\text { EAS - trabalho } \\
\text { EAS - situação financeira } \\
\text { TFB - dinheiro gasto em jogo } \\
\text { Questionário do colateral, questão } 5 \\
\text { EAS - lazer } \\
\text { Questionário do colateral, questão } 6\end{array}$ \\
\hline
\end{tabular}




\begin{tabular}{|c|c|}
\hline . & $\begin{array}{l}\text { Com que freqüência você jogou nas últimas } 4 \text { semanas? } \\
\text { 6) joguei diariamente } \\
\text { 7) joguei em média mais de uma vez por semana } \\
\text { 8) joguei em média uma vez por semana } \\
\text { 9) joguei ocasionalmente, em média menos de uma vez por semana } \\
\text { 10) não joguei }\end{array}$ \\
\hline ASI & Nos últimos 30 dias, quantos dias você jogou? \\
\hline TFB & Número total de dias de jogo nos últimos 30 dias relatado pelo paciente nesta entrevista. \\
\hline Colateral 1 & $\begin{array}{l}\text { Com que frequiência ele /ela jogou nas últimas } 4 \text { semanas? } \\
\text { 1) jogou diariamente } \\
\text { 2) jogou em média mais de uma vez por semana } \\
\text { 3) jogou em média uma vez por semana } \\
\text { 4) jogou ocasionalmente, em média menos de uma vez por semana } \\
\text { não jogou }\end{array}$ \\
\hline
\end{tabular}


Quadro 2: Conteúdo das questões para validade cruzada sobre tempo gasto em jogo.

\begin{tabular}{|c|c|}
\hline . & $\begin{array}{l}\text { Nas últimas } 4 \text { semanas, da vez em que jogou por mais tempo, quanto tempo jogou? } \\
\text { 1) joguei mais de } 12 \text { horas seguidas } \\
\text { 2) joguei entre } 8 \text { e } 12 \text { horas seguidas } \\
\text { 3) joguei entre } 4 \text { e } 8 \text { horas seguidas } \\
\text { 4) joguei menos de } 4 \text { horas seguidas } \\
\text { 5) não joguei }\end{array}$ \\
\hline $\begin{array}{l}\text { TFB } \\
\text { Tempo }\end{array}$ & Número total de horas de jogo nos últ imos 30 dias relatado pelo paciente nesta entrevista \\
\hline G-SAS 8 & $\begin{array}{l}\text { Durante a última semana, aproximadamente quanto tempo no total você passou jogando ou em atividades relacionadas ao } \\
\text { jogo? Por favor, circule o número mais apropriado: } \\
\text { 0) nenhum } \\
\text { 1) } 2 \text { horas ou menos } \\
\text { 2) } 2 \text { a } 7 \text { horas } \\
\text { 3) } 7 \text { a } 21 \text { horas } \\
\text { 4) Mais de } 21 \text { horas }\end{array}$ \\
\hline Colateral 2 & $\begin{array}{l}\text { Nas últimas } 4 \text { semanas, da vez em que jogou por mais tempo, quanto tempo ele /ela jogou? } \\
\text { 1) jogou mais de } 12 \text { horas seguidas } \\
\text { 2) jogou entre } 8 \text { e } 12 \text { horas seguidas } \\
\text { 3) jogou entre } 4 \text { e } 8 \text { horas seguidas } \\
\text { 4) jogou menos de } 4 \text { horas seguidas } \\
\text { 5) não jogou }\end{array}$ \\
\hline
\end{tabular}


Quadro 3: Conteúdo das questões para validade cruzada sobre dinheiro gasto em jogo.

\begin{tabular}{|c|c|}
\hline ESJ 3 & $\begin{array}{l}\text { Nas últimas } 4 \text { semanas, quanto dinheiro você perdeu no jogo em relação à sua renda? } \\
\text { 1) joguei sem ter renda própria, OU fiz empréstimos, desfiz-me de bem pessoal, economias, OU roubei (passei cheques sem fundos, } \\
\text { falsifiquei cheques) para jogar ou pagar dívidas de jogo } \\
\text { 2) possuo renda própria e perdi mais que o equivalente a minha renda } \\
\text { 3) possuo renda própria e perdi o equivalente a minha renda ou mais que a metade desse valor } \\
\text { 4) possuo renda própria e perdi menos que a metade desse valor } \\
\text { 5) não tive perdas }\end{array}$ \\
\hline ASI & Nos últimos 30 dias, quanto dinheiro você gastou em jogo? \\
\hline $\begin{array}{l}\text { TFB - } \\
\text { Dinheiro } \\
\text { gasto }\end{array}$ & Número total de dinheiro gasto em jogo nos últimos 30 dias relatado pelo paciente nesta entrevista \\
\hline $\begin{array}{l}\text { TFB - } \\
\text { Saldo }\end{array}$ & Diferença do total de dinheiro gasto em jogo e o total de dinheiro ganho em jogo nos últimos 30 dias, relatada pelo paciente nesta entrevista \\
\hline $\begin{array}{l}\text { EAS - } \\
\text { Situação } \\
\text { Financeira } \\
54\end{array}$ & $\begin{array}{l}\text { Você teve dinheiro suficiente para suprir suas necessidades e as de sua família nas duas últimas semanas? } \\
\text { 1) tive dinheiro suficiente para as necessidades básicas } \\
\text { 2) no geral tive dinheiro suficiente, porém com pequenas dificuldades } \\
\text { 3) cerca de metade do tempo tive dificuldades financeiras, porém não precisei pedir dinheiro emprestado } \\
\text { 4) no geral não tive dinheiro suficiente e precisei pedir dinheiro emprestado } \\
\text { 5) tive sérias dificuldades }\end{array}$ \\
\hline Colateral 3 & $\begin{array}{l}\text { Nas últimas } 4 \text { semanas, quanto dinheiro ele /ela perdeu no jogo em relação à renda dele /dela? } \\
\text { 1) jogou sem ter renda própria, OU fez empréstimos, desfez-se de bem pessoal, economias, OU roubou (passou cheques sem fundos, } \\
\text { falsificou cheques) para jogar ou pagar dívidas de jogo } \\
\text { 2) ele /ela possui renda própria e perdeu mais que o equivalente à renda dele /dela } \\
\text { 3) ele /ela possui renda própria e perdeu o equivalente à renda dele /dela, OU mais que a metade desse valor } \\
\text { 4) ele /ela possui renda própria e perdeu menos que a metade desse valor } \\
\text { 5) não houve perdas }\end{array}$ \\
\hline
\end{tabular}




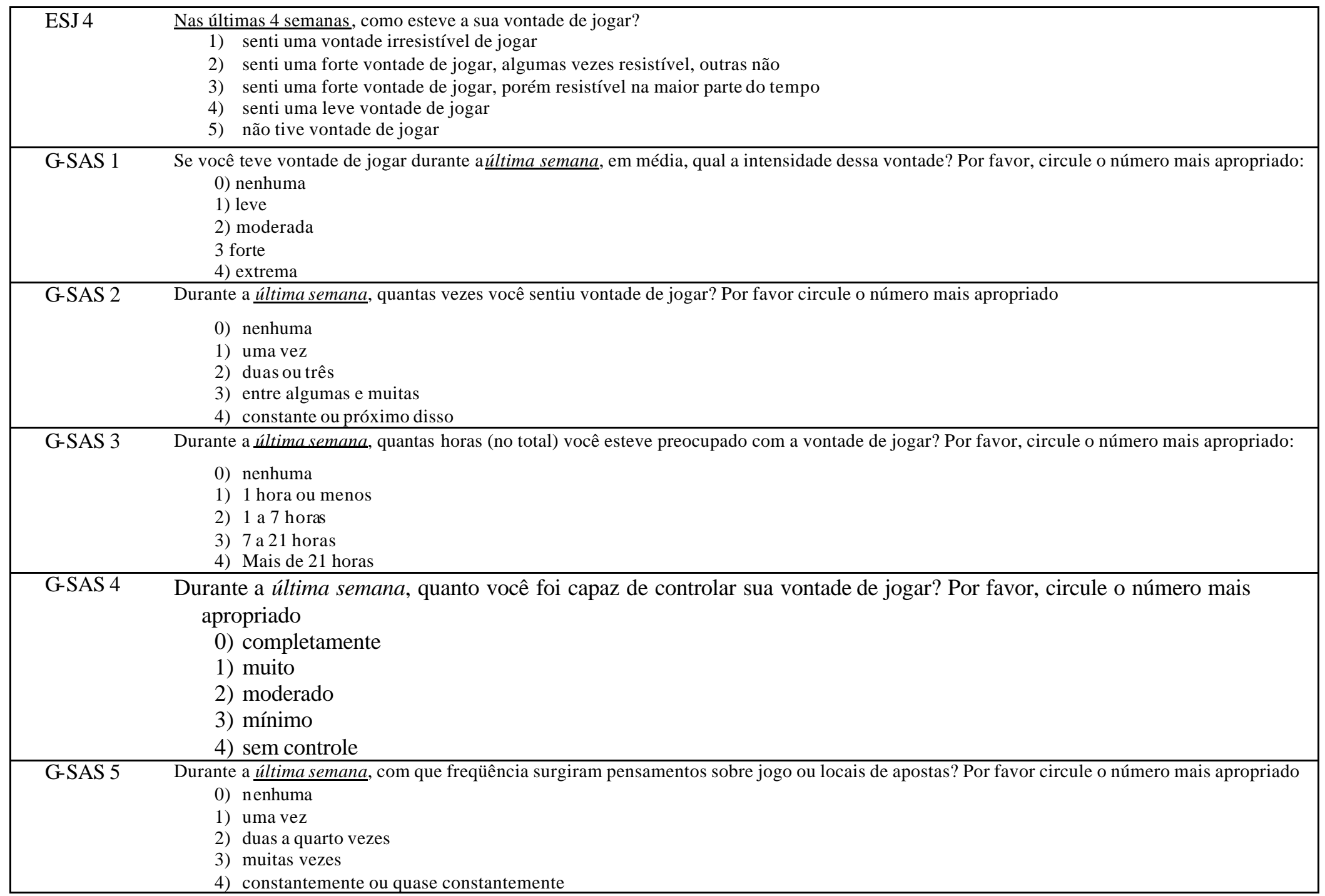


Quadro 4: Conteúdo das questões para validade cruzada sobre vontade de jogar (cont.).

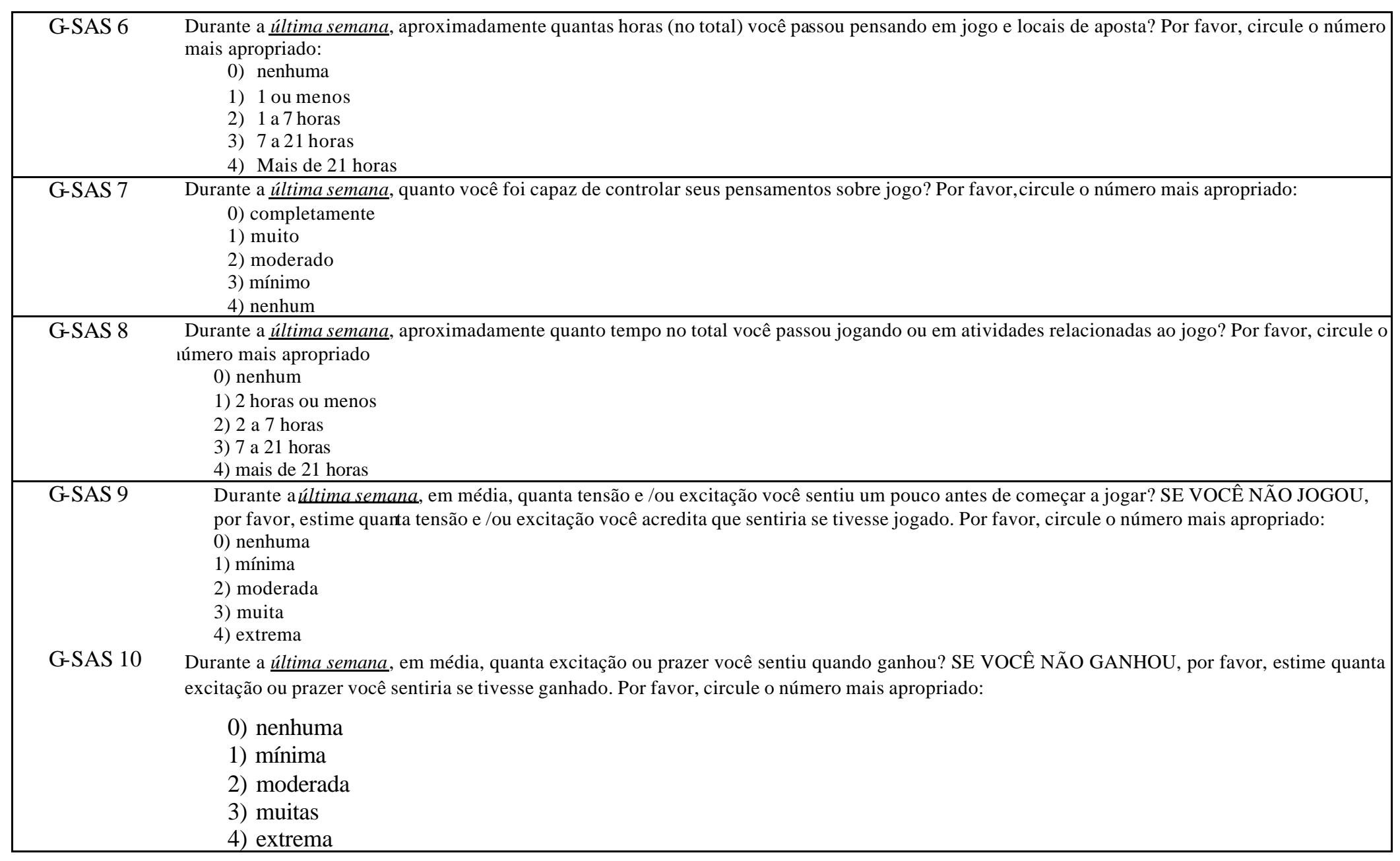


Quadro 4: Conteúdo das questões para validade cruzada sobre vontade de jogar (cont.).

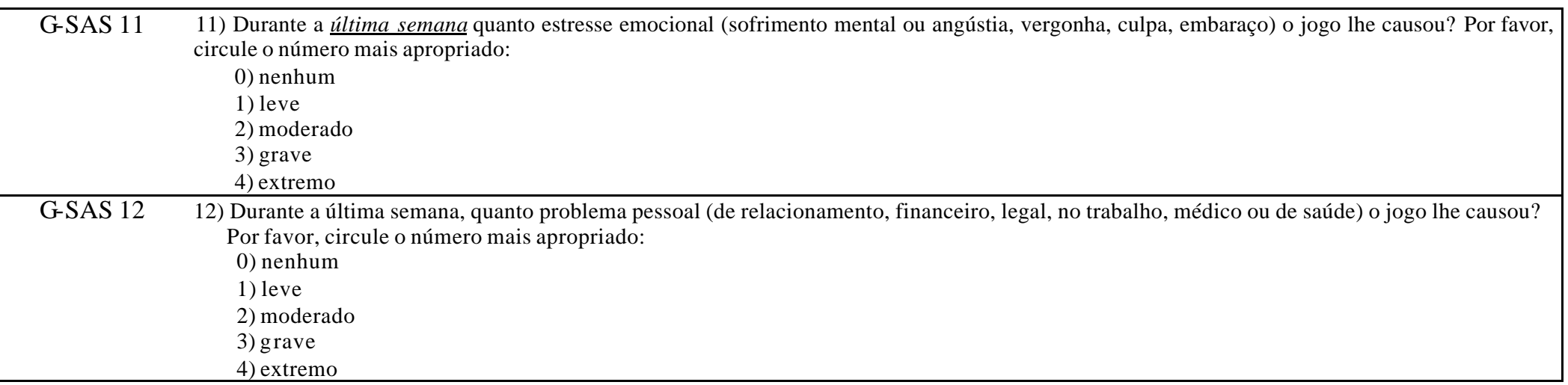




\begin{tabular}{|ll|}
\hline ESJ 5 & Como você tem se sentido em relação a suas dívidasnas últimas 4 semanas ? \\
1) & sinto-me extremamente pressionado, tenho jogado como forma de tentar obter dinheiro para saldar dívidas ou para aliviar as preocupações \\
& com elas \\
2) & sinto-me extremamente pressionado, porém não joguei, ou se joguei não foi motivado pelas dívidas \\
3) & tenho dívidas, mas elas não me preocupam no momento \\
4) & não tenho dívidaS \\
\hline EAS 54 Você teve dinheiro suficiente para suprir suas necessidades e as de sua família nas duas últimas semanas? \\
1) tive dinheiro suficiente para as necessidades básicas \\
2) no geral tive dinheiro suficiente, porém com pequenas dificuldades \\
3) cerca de metade do tempo tive dificuldades financeiras, porém não precisei pedir dinheiro emprestado \\
4) no geral não tive dinheiro suficiente e precisei pedir dinheiro emprestado \\
5) tive sérias dificuldades
\end{tabular}




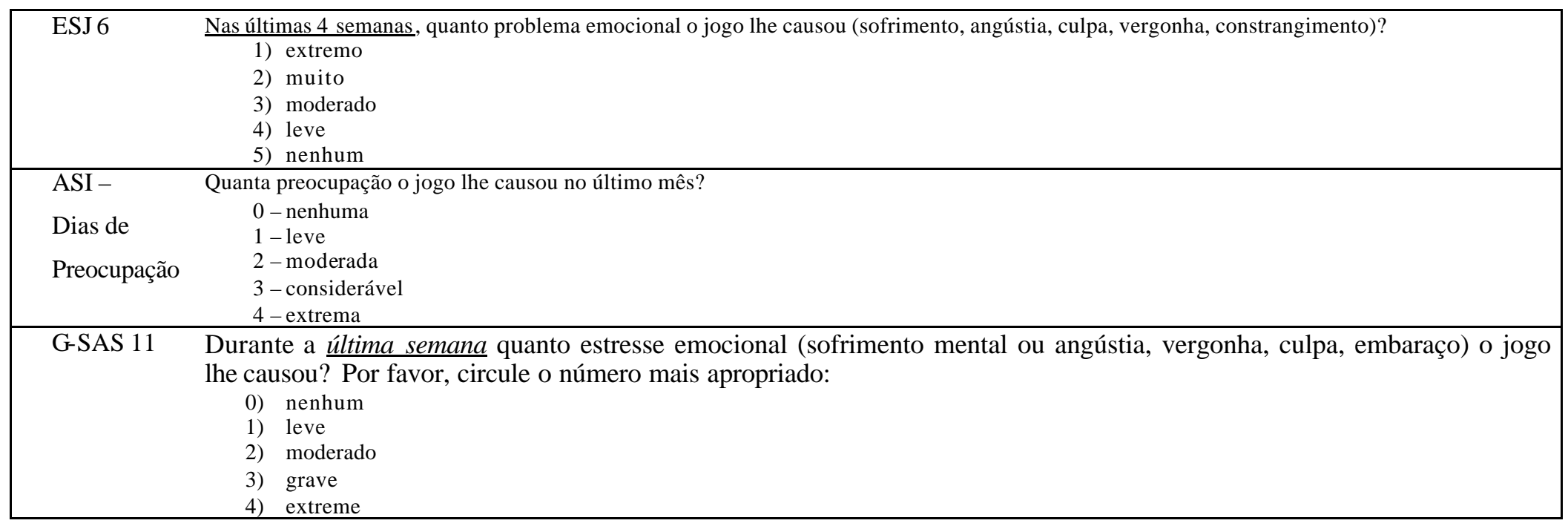


Quadro 7: Conteúdo das questões para validade cruzada sobre vida familiar.

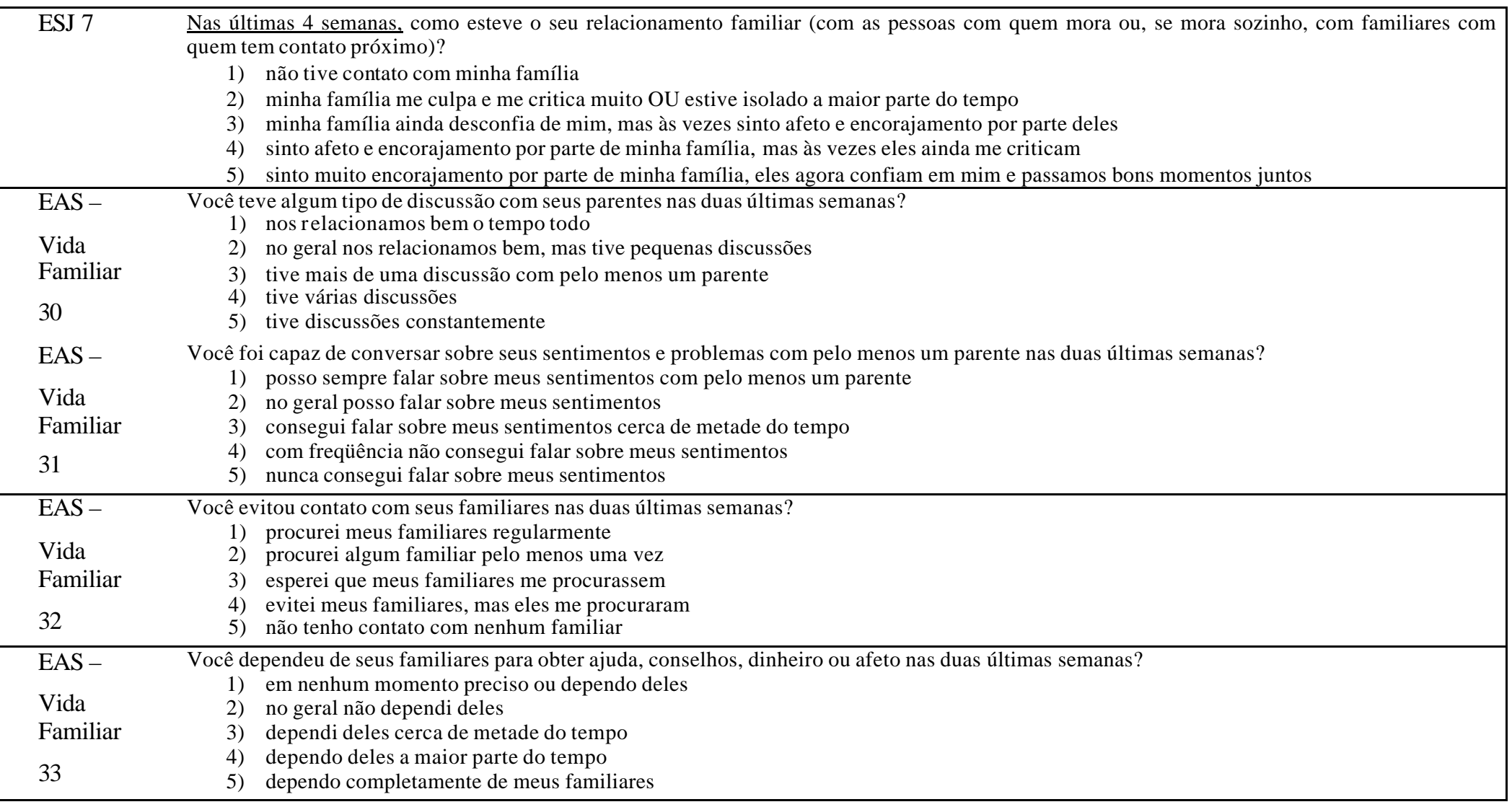




\begin{tabular}{|c|c|}
\hline EAS - & $\begin{array}{l}\text { Você quis contrariar seus familiares a fim de provocá-los nas duas últimas semanas? } \\
\text { 1) não quis contrariá-los }\end{array}$ \\
\hline Vida & 2) uma ou duas vezes quis contrariá-los \\
\hline Familiar & 3) quis contrariá-los cerca de metade do tempo \\
\hline \multirow{2}{*}{34} & 4) quis contrariá-los a maior parte do tempo \\
\hline & 5) eu os contrariei o tempo todo \\
\hline EAS - & Você se preocupou, sem nenhuma razão, com coisas que pudessem acontecer a seus familiares nas duas últimas semanas? \\
\hline Vida & 1) não me preocupei sem razão \\
\hline & 2) me preocuper uma ou duas vezes \\
\hline Familiar & 3) me preocupei cerca de metade do tempo \\
\hline \multirow{2}{*}{35} & 4) me preocupei a maior parte do tempo \\
\hline & $\begin{array}{l}\text { 5) me preocupei o tempo todo } \\
\text { 8) não se aplica, não tenho familiares }\end{array}$ \\
\hline EAS - & Nas duas últimas semanas, você achou que decepcionou ou foi injusto com seus familiares? \\
\hline & 1) não achei que os decepcionei em nada \\
\hline Vida & 2) no geral não achei que os decepcionei \\
\hline Familiar & 3) cerca de metade do tempo achei que os decepcionei \\
\hline 36 & 4) a maior parte do tempo achei que os decepcionei \\
\hline EAS - & $\begin{array}{l}\text { Em algum momento nas últimas duas semanas você achou que seus familiares o decepcionaram ou foram injustos com você? } \\
\text { 1) em nenhum momento achei que eles me decepcionaram }\end{array}$ \\
\hline Vida & 2) no geral achei que eles não me decepcionaram \\
\hline Familiar & cerca de metade do tempo achei que eles me decepcionaram \\
\hline \multirow{2}{*}{37} & a maior parte do tempo achei que eles me decepcionaram \\
\hline & 5) tenho muita mágoa porque eles me decepcionaram \\
\hline EAS - & Você teve algum tipo de discussão com seu companheiro nas duas últimas semanas? \\
\hline Vida Marital & 2) no geral nos relacionamos bem, mas tivemos pequenas discussões \\
\hline \multirow{3}{*}{38} & 3) tivemos mais de uma discussão \\
\hline & 4) tivemos várias discussões \\
\hline & 5) tivemos discussões constantemente \\
\hline
\end{tabular}


Quadro 7: Conteúdo das questões para validade cruzada sobre vida familiar (cont).

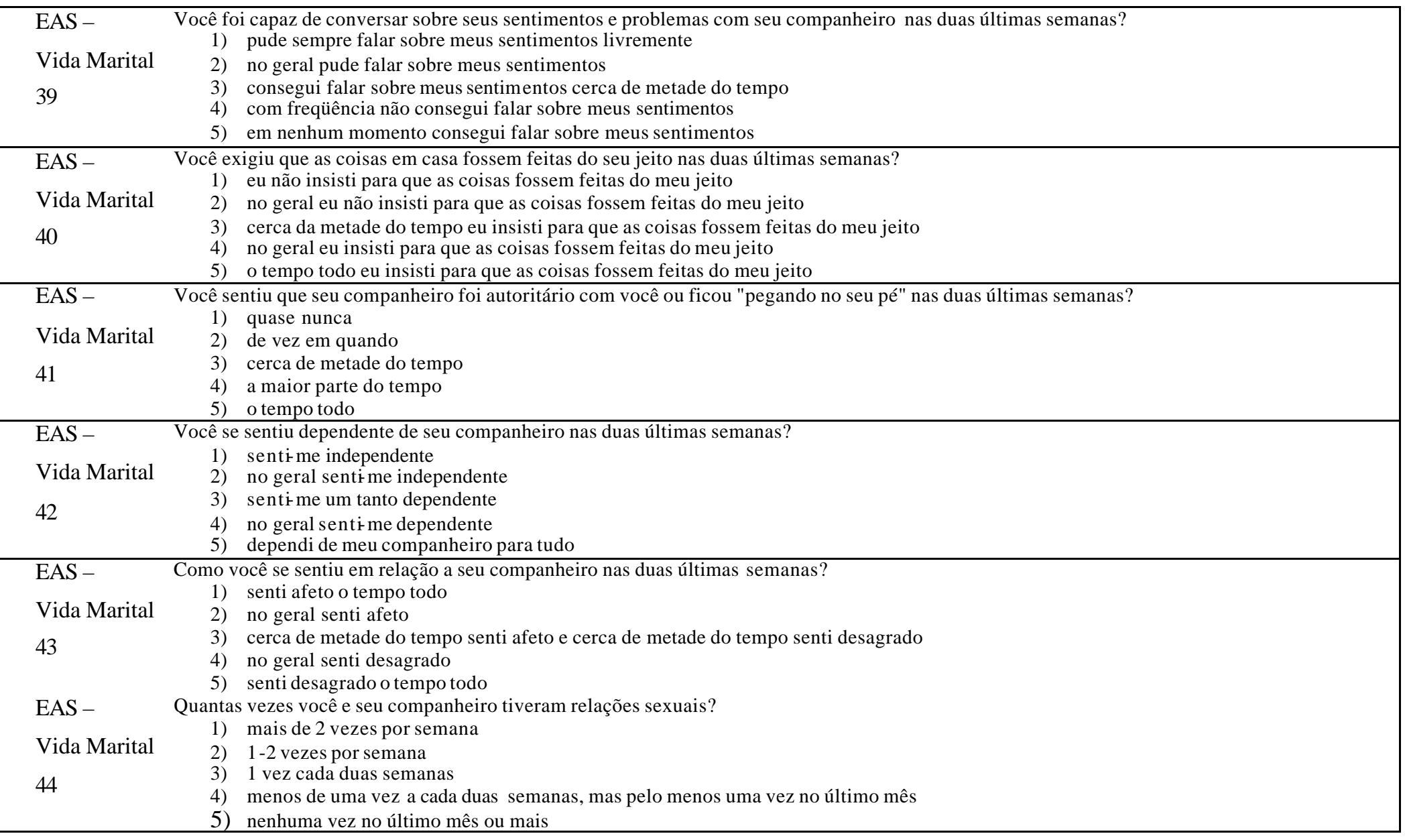


Quadro 7: Conteúdo das questões para validade cruzada sobre vida familiar (cont).

\begin{tabular}{|c|c|}
\hline $\begin{array}{l}\text { EAS - } \\
\text { Vida Marital } \\
45\end{array}$ & $\begin{array}{l}\text { Você teve algum problema durante relações sexuais, tal como dor, nas duas últimas semanas? } \\
\text { 1) nenhum } \\
\text { 2) uma ou duas vezes } \\
\text { 3) cerca de metade das vezes } \\
\text { 4) a maior parte das vezes } \\
\text { 5) todas as vezes } \\
\text { 8) não se aplica, não tive relações sexuais nas duas últimas semanas }\end{array}$ \\
\hline $\begin{array}{l}\text { EAS - } \\
\text { Vida Marital } \\
46\end{array}$ & $\begin{array}{l}\text { Como você se sentiu quanto às relaçõessexuais nas duas últimas semanas? } \\
\text { 1) senti prazer todas as vezes } \\
\text { 2) no geral senti prazer } \\
\text { 3) senti prazer cerca de metade das vezes } \\
\text { 4) no geral não senti prazer } \\
\text { 5) não senti prazer nenhuma das vezes } \\
\text { 8) não se aplica, não tive relações }\end{array}$ \\
\hline $\begin{array}{l}\text { EAS - } \\
\text { Filhos } \\
47\end{array}$ & $\begin{array}{l}\text { Você tem se interessado pelas atividades de seus filhos, escola, lazer, durante as duas últimas semanas? } \\
\text { 1) interessei-me e estive ativamente envolvido o tempo todo } \\
\text { 2) no geral interessei- me e estive envolvido } \\
\text { 3) cerca de metade do tempo interessei me } \\
\text { 4) no geral não me interessei } \\
\text { 5) estive desinteressado o tempo todo }\end{array}$ \\
\hline $\begin{array}{l}\text { EAS - } \\
\text { Filhos } \\
48\end{array}$ & $\begin{array}{l}\text { Você foi capaz de conversar e ouvir seus filhos nas duas últimassemanas? (crianças maiores de } 2 \text { anos) } \\
\text { 1) sempre consegui comunicar-me com eles } \\
\text { 2) no geral consegui comunicar-me com eles } \\
\text { 3) cerca de metade das vezes consegui comunicar-me com eles } \\
\text { 4) no geral não consegui comunicar-me com eles } \\
\text { 5) não consegui comunicar-me com eles } \\
\text { 8) não se aplica, não tenho filhos maiores de } 2 \text { anos }\end{array}$ \\
\hline $\begin{array}{l}\text { EAS - } \\
\text { Filhos } \\
49\end{array}$ & $\begin{array}{l}\text { Como você se relacionou com seus filhos nas duas últimas semanas? } \\
\text { 1) não tive nenhuma discussão e me relacionei muito bem } \\
\text { 2) no geral me relacionei bem, mas tive pequenas discussões } \\
\text { 3) tive mais de uma discussão } \\
\text { 4) tive várias discussões } \\
\text { 5) tive discussões constantemente }\end{array}$ \\
\hline
\end{tabular}


Quadro 7: Conteúdo das questões para validade cruzada sobre vida familiar (cont).

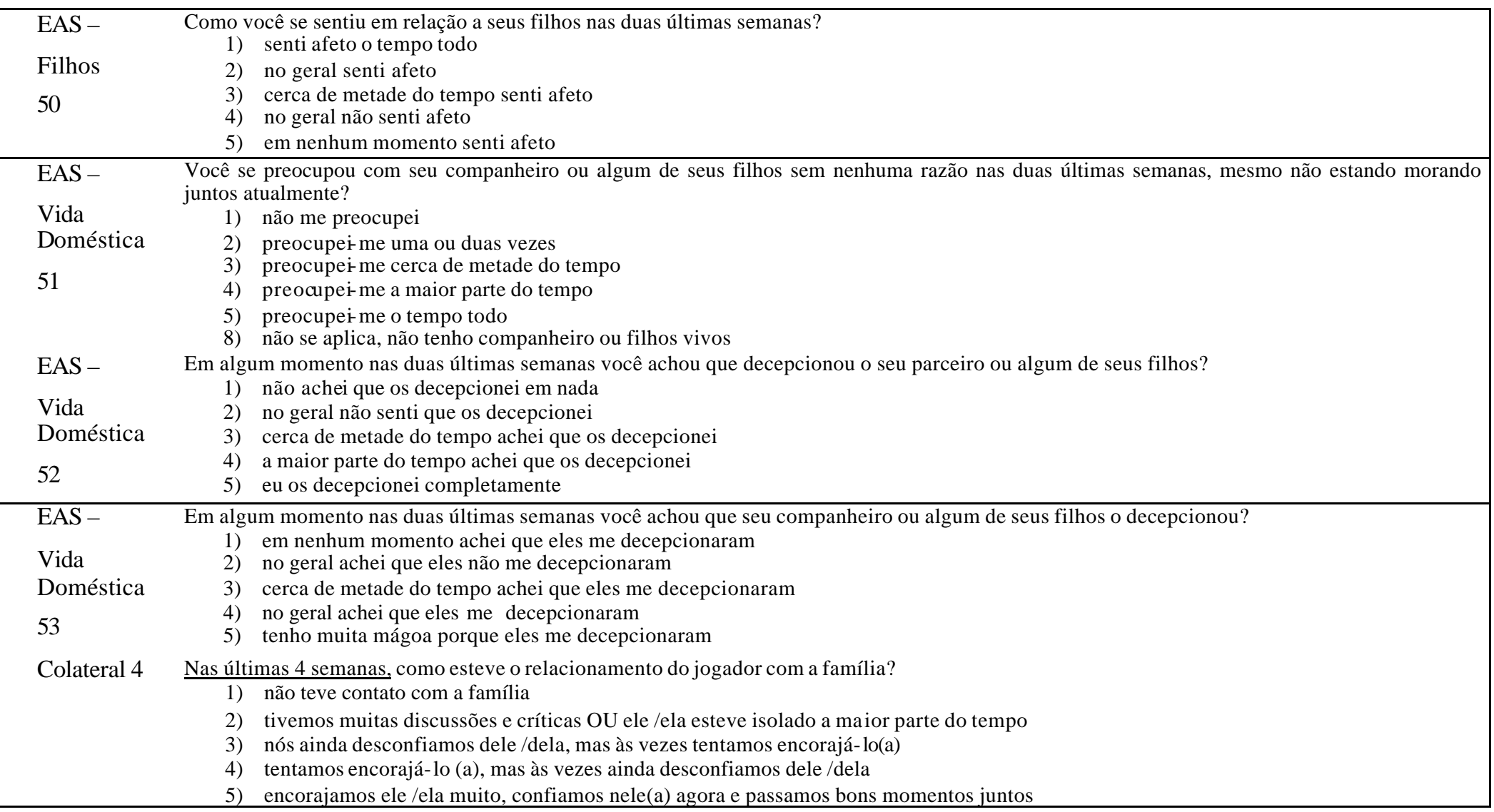




\begin{tabular}{|c|c|}
\hline ESJ 8 & $\begin{array}{l}\text { Nas últimas } 4 \text { semanas você trabalhou ou teve renda própria para manutenção de suas necessidades básicas: asseio, saúde, alimentação e moradia? } \\
\text { Você está satisfeito com seu trabalho? } \\
\text { 1) estou desempregado, inativo ou sem renda própria no momento, OU a manutenção das minhas necessidades básicas passaram para a } \\
\text { responsabilidade de outra pessoa } \\
\text { 2) estou desempregado, sem renda no momento, mas desempenhando atividades úteis para a manutenção das minhas necessidades básicas } \\
\text { (inclui atividades não remuneradas como dona de casa) } \\
\text { 3) estou empregado ou com outra fonte de renda própria, porém insuficiente para a manutenção de todas as minhas necessidades básicas } \\
\text { 4) estou empregado ou com outra fonte de renda própria suficiente para a manutenção das minhas necessidades básicas } \\
\text { 5) estou empregado ou com outra fonte de renda própria que excede minhas necessidades básicas, OU estou prosperando, OU sinto muita } \\
\text { satisfação no meu trabalho }\end{array}$ \\
\hline $\begin{array}{l}\text { EAS - } \\
\text { Trabalho fora } \\
\text { de casa }\end{array}$ & $\begin{array}{l}\text { Quantos dias de trabalho remunerado você perdeu nas duas últimas semanas? } \\
\text { 1) não perdi nenhum dia } \\
\text { 2) perdi um dia } \\
\text { 3) perdi cerca de metade do tempo de trabalho } \\
\text { 4) perdi mais da metade do tempo de trabalho, mas trabalhei pelo menos um dia } \\
\text { 5) não trabalhei nenhum dia } \\
\text { 8) estive de férias nesse período }\end{array}$ \\
\hline $\begin{array}{l}\text { EAS - } \\
\text { Trabalho fora }\end{array}$ & $\begin{array}{l}\text { Você foi capaz de realizar seu trabalho nas duas últimas semanas? } \\
\text { 1) fiz meu trabalho muito bem } \\
\text { 2) fiz meu trabalho bem, porém tive algumas pequenas dificuldades } \\
\text { 3) necessitei de auxílio no trabalho e cerca de metade do tempo não o fiz adequadamente } \\
\text { 4) fiz meu trabalho de maneira inadequada na maior parte do tempo } \\
\text { 5) fiz meu trabalho de maneira inadequada durante o tempo todo }\end{array}$ \\
\hline $\begin{array}{l}\text { EAS - } \\
\text { Trabalho fora } \\
\text { de casa } \\
3\end{array}$ & $\begin{array}{l}\text { Você se sentiu envergonhado de seu desempenho no trabalho nas duas últimas semanas? } \\
\text { 1) em nenhum momento me senti envergonhado } \\
\text { 2) uma ou duas vezes me senti um pouco envergonhado } \\
\text { 3) cerca de metade do tempo me senti envergonhado } \\
\text { 4) senti me envergonhado a maior parte do tempo } \\
\text { 5) sentime envergonhado o tempo todo }\end{array}$ \\
\hline $\begin{array}{l}\text { EAS - } \\
\text { Trabalho fora } \\
\text { de casa } \\
4\end{array}$ & $\begin{array}{l}\text { Você teve algum tipo de discussão com as pessoas com quem você trabalha, nas duas últimas semanas? } \\
\text { 1) não tive nenhuma discussão e me relacionei muito bem } \\
\text { 2) no geral me relacionei bem, mas tive pequenas discussões } \\
\text { 3) tive mais de uma discussão } \\
\text { 4) tive várias discussões } \\
\text { 5) tive discussões constantemente }\end{array}$ \\
\hline
\end{tabular}




\begin{tabular}{|c|c|}
\hline $\mathrm{EAS}-$ & $\begin{array}{l}\text { Você se sentiu chateado, preocupado ou desconfortável enquanto realizava seu trabalho, nas duas últimas semanas? } \\
\text { 1) em nenhum momento me senti assim }\end{array}$ \\
\hline Trabalho fora & 2) sentime assim uma ou duas vezes \\
\hline de casa & 3) senti-me assim cerca de metade do tempo \\
\hline & 4) sentime assim a maior parte do tempo \\
\hline 5 & 5) sentime assim o tempo todo \\
\hline EAS - & Você achou seu trabalho int eressante nas duas últimas semanas? \\
\hline Trabalho fora & $\begin{array}{l}\text { 1) meu trabalho foi interessante praticamente o tempo todo } \\
\text { 2) uma ou duas vezes meu trabalho não foi interessante }\end{array}$ \\
\hline & 3) cerca de metade do tempo meu trabalho não foi interessante \\
\hline de casa & meu trabalho não foi interessante a maior parte do t empo \\
\hline 6 & meu trabalho não foi interessante o tempo todo \\
\hline EAS - & Quantos dias você realizou tarefas domésticas nas duas últimas semanas? \\
\hline Trabalhoem & 1) diariamente \\
\hline 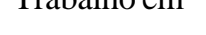 & realizei tarefas domésticas quase todos os dias \\
\hline casa & $\begin{array}{l}\text { 3) realizei tarefas domésticas cerca de metade do tempo } \\
\text { 4) no geral não realizei tarefas domésticas }\end{array}$ \\
\hline 7 & 5) fui totalmente incapaz de realizar tarefas domésticas \\
\hline & estive ausente de casa nas duas últimas semanas \\
\hline EAS - & $\begin{array}{l}\text { Nas duas últimas semanas, você foi capaz de realizar suas tarefas domésticas, tais como cozinhar, limpar, lavar, fazer compras, consertos caseiros, } \\
\text { etc.? }\end{array}$ \\
\hline Trabalho em & realizei as tarefas muito bem \\
\hline casa & realizei as tarefas bem, porém tive pequenas dificuldades \\
\hline casa & necessitei de auxílio nas tarefas e cerca de metade do tempo não as fiz adequadamente \\
\hline 8 & $\begin{array}{l}\text { 4) fiz minhas tarefas de maneira inadequada na maior parte do tempo } \\
\text { 5) fiz minhas tarefas de maneira inadequada o tempo todo }\end{array}$ \\
\hline $\mathrm{EAS}-$ & Você se sentiu envergonhado de seu desempenho nas tarefas domésticas, nas duas últimas semanas? \\
\hline Trabalho em & 1) em nenhum momento me senti envergonhado \\
\hline H Tavanto chit & $\begin{array}{l}\text { 2) uma ou duas vezes me senti um pouco envergonhado } \\
\text { 3) cerca de metade do tempo me senti envergonhado }\end{array}$ \\
\hline casa & 4) sentime envergonhado a maior parte do tempo \\
\hline 9 & sentime envergonhado o tempo todo \\
\hline
\end{tabular}




\begin{tabular}{|c|c|}
\hline $\begin{array}{l}\text { EAS - } \\
\text { Trabalho em } \\
\text { casa } \\
10\end{array}$ & $\begin{array}{l}\text { Você teve algum tipo de discussão com vendedores, comerciantes ou vizinhos, nas duas últimas semanas? } \\
\text { 1) não tive nenhuma discussão e me relacionei muito bem } \\
\text { 2) no geral me relacionei bem, mas tive peque nas discussões } \\
\text { 3) tive mais de uma discussão } \\
\text { 4) tive várias discussões } \\
\text { 5) tive discussões constantemente }\end{array}$ \\
\hline $\begin{array}{l}\text { EAS - } \\
\text { Trabalho em } \\
\text { casa } \\
11\end{array}$ & $\begin{array}{l}\text { Você se sentiu incomodado com o seu trabalho doméstico, nas duas últimas semanas? } \\
\text { 1) em nenhum momento me senti incomodado } \\
\text { 2) sentime in comodado uma ou duas vezes } \\
\text { 3) senti me incomodado cerca de metade do tempo } \\
\text { 4) senti me incomodado a maior parte do tempo } \\
\text { 5) sentime incomodado o tempo todo }\end{array}$ \\
\hline $\begin{array}{l}\text { EAS - } \\
\text { Trabalho em } \\
\text { casa } \\
12\end{array}$ & $\begin{array}{l}\text { Você achou seu trabalho doméstico interessante, nas duas últimas semanas? } \\
\text { 1) meu trabalho foi interessante na maior parte do tempo } \\
\text { 2) uma ou duas vezes meu trabalho não foi interessante } \\
\text { 3) cerca de metade do tempo meu trabalho não foi interessante } \\
\text { 4) meu trabalho não foi interessante a maior parte do tempo } \\
\text { 5) meu trabalho não foi interessante o tempo todo }\end{array}$ \\
\hline $\begin{array}{l}\text { EAS - } \\
\text { Estudantes } \\
13\end{array}$ & $\begin{array}{l}\text { Quantos dias de aula você perdeu, nas duas últimas semanas? } \\
\text { 1) não perdi nenhum dia } \\
\text { 2) perdi poucos dias de aula } \\
\text { 3) perdi cerca de metade do tempo de aula } \\
\text { 4) perdi mais da metade do tempo de aula } \\
\text { 5) não fui à escola nenhum dia } \\
\text { 8)estive de férias nesse período }\end{array}$ \\
\hline $\begin{array}{l}\text { EAS - } \\
\text { Estudantes } \\
14\end{array}$ & $\begin{array}{l}\text { Você foi capaz de realizar suas tarefas escolares, nas duas últimas semanas? } \\
\text { 1) fiz minhas tarefas muito bem } \\
\text { 2) fiz minhas tarefas, porém tive pequenas dificuldades } \\
\text { 3) necessitei de ajuda nas minhas tarefas e cerca de metade do tempo não as fiz adequadamente } \\
\text { 4) fiz minhas tarefas de maneira inadequada na maior parte do tempo } \\
\text { 5) fiz minhas tarefas de maneira inadequada o tempo todo } \\
\end{array}$ \\
\hline $\begin{array}{l}\text { EAS - } \\
\text { Estudantes } \\
15\end{array}$ & $\begin{array}{l}\text { Você se sentiu envergonhado de seu desempenho escolar, nas duas últ imas semanas? } \\
\text { 1) em nenhum momento me senti envergonhado } \\
\text { 2) uma ou duas vezes me senti envergonhado } \\
\text { 3) cerca de metade do tempo me senti envergonhado } \\
\text { 4) sentime envergonhado a maior parte do tempo } \\
\text { 5) sentime envergonhado o tempo todo }\end{array}$ \\
\hline
\end{tabular}




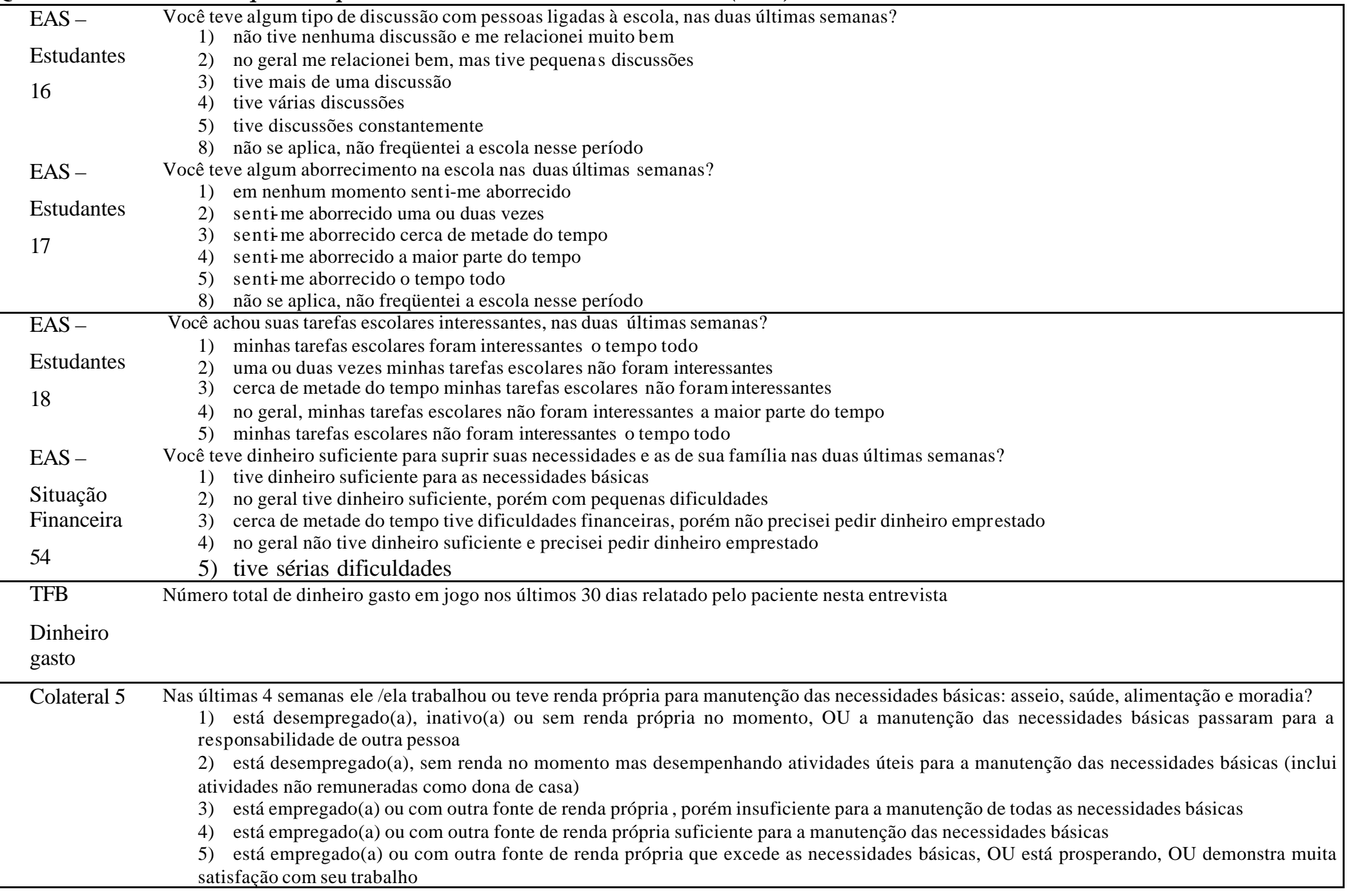




\begin{tabular}{|c|c|c|c|c|c|c|}
\hline \multirow[t]{16}{*}{ ESJ 9} & \multicolumn{6}{|c|}{$\begin{array}{l}\text { Como você tem ocupado seu tempo livre nas últimas } 4 \text { semanas? Utilize os números abaixo para marcar o número de vezes que realizou cada uma } \\
\text { das atividades descritas. }\end{array}$} \\
\hline & $\begin{array}{l}\text { em academias ou clubes } \\
\text { em ambiente externo, como corridas ou }\end{array}$ & 0 & 1 & 2 & 3 & $4 \mathrm{ou}+$ \\
\hline & caminhadas & 0 & 1 & 2 & 3 & $4 \mathrm{ou}+$ \\
\hline & joguei futebol ou outros esportes coletivos & 0 & 1 & 2 & 3 & $4 \mathrm{ou}+$ \\
\hline & outras._Especifique: & 0 & 1 & 2 & 3 & $4 \mathrm{ou}+$ \\
\hline & \multicolumn{6}{|l|}{ Atividades culturais } \\
\hline & \multirow{2}{*}{$\begin{array}{l}\text { fui ao cinema, teatro, museu ou exposição de arte } \\
\text { ouvi música }\end{array}$} & 0 & 1 & 2 & 3 & $4 \mathrm{ou}+$ \\
\hline & & 0 & 1 & 2 & 3 & 4 ou + \\
\hline & leitura individual, em grupo ou participei de um curso0 & 1 & 2 & 3 & $4 \mathrm{ou}+$ & \\
\hline & \multirow{2}{*}{\multicolumn{6}{|c|}{$\begin{array}{l}\text { outras. Especifique: } \\
\text { Atividades de grupo }\end{array}$}} \\
\hline & & & & & & \\
\hline & \multicolumn{6}{|l|}{ fui ao JA ou outro grupo de anônimos, grupos } \\
\hline & \multirow{2}{*}{$\begin{array}{l}\text { religiosos ou de reflexão, grupos de atividade voluntária } \\
\text { fui à igreja }\end{array}$} & 0 & 1 & 2 & 3 & 4 ou + \\
\hline & & 0 & 1 & 2 & 3 & $4 \mathrm{ou}+$ \\
\hline & passei meu tempo com amigos & 0 & 1 & 2 & & $4 \mathrm{ou}+$ \\
\hline & outras. Especifique: & 01 & 2 & 3 & $4 \mathrm{ou}+$ & \\
\hline \multirow[t]{6}{*}{ ESJ 10} & \multicolumn{6}{|l|}{ Qual foi a sua satisfação em realizar as atividades acima? } \\
\hline & \multicolumn{6}{|l|}{ 1) Nenhuma, ou não fiz nada } \\
\hline & \multicolumn{6}{|l|}{ 2) Muito pouca satisfação } \\
\hline & \multicolumn{6}{|l|}{ 3) Pouca satisfação } \\
\hline & \multicolumn{6}{|l|}{ 4) Razoável satisfação } \\
\hline & \multicolumn{6}{|l|}{ 5) Muita satisfação } \\
\hline EAS - & \multicolumn{6}{|c|}{ Quantos amigos você viu ou conversou ao telefone nas duas últimas semanas? } \\
\hline & \multicolumn{6}{|c|}{ 1) 9 ou mais amigos } \\
\hline Lazer & \multicolumn{6}{|l|}{ 2) 5 a 8 amigos } \\
\hline 19 & \multirow{2}{*}{\multicolumn{6}{|c|}{ 3) 2 a 4 amigos }} \\
\hline & \multirow{2}{*}{\multicolumn{6}{|c|}{$\begin{array}{l}\text { 4) um amigo } \\
\text { 5) nenhum amigo }\end{array}$}} \\
\hline & & & & & & \\
\hline EAS - & \multirow{2}{*}{\multicolumn{6}{|c|}{$\begin{array}{l}\text { Você foi capaz de conversar sobre seus sentimentos e problemas com pelo menos um amigo nas duas últimas semanas? } \\
\text { 1) posso sempre falar sobre meus sentimentos }\end{array}$}} \\
\hline & & & & & & \\
\hline Lazer & \multicolumn{6}{|l|}{ 2) no geral, posso falar sobre meus sentimentos } \\
\hline 20 & 3) consegui falar sobre meus sentimentos cerca de & tade & $\mathrm{m}_{\mathrm{l}} \mathrm{rar}$ & & & \\
\hline & 4) com frequiência não consegui falar sobre meus se & men & & & & \\
\hline & 5) em nenhum momento consegui falar sobre meus & & & & & \\
\hline
\end{tabular}


Quadro 9: Conteúdo das questões para validade cruzada sobre lazer (cont.).

\begin{tabular}{|c|c|}
\hline EAS - & $\begin{array}{l}\text { Nas duas últimas semanas, quantas vezes você saiu socialmente com outras pessoas? Por exemplo, visitou amigos, foi ao cinema, a restaurantes, à } \\
\text { igreja, convidou amigos para sua casa? }\end{array}$ \\
\hline Lazer & 1) mais de 3 vezes \\
\hline \multirow[t]{4}{*}{21} & 2) 3 vezes \\
\hline & 3) 2 vezes \\
\hline & 4) uma vez \\
\hline & 5) nenhuma vez \\
\hline EAS - & Quanto tempo você dedicou a suas atividades de lazer, nas duas últimas semanas? Por exemplo, esportes, leitura,ouvir música, etc \\
\hline I & 1) dediquei a maior parte do tempo livre ao lazer praticamente todos os dias \\
\hline Lazer & 2) dediquei parte do tempo livre ao lazer em alguns dias \\
\hline \multirow[t]{3}{*}{22} & 3) dediquei pouco tempo livre ao lazer \\
\hline & 4) no geral não dediquei nenhum tempo ao lazer, mas assisti televisão \\
\hline & $\begin{array}{l}\text { 5) não dediquei nenhum tempo ao lazer, nem assisti televisão } \\
\text { Você teve aloum tino de discussão com seus amigos nas duas últimas semanas? }\end{array}$ \\
\hline EAS - & $\begin{array}{l}\text { Você teve algum tipo de discussão com seus amigos, nas duas últimas semanas? } \\
\text { 1) não tive nenhuma discussão e me relacionei muito bem }\end{array}$ \\
\hline Lazer & 2) no geral me relacionei bem, mas tive pequenas discussões \\
\hline \multirow{4}{*}{23} & 3) tive mais de uma discussão \\
\hline & 4) tive várias discussões \\
\hline & 5) tive discussões constantes \\
\hline & 8) não se aplica, não tenho amigos \\
\hline EAS - & Se seus sentimentos foram feridos ou se você foi ofendido por umamigo durante as duas últimas semanas, quanto isso o afetou? \\
\hline & 1) isso não me afetou ou não aconteceu \\
\hline Lazer & 2) superei em poucas horas \\
\hline \multirow{4}{*}{24} & 3) superei em poucos dias \\
\hline & 4) superei em uma semana \\
\hline & 5) vai levar meses até que eu me recupere \\
\hline & 8) não se aplica, não tenho amigos \\
\hline $\mathrm{EAS}-$ & Você se sentiu tímido ou desconfortável quando em companhia de outras pessoas nas duas últimas semanas? \\
\hline Lazer & $\begin{array}{l}\text { 1) sempre me sent1 confortável } \\
\text { 2) algumas vezes me senti desconfortável, mas relaxei depois de pouco tempo }\end{array}$ \\
\hline \multirow{4}{*}{25} & 3) sentime desconfortável cerca de metade do tempo \\
\hline & 4) no geral me senti desconfortável \\
\hline & 5) senti-me desconfortável o tempo todo \\
\hline & 8) não se aplica, não estive com outras pessoas \\
\hline
\end{tabular}




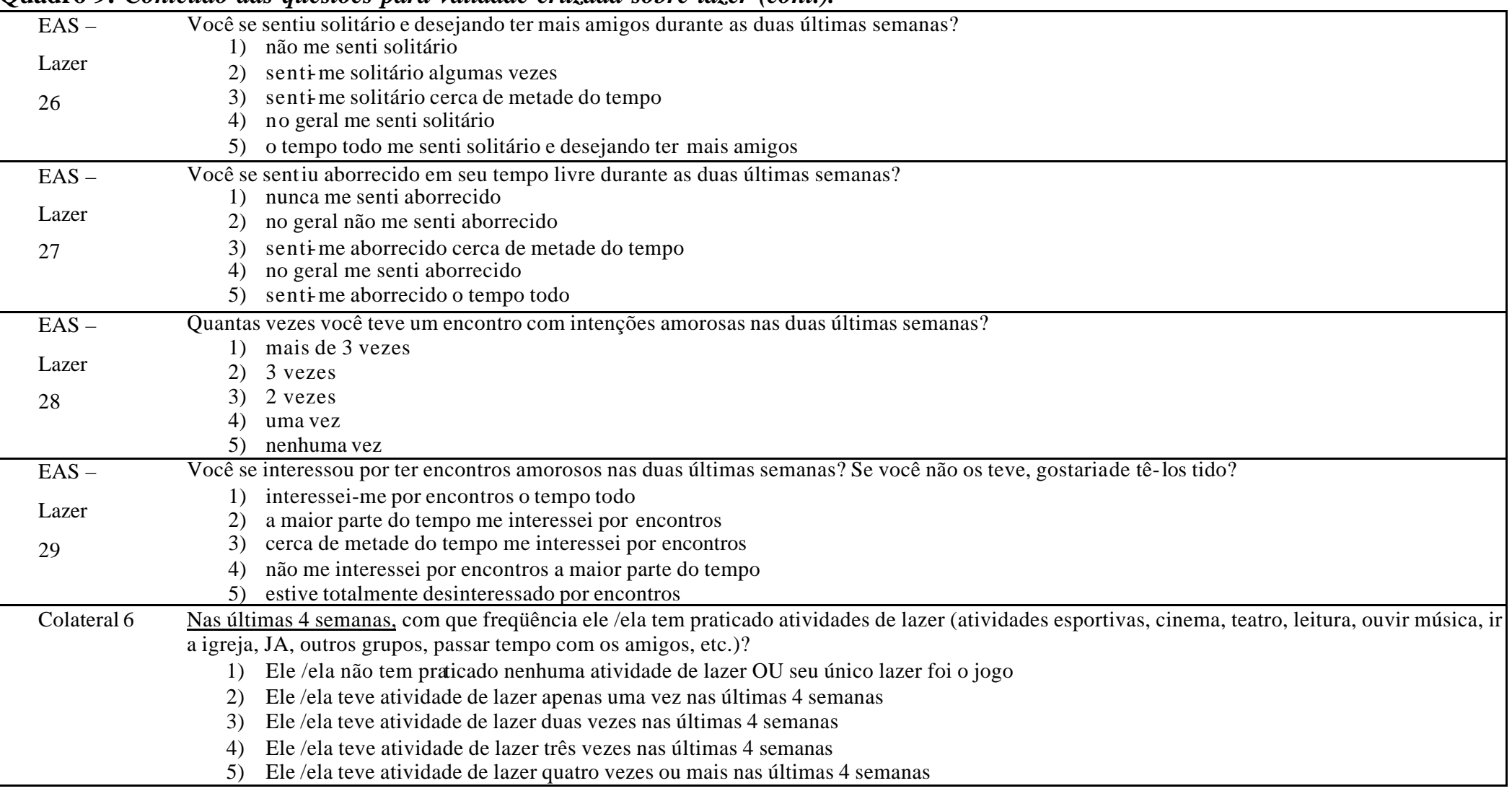


A ESJ 9 possui estrutura diferente das demais. Em sua elaboração, foi dividida em 12 subitens, colocados em 3 categorias (atividades esportivas, atividades culturais e atividades sociais), com intervalo de 0 a 4 em cada um deles. Dessa forma, o escore da questão 9 pode variar de 0 a 48, pontuação muito diferente das demais questões que variam de 1 a 5 . Se o escore da ESJ 9 fosse simplesmente o somatório das respostas assinaladas pelo paciente, o item lazer seria supervalorizado, com seu peso desproporcional em detrimento das demais questões no escore total da ESJ. Para essa correção, o escore da questão 9 foi ajustado proporcionalmente a uma escala de 1 a 5 , como mostra a figura 1 , segundo a fórmula seguinte:

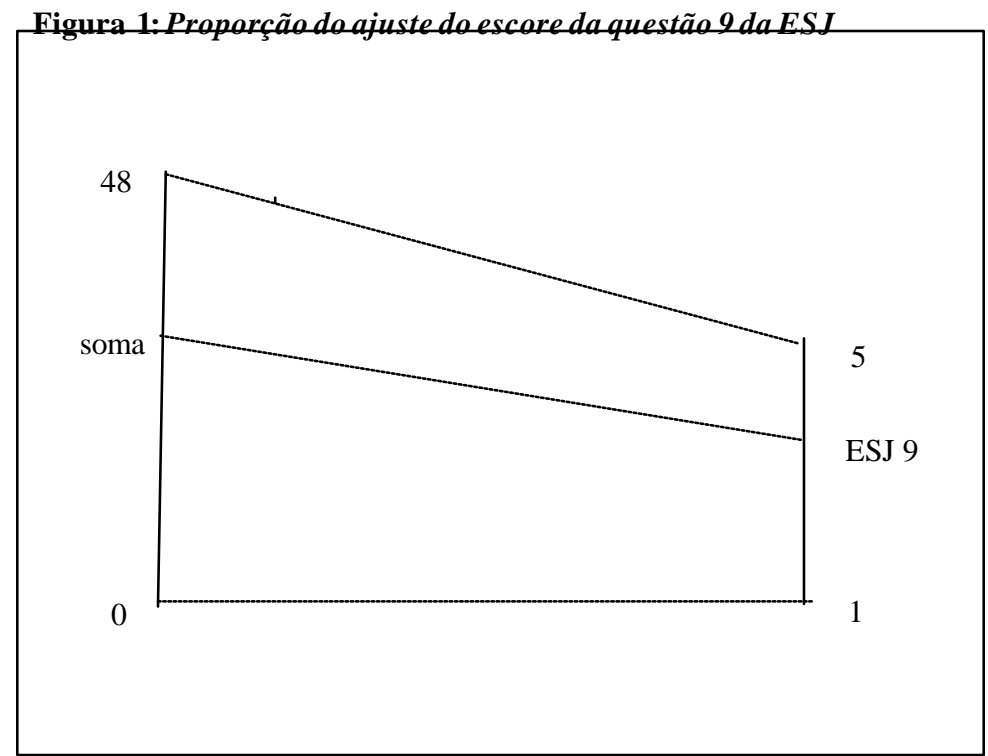

ESJ 9: escore final da questão 9

soma: somatório dos sub-itens da ESJ 9

$$
\mid \frac{\text { ESJ } 9-1}{\text { soma }-0}=\frac{5-1}{48-0} \Leftrightarrow \text { ESJ } 9=\frac{4 \text { soma }}{48}+1 \Leftrightarrow \text { ESJ } 9=\frac{\text { soma }}{12}+1 \mid
$$




\subsubsection{Consistência interna}

Nas análises de consistência interna foi utilizada a amostra total de 120 pacientes.

A análise do perfil sócio-demográfico dos 70 pacientes não incluídos nas análises anteriores exibiu perfil semelhante à sub-amostra de 50 pacientes, sem qualquer diferença significativa para todas as variáveis consideradas.

Foi calculado o Alfa de Cronbach dos 10 itens da ESJ.

\subsubsection{Análise Fatorial}

Foram utilizados os dados dos 120 pacientes para o cálculo da análise fatorial com rotação Varimax (Tabachnick \& Fidell, 2001).

\subsubsection{Sensibilidade à mudança no tempo}

Para essa análise foram utilizados os dados da sub-amostra de 50 pacientes.

Foram comparados os escores de cada questão da ESJ, o número de critérios DSM-IV, os dados da ASI, TFB, G-SAS e EAS nos dois tempos (antes e depois do tratamento), usando-se o teste de Wilcoxon. Optou-se pelo teste de Wilcoxon, ao invés do teste t, pois as variáveis podem apresentar medidas fora da distribuição normal, sendo necessário utilizar um teste não paramétrico. 


\section{RESULTADOS}

\subsection{Descrição da amostra}

Dos 120 pacientes que iniciaram tratamento no AMJO, 50 foram avaliados nos momentos pré e pós-tratamento. A tabela 2 mostra o perfil demográfico dessa subamostra.

\subsection{Dados clínicos da amostra}

A tabela 3 mostra os dados clínicos avaliados para jogadoras e jogadores patológicos. 
Tabela 2: Características sócio-demográficas de jogadoras e jogadores patológicos em início de tratamento.

\begin{tabular}{|c|c|c|c|c|c|}
\hline Características & $\begin{array}{l}\text { Homens } \\
\mathrm{n}=24\end{array}$ & $\begin{array}{l}\text { Mulheres } \\
\mathrm{n}=26\end{array}$ & $\begin{array}{l}\text { Total } \\
\mathrm{n}=50\end{array}$ & teste & $\mathrm{p}$ \\
\hline \multicolumn{6}{|l|}{ Idade (anos) } \\
\hline Média [Desvio Padrão] & $45,9[10,0]$ & $45,9[10,8]$ & $45,9[10,2]$ & $\mathrm{t}_{[48]}=-0,01$ & 0,99 \\
\hline \multicolumn{6}{|l|}{ Etnia } \\
\hline Caucasiano & $18(75 \%)$ & $24(92 \%)$ & $42(84 \%)$ & $?_{[1]}^{2}=1,64^{*}$ & 0,20 \\
\hline Outros & $6(25 \%)$ & $2(8 \%)$ & $8(16 \%)$ & & \\
\hline \multicolumn{6}{|l|}{ Estado Civil } \\
\hline Casado & $16(67 \%)$ & $13(50 \%)$ & $29(58 \%)$ & $?^{2}{ }_{[1]}=0,82^{*}$ & 0,39 \\
\hline Solteiro & $8(33 \%)$ & $13(50 \%)$ & $21(42 \%)$ & & \\
\hline \multicolumn{6}{|l|}{ Procedência Remota } \\
\hline São Paulo Capital & $14(58 \%)$ & $13(50 \%)$ & $27(54 \%)$ & $?^{2}{ }_{[2]}=2,28$ & 0,32 \\
\hline São Paulo Interior & $4(17 \%)$ & $9(35 \%)$ & $13(26 \%)$ & & \\
\hline Outros & $6(25 \%)$ & $4(15 \%)$ & $10(20 \%)$ & & \\
\hline
\end{tabular}


Tabela 2: Características sócio-demográficas de jogadoras e jogadores patológicos em início de tratamento (cont.).

\begin{tabular}{|c|c|c|c|c|c|}
\hline Características & $\begin{array}{l}\text { Homens } \\
\mathrm{n}=24\end{array}$ & $\begin{array}{l}\text { Mulheres } \\
\mathrm{n}=26\end{array}$ & $\begin{array}{l}\text { Total } \\
\mathrm{n}=50\end{array}$ & teste & $\mathrm{p}$ \\
\hline \multicolumn{6}{|l|}{ Religião } \\
\hline Católica & $17(71 \%)$ & $17(65 \%)$ & $34(68 \%)$ & $?_{[1]}^{2}=0,01 *$ & 0,91 \\
\hline Outras & $7(29 \%)$ & $9(35 \%)$ & $16(32 \%)$ & & \\
\hline \multicolumn{6}{|c|}{ Freqüência da prática religiosa } \\
\hline Não praticante & $8(33 \%)$ & $10(38 \%)$ & $18(36 \%)$ & $?_{[2]}^{2}=0,27$ & 0,87 \\
\hline$<1$ vez por semana & $6(25 \%)$ & $7(27 \%)$ & $13(26 \%)$ & & \\
\hline$=1 \mathrm{vez}$ por semana & $10(42 \%)$ & $9(35 \%)$ & $19(38 \%)$ & & \\
\hline \multicolumn{6}{|l|}{ Anos de Educação Formal } \\
\hline Média [Desvio Padrão] & $12,4[3,6]$ & $12,8[3,3]$ & $12,6[3,5]$ & $\mathrm{t}_{[48]}=0,45$ & 0,43 \\
\hline \multicolumn{6}{|l|}{ Situação Profissional } \\
\hline Trabalho externo regular & $13(54 \%)$ & $10(38 \%)$ & $23(46 \%)$ & $?_{[1]}^{2}=0,69 *$ & 0,11 \\
\hline Trabalho irregular e outros $^{l}$ & $11(46 \%)$ & $16(62 \%)$ & $27(54 \%)$ & & \\
\hline \multicolumn{6}{|c|}{ Indicador de Classe Econômica ${ }^{2}$} \\
\hline Média [Desvio Padrão] & $6,6[3,3]$ & $7,9[3,7]$ & $7,26[3,5]$ & $\mathrm{t}_{[48]}=1,36$ & 0,18 \\
\hline
\end{tabular}

* Com correção de Yates para matrizes 2x2

** Teste ajustado para variâncias desiguais

${ }^{1}$ Inclui tempo parcial, aposentados, estudantes, donas de casa e desempregados.

${ }^{2}$ O Indicador de Classe Econômica é calculado através da soma do número total de cômodos, banheiros, automóveis de passeio, televisões coloridas, empregados, apare lhos de som, máquinas de lavar, vídeo cassetes, computadores, geladeiras e aspiradores de pó ou equivalente, existentes na moradia do indivíduo, dividido pelo total de habitantes (IBGE, 1998). 
Tabela 3: Características clínicas de jogadoras e jogadores patológicos em início de tratamento.

\begin{tabular}{llllll}
\hline Características & $\mathrm{q}$ & Homens & Mulheres & Total & teste
\end{tabular}

$\mathrm{n}=24 \quad \mathrm{n}=26 \quad \mathrm{n}=50$

Idade de início de jogo (anos) Média [Desvio Padrão]

Idade de início de problemas

com jogo (anos)

Média [Desvio Padrão]

Idade de procura do primeiro tratamento para jogo (anos) Média [Desvio Padrão]

Intervalo de jogo social (anos) início até problema

Média [Desvio Padrão]

Intervalo de jogo problemático

(anos) - problema até tratamento Média [Desvio Padrão]

Intervalo total (anos) início até tratamento Média [Desvio Padrão]

\section{* Com correção de Yates para matrizes 2x2}

** Teste ajustado para variâncias desiguais 
Tabela 3: Características clínicas de jogadoras e jogadores patológicos em início de tratamento (cont.).

Características

Homens

$\mathrm{n}=24$

Mulheres

$\mathrm{n}=26$

Total

$\mathrm{n}=50$

Total de horas gastas num

episódio típico de jogo

Média [Desvio Padrão]

$5,1[3,0]$

$6,9[4,5]$

$6,0[3,9]$

$\mathrm{t}_{[44]}=1,74 * *$

0,089

Período máximo de

abstinência voluntária (meses)

Média [Desvio Padrão]

$8,5[10,7]$

$1,3[2,2]$

$4,8[8,2]$

$\mathrm{t}_{[25]}=-3,20 * *$

0,004

Apostas em jogos eletrônicos

Sim

$21(88 \%)$

$3(12 \%)$

Apostas em bingo

tradicional (cartela)

Sim

Não

$7(29 \%)$

$17(71 \%)$

Apostas em jogos tradicionais:

baralho, cavalo, loterias e

jogo do bicho

Sim

$13(54 \%)$

$11(46 \%)$
$24(93 \%)$

$2(7 \%)$

$45(90 \%)$

$5(10 \%)$

$16(62 \%)$

$10(38 \%)$

$23(46 \%)$

$27(54 \%)$

$?^{2}{ }_{[1]}=4,04^{*}$

0,044

$1(4 \%)$

$14(28 \%)$

$36(72 \%)$

$?_{[1]}^{2}=0,92^{*}$

0,925

$25(96 \%)$
$?_{[1]}^{2}=13,3 *$

$<, 001$

* Com correção de Yates para matrizes 2x2

**Teste ajustado para variâncias desiguais 
Tabela 3: Características clínicas de jogadoras e jogadores patológicos em início de tratamento (cont.).

Características

Homens

$\mathrm{n}=24$

Mulheres

$\mathrm{n}=26$

Envolvimento em atividades

ilegais

Sim

Não

Tentativa de suicídio

Sim

Não

Comportamento de risco para

doença sexualmente transmissível

Sim

Não

$4(17 \%)$

$20(83 \%)$

$2(8 \%)$

$24(92 \%)$

$15(58 \%)$

$11(42 \%)$

$15(58 \%)$

$?_{[1]}^{2}=0,31 *$

0,579

$11(46 \%)$

$1(4 \%)$

$23(96 \%)$

$?^{2}{ }_{[1]}=7,9 *$

0,005

* Com correção de Yates para matrizes 2x2

** Teste ajustado para variâncias desiguais
$24(48 \%)$

$26(52 \%)$

$12(24 \%)$

$38(76 \%)$

teste

$6(12 \%)$

$44(88 \%)$
$?_{[1]}^{2}=0,29 *$

0,589 


\subsection{Confiabilidade}

As tabelas de 4 a 9 mostram a contagem dos escores marcados pelos jogadores na ESJ e pelos familiares na escala adaptada para colateral e a concordância entre eles.

A tabela 4 mostra a contagem dos escores da ESJ e da escala para colateral sobre freqüência de jogo. O valor calculado do Kappa é de 0,409, com p <0,001

Tabela 4: Contagem dos escores sobre freqüência de jogo para medida de concordância inter-juizes.

\begin{tabular}{|c|c|c|c|c|c|c|c|}
\hline & \multicolumn{5}{|c|}{ ESJ 1} & \multirow{2}{*}{ Total } \\
\hline & & 1 & 2 & 3 & 4 & 5 & \\
\hline \multirow{5}{*}{ COL1 } & 1 & 1 & 2 & & 1 & 1 & 5 \\
\hline & 2 & 1 & 10 & 3 & 1 & 2 & 17 \\
\hline & 3 & & 3 & 3 & & & 6 \\
\hline & 4 & & 5 & 1 & 3 & 2 & 11 \\
\hline & 5 & & & & 1 & 12 & 13 \\
\hline \multicolumn{2}{|c|}{ Total } & 2 & 20 & 7 & 6 & 17 & 52 \\
\hline \multicolumn{5}{|c|}{ concordância ideal } & \multicolumn{3}{|c|}{ diferença de um ponto } \\
\hline \multicolumn{5}{|c|}{ diferença de dois pontos } & \multicolumn{3}{|c|}{ diferença de três pontos } \\
\hline
\end{tabular}


A tabela 5 mostra os escores da ESJ e da escala para colateral sobre tempo gasto em jogo. O valor calculado do Kappa é de 0,486, com $\mathrm{p}<0,001$.

Tabela 5: Contagem dos escores sobre tempo gasto em jogo para medida de concordância inter-juízes.

\begin{tabular}{|c|c|c|c|c|c|c|}
\hline & \multicolumn{4}{|c|}{ ESJ2 } & \multirow{2}{*}{ Total } \\
\hline & & 2 & 3 & 4 & 5 & \\
\hline \multirow{4}{*}{ COL2 } & 2 & 1 & 5 & & & 6 \\
\hline & 3 & 1 & 6 & 3 & 3 & 13 \\
\hline & 4 & & 4 & 14 & 2 & 20 \\
\hline & 5 & & 1 & & 12 & 13 \\
\hline \multicolumn{2}{|c|}{ Total } & 2 & 16 & 17 & 17 & 52 \\
\hline \multicolumn{5}{|c|}{ concordância ideal } & enç & $\mathrm{m}$ ponto \\
\hline \multicolumn{4}{|c|}{ diferença de dois pontos } & \multicolumn{3}{|c|}{ diferença de três pontos } \\
\hline
\end{tabular}

A tabela 6 mostra os escores da ESJ e da escala para colateral sobre dinheiro gasto em jogo. O valor do Kappa é de 0,356 com p <0,001.

Tabela 6: Contagem dos escores sobre dinheiro gasto em jogo para medida de concordância interjuizes.

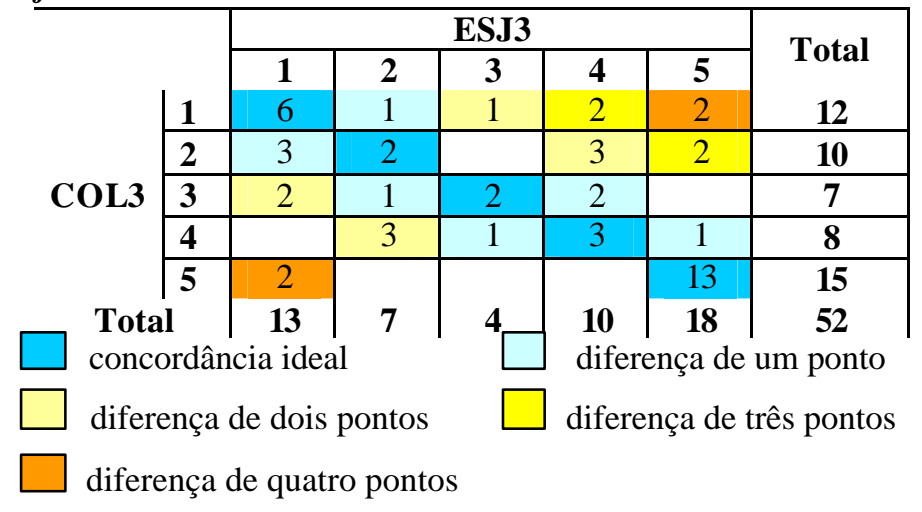


A tabela 7 mostra os escores da ESJ e da escala para colateral sobre relacionamentos familiares. O valor calculado do Kappa é de 0,170 com p = 0,039.

\begin{tabular}{l} 
Tabela 7: Contagem dos escores sobre \\
relacionamentos familiares para medida de \\
concordância inter-juízes. \\
\hline
\end{tabular}

A tabela 8 mostra os escores da ESJ e da escala para colateral sobre autonomia. O valor calculado do Kappa é de 0,297, com p <0,001.

Tabela 8: Contagem dos escores sobre autonomia para medida de concordância inter-juízes.

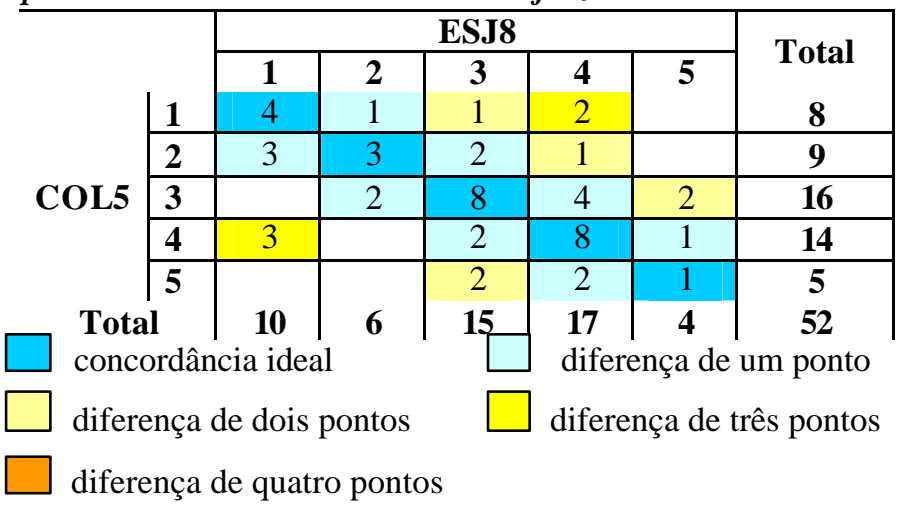


A tabela 9 mostra os escores da ESJ e da escala para colateral sobre freqüência de lazer. O valor calculado do Kappa é de 0,214, com p =0,001.

Tabela 9: Contagem dos escores sobre freqüiência de lazer para medida de concordância inter-juízes.

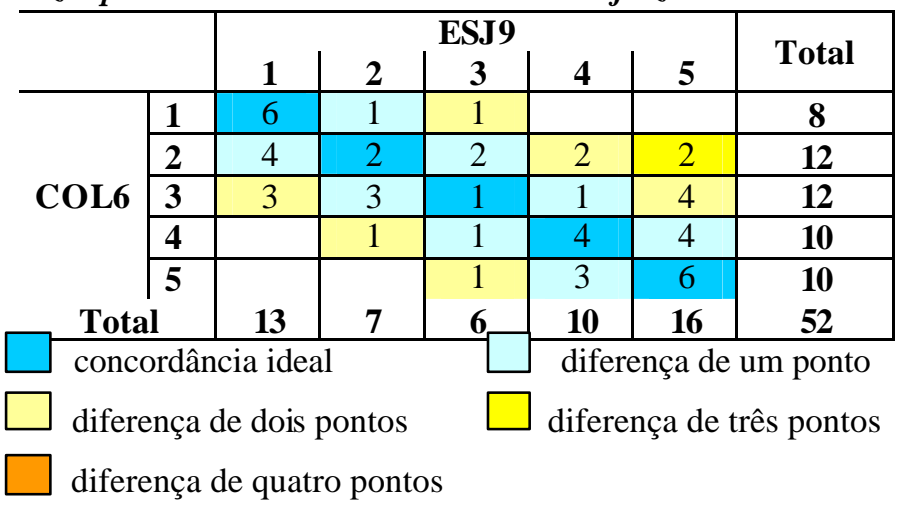




\subsection{Validação Cruzada}

As tabelas de 10 a 16 mostram os resultados das correlações dos escores obtidos nas escalas no início de tratamento.

A tabela 10 mostra os resultados das correlações entre a questão 1 da ESJ (freqüência de jogo) e as questões correspondentes na ASI, na TFB e na escala correspondente do informante colateral.

Tabela 10: Coeficientes de correlação de Spearman para os escores de freqüência de apostas no início de tratamento.

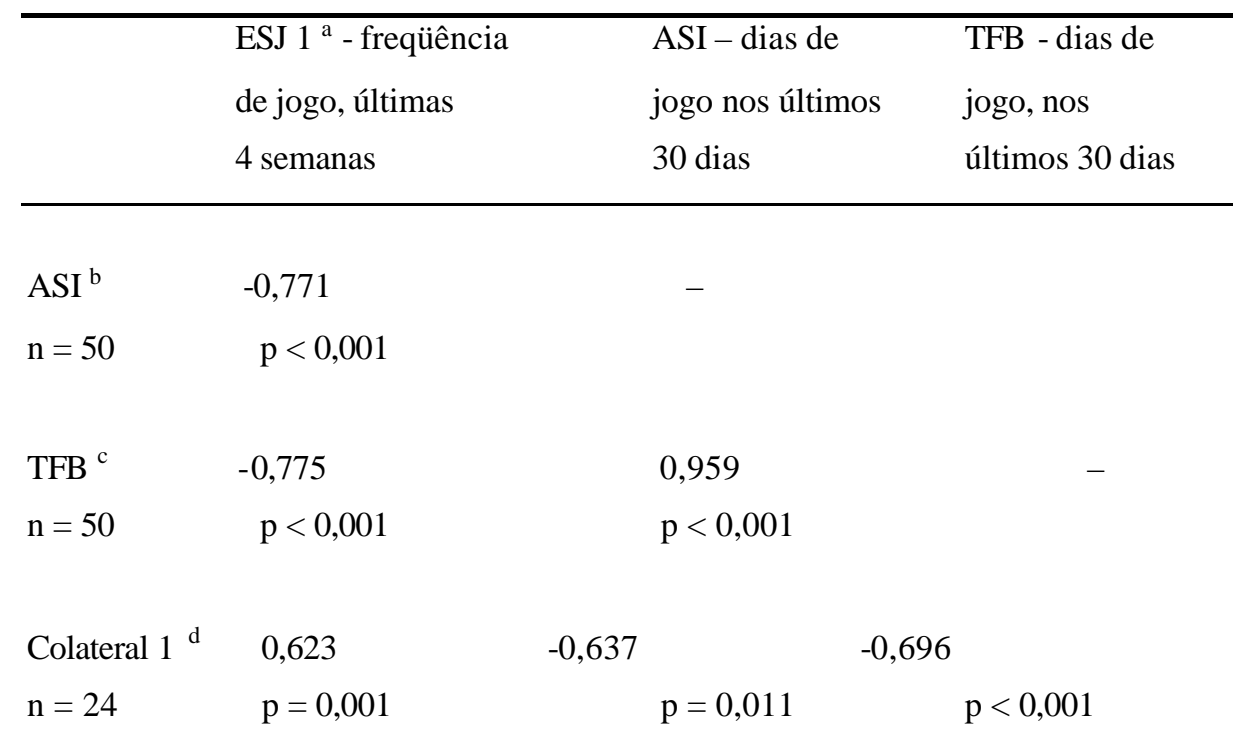

\footnotetext{
${ }^{\mathrm{a}}$ Escala de Seguimento de Jogadores, questão 1

${ }^{\mathrm{b}}$ Addiction Severity Index (Índice de Gravidade de Dependência), dias de jogo

${ }^{c}$ Timeline Follow-back (Entrevista Retroativa)

${ }^{\mathrm{d}}$ ESJ adaptada para informante colateral, questão 1
} 
A tabela 11 mostra os resultados das correlações entre a questão 2 da ESJ (tempo gasto em jogo) e as questões correspondentes na TFB, na G-SAS e na escala correspondente do informante colateral.

Tabela 11: Coeficientes de correlação de Spearman para os escores de tempo gasto em jogo no início de tratamento.

\begin{tabular}{|c|c|c|c|}
\hline & $\begin{array}{l}\text { ESJ } 2^{\text {a }} \text { - tempo } \\
\text { de jogo, últimas } \\
4 \text { semanas }\end{array}$ & $\begin{array}{l}\text { TFB - tempo de jogo, } \\
\text { últimos } 30 \text { dias }\end{array}$ & $\begin{array}{l}\text { G-SAS 8- tempo } \\
\text { de jogo, última } \\
\text { semana }\end{array}$ \\
\hline $\mathrm{TFB}^{\mathrm{b}}$ & $-0,767$ & - & \\
\hline $\mathrm{n}=50$ & $\mathrm{p}<0,001$ & & \\
\hline $\mathrm{G}^{-S A S}{ }^{\mathrm{c}}$ & $-0,629$ & 0,665 & - \\
\hline $\mathrm{n}=50$ & $\mathrm{p}<0,001$ & $\mathrm{p}<0,001$ & \\
\hline Colateral $2^{\mathrm{d}}$ & $0,670(\mathrm{n}=24)$ & $-0,558$ & $-0,664$ \\
\hline$n=24$ & $\mathrm{p}<0,001$ & $\mathrm{p}=0,005$ & $\mathrm{p}<0,001$ \\
\hline
\end{tabular}

\footnotetext{
${ }^{a}$ Escala de Seguimento de Jogadores, questão 2

${ }^{\mathrm{b}}$ Timeline Follow-back (Entrevista Retroativa), tempo de jogo

${ }^{\mathrm{c}}$ Gambling Symptom Assessment Scale, questão 8

${ }^{\mathrm{d}}$ ESJ adaptada para informante colateral, questão 2
}

A tabela 12 mostra os resultados das correlações entre a questão 3 da ESJ (dinheiro gasto em jogo) e as questões correspondentes na ASI, na TFB, na EAS e na escala correspondente do informante colateral.

A tabela 13 mostra os resultados das correlações entre a questão 4 da ESJ (vontade de jogar) e as questões da G-SAS. 
Tabela 12: Coeficientes de correlação de Spearman para os escores de dinheiro gasto em jogo no início de tratamento.

gasto em jogo, entrada, últimos dinheiro gasto, gasto, últimos Situação

últimas 4 semanas $\quad 30$ dias últimos 30 dias $\quad 30$ dias $\quad$ Econômica

TFB

(Dinheiro entrada) $^{b} \quad-0,560$

$\mathrm{n}=50 \quad \mathrm{p}<0,001$

TFB

(Saldo) $^{\mathrm{c}} \quad-0,511 \quad 0,968$

$\mathrm{n}=50 \quad \mathrm{p}<0,001 \quad \mathrm{p}<0,001$

$\begin{array}{llll}\text { ASI }^{\mathrm{d}} & -0,570 & 0,969 & 0,925 \\ \mathrm{n}=50 & \mathrm{p}<0,001 & \mathrm{p}<0,001 & \mathrm{p}<0,001\end{array}$

$\begin{array}{lllll}\text { EAS }^{\mathrm{e}} & -0,434 & 0,135 & 0,095 & 0,092 \\ \mathrm{n}=50 & \mathrm{p}=0,002 & \mathrm{p}=0,350 & \mathrm{p}=0,513 & \mathrm{p}=0,523\end{array}$

\begin{tabular}{llllll} 
Colateral 3 $^{\mathrm{f}}$ & 0,498 & $-0,434$ & $-0,456$ & $-0,406$ & $-0,408$ \\
$\mathrm{n}=24$ & $\mathrm{p}=0,013$ & $\mathrm{p}=0,034$ & $\mathrm{p}=0,025$ & $\mathrm{p}=0,049$ & $\mathrm{p}=0,048$ \\
\hline${ }^{\mathrm{a}}$ Escala de Seguimento de Jogadores, questão 3 &
\end{tabular}

${ }^{\mathrm{b}}$ Timeline Follow-back, (Entrevista Retroativa), dinheiro gasto em jogo na entrada

c Timeline Follow-back (Entrevista Retroativa) saldo do dinheiro gasto em jogo

${ }^{\mathrm{d}}$ Addiction Severity Index (Índice de Gravidade de Dependência), dinheiro gasto

${ }^{\mathrm{e}}$ Escala de Adequação Social, questão 54

${ }^{\mathrm{f}}$ ESJ adaptada para informante colateral, questão 3 
Tabela 13: Coeficientes de correlação de Spearman para os escores de vontade de jogar no início de tratamento.

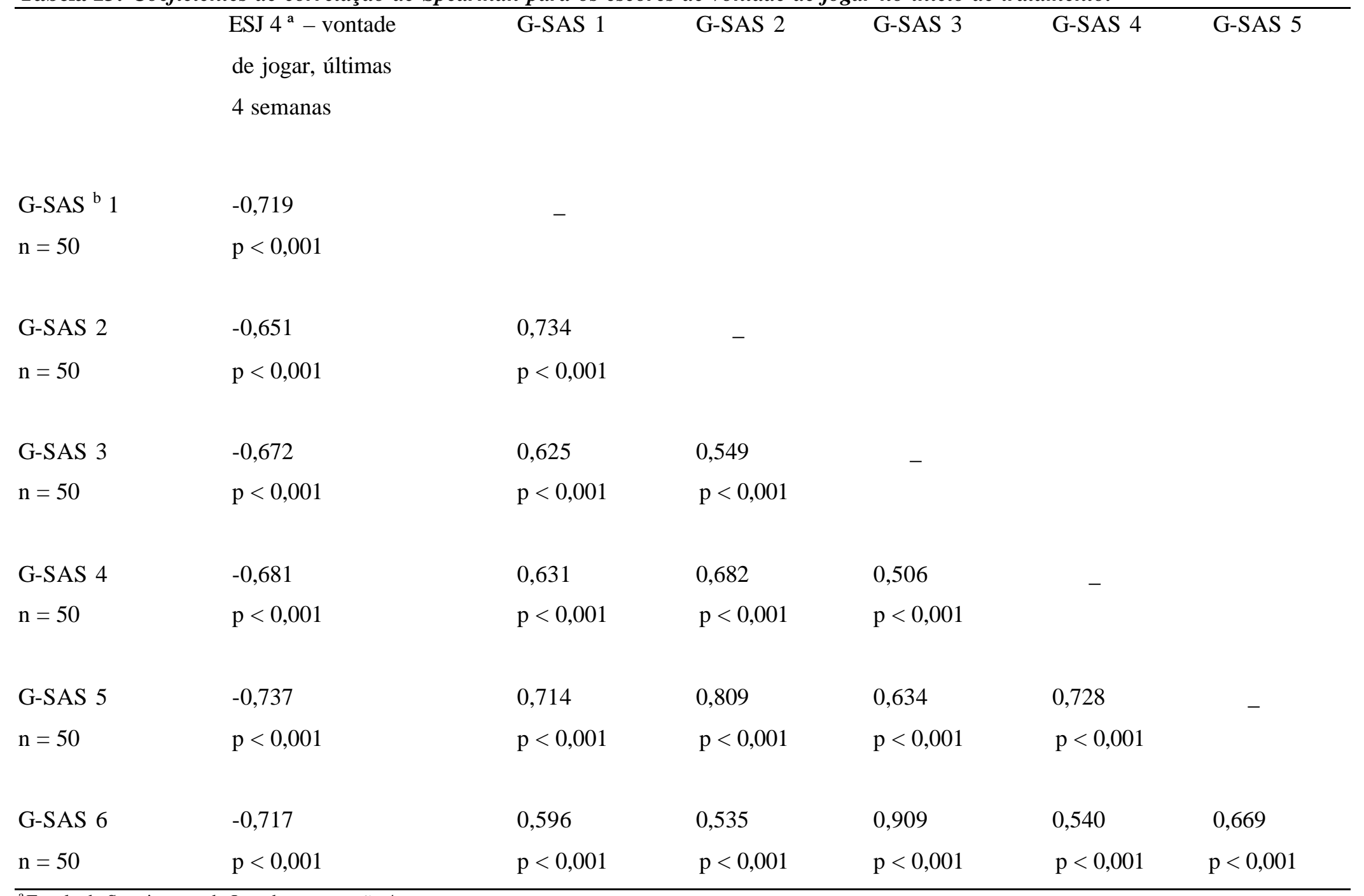

${ }^{a}$ Escala de Seguimento de Jogadores, questão 4

${ }^{\mathrm{b}}$ Gambling Symptom Assessment Scale 
Tabela 13: Coeficientes de correlação de Spearman para os escores de vontade de jogar no início de tratamento (cont.).

\begin{tabular}{|c|c|c|c|c|c|c|}
\hline & $\begin{array}{l}\text { ESJ } 4^{\text {a }} \text { - vontade } \\
\text { de jogar, últimas } \\
4 \text { semanas }\end{array}$ & G-SAS 6 & G-SAS 7 & G-SAS 8 & G-SAS 9 & G-SAS 10 \\
\hline$\overline{\mathrm{G}^{-S A S}{ }^{\mathrm{b}} 7}$ & $-0,800$ & 0,698 & - & & & \\
\hline $\mathrm{n}=50$ & $\mathrm{p}<0,001$ & $\mathrm{p}<0,001$ & & & & \\
\hline G-SAS 8 & $-0,538$ & 0,589 & 0,687 & - & & \\
\hline $\mathrm{n}=50$ & $\mathrm{p}<0,001$ & $\mathrm{p}<0,001$ & $\mathrm{p}<0,001$ & & & \\
\hline G-SAS 9 & $-0,433$ & 0,488 & 0,459 & 0,183 & - & \\
\hline $\mathrm{n}=50$ & $\mathrm{p}=0,002$ & $\mathrm{p}=0,001$ & $\mathrm{p}<0,001$ & $\mathrm{p}=0,204$ & & \\
\hline G-SAS 10 & $-0,560$ & 0,399 & 0,436 & 0,162 & 0,577 & - \\
\hline $\mathrm{n}=50$ & $\mathrm{p}<0,001$ & $\mathrm{p}=0,004$ & $\mathrm{p}=0,002$ & $\mathrm{p}=0,206$ & $\mathrm{p}<0,001$ & \\
\hline G-SAS 11 & $-0,342$ & 0,351 & 0,365 & 0,170 & 0,536 & 0,508 \\
\hline $\mathrm{n}=50$ & $\mathrm{p}=0,015$ & $\mathrm{p}=0,013$ & $\mathrm{p}=0,009$ & $\mathrm{p}=0,238$ & $\mathrm{p}<0,001$ & $\mathrm{p}<0,001$ \\
\hline G-SAS 12 & $-0,253$ & 0,331 & 0,301 & 0,104 & 0,374 & 0,381 \\
\hline $\mathrm{n}=50$ & $\mathrm{p}=0,076$ & $\mathrm{p}=0,019$ & $\mathrm{p}=0,034$ & $\mathrm{p}=0,471$ & $\mathrm{p}=0,007$ & $\mathrm{p}=0,006$ \\
\hline
\end{tabular}

${ }^{\mathrm{b}}$ Gambling Symptom Assessment Scale 
Tabela 13: Coeficientes de correlação de Spearman para os escores de vontade de jogar no início de tratamento (cont.).

ESJ $4^{\text {a }}$ - vontade

G-SAS 11

G-SAS 12

de jogar, últimas

4 semanas

G-SAS ${ }^{b}$ Total $\quad-0,818$

$\mathrm{p}<0,001$

$\mathrm{n}=50$

0,542

0,456

$\mathrm{p}<0,001$

$\mathrm{p}=0,001$

${ }^{\mathrm{a}}$ Escala de Seguimento de Jogadores, questão 4

${ }^{\mathrm{b}}$ Gambling Symptom Assessment Scale 
O coeficiente de correlação de Spearman para os escores sobre dívidas, comparando a questão 5 da ESJ com a questão 54 da EAS (Situação Financeira) foi igual a $-0,458$, com $\mathrm{p}<0,001$.

A tabela 14 mostra os resultados das correlações da questão 6 da ESJ (sofrimento emocional) com as questões correspondentes na ASI e na G-SAS.

Tabela 14: Coeficientes de correlação de Spearman para os escores de sofrimento emocional no início de tratamento.

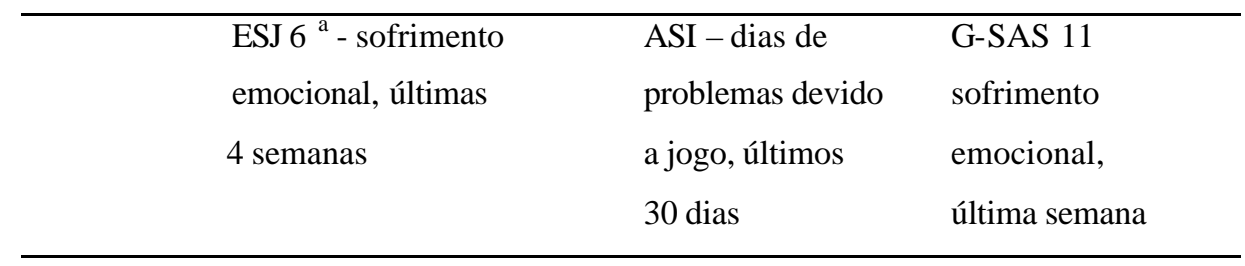

$\begin{array}{ll}\text { ASI }^{\mathrm{b}} & -0,477 \\ \mathrm{n}=50 & \mathrm{p}<0,001\end{array}$

G-SAS $11^{\mathrm{c}} \quad-0,640 \quad 0,638$

$\mathrm{n}=50 \quad \mathrm{p}<0,001 \quad \mathrm{p}<0,001$

\footnotetext{
${ }^{a}$ Escala de Seguimento de Jogadores, questão 6

${ }^{\mathrm{b}}$ Addiction Severity Index (Índice de Gravidade de Dependência), dias de problema devido a jogo

${ }^{\mathrm{c}}$ Gambling Symptom Assessment Scale, questão 11
}

O coeficiente de correlação de Spearman para os escores sobre relacionamentos familiares, comparando-se a questão 7 da ESJ e o escore Família Total da EAS, foi 0,447 com $\mathrm{p}=0,001$. 
A tabela 15 mostra os resultados das correlações da questão 8 da ESJ, sobre autonomia, com as questões correspondentes da EAS e da escala do informante colateral.

Tabela 15: Coeficientes de correlação de Spearman para os escores de autonomia no início de tratamento.

$\begin{array}{llll}\text { ESJ } 8^{a}- & \text { EAS } & \text { EAS } & \text { Colateral } 4 \\ \text { autonomia, últimas } & \text { Trabalho } & \text { Situação } & \\ 4 \text { semanas } & & \text { econômica } & \end{array}$

$\begin{array}{ll}\text { EAS }^{\mathrm{b}} & -0,291 \\ \text { Trabalho } & \mathrm{p}=0,043\end{array}$

$\mathrm{n}=50$

EAS

$$
-0,362
$$

Situação

$$
\mathrm{p}=0,010
$$$$
\mathrm{p}=0,049
$$

Econômica

$\mathrm{n}=50$

$\begin{array}{llll}\text { Colateral }^{\mathrm{c}} & 0,676 & -0,426 & -0,147 \\ \mathrm{n}=24 & \mathrm{p}<0,001 & \mathrm{p}=0,038 & \mathrm{p}=0,494\end{array}$

\footnotetext{
${ }^{a}$ Escala de Seguimento de Jogadores, questão 8

${ }^{\mathrm{b}}$ Escala de Adequação Social

${ }^{\mathrm{c}}$ ESJ adaptada para informante colateral, questão 4
}

A tabela 16 mostra o resultado das correlações dos escores das questões 9 e 10 da ESJ, sobre lazer, com os correspondentes na EAS e na escala do informante colateral. 
Tabela 16: Coeficientes de correlação de Spearman para os escores de lazer no início de tratamento.

$\begin{array}{llll}\text { ESJ } 9^{\text {a }} \text { - } & \text { ESJ 10 - } & \text { EAS } & \text { Colateral 5 } \\ \text { lazer, últimas } & \text { satisfação, } & \text { Lazer } & \\ 4 \text { semanas } & \text { últimas } 4 & & \\ & \text { semanas } & & \end{array}$

$\begin{array}{llc}\text { ESJ } 10^{\mathrm{b}} & 0,516 & - \\ \mathrm{n}=50 & \mathrm{p}<0,001 & \\ & & \\ \text { EAS }^{\mathrm{c}} & -0,774 & -0,484 \\ \text { lazer } & \mathrm{p}<0,001 & \mathrm{p}<0,001 \\ \mathrm{n}=50 & & \end{array}$

$\begin{array}{llll}\text { Colateral }^{\mathrm{d}} & 0,519 & * & -0,409 \\ \mathrm{n}=24 & \mathrm{p}=0,009 & \mathrm{p}=0,047\end{array}$

${ }^{\mathrm{a}}$ Escala de Seguimento de Jogadores, questão 9

${ }^{\mathrm{b}}$ Escala de Seguimento de Jogadores, questão 10

${ }^{\mathrm{c}}$ Escala de Adequação Social

${ }^{\mathrm{d}}$ ESJ adaptada para informante colateral, questão 5

* A questão 6 da ESJ para informante colateral não tem correlação com a questão 10 da ESJ por esta avaliar quesito subjetivo

As tabelas de 17 a 23 mostram os resultados das correlações dos escores obtidos nas escalas no final de tratamento.

A tabela 17 mostra os resultados das correlações entre a questão 1 da ESJ (freqüência de jogo) e as questões correspondentes na ASI e na TFB. 
Tabela 17: Coeficientes de correlação de Spearman para os escores de freqüência de apostas no final de tratamento.

\begin{tabular}{|c|c|c|c|}
\hline & $\begin{array}{l}\text { ESJ } 1^{\text {a }} \text { - freqüência } \\
\text { de jogo, últimas } \\
4 \text { semanas }\end{array}$ & $\begin{array}{l}\text { ASI - dias de jogo } \\
\text { nos últimos } 30 \text { dias }\end{array}$ & $\begin{array}{l}\text { TFB - dias de jogo } \\
\text { nos últimos } 30 \\
\text { dias }\end{array}$ \\
\hline $\begin{array}{l}\mathrm{ASI}^{\mathrm{b}} \\
\mathrm{n}=50\end{array}$ & $\begin{array}{l}-0,870 \\
p<0,001\end{array}$ & - & \\
\hline $\begin{array}{l}\mathrm{TFB}^{\mathrm{c}} \\
\mathrm{n}=50\end{array}$ & $\begin{array}{l}-0,893 \\
p<0,001\end{array}$ & $\begin{array}{l}0,994 \\
p<0,001\end{array}$ & - \\
\hline
\end{tabular}

A tabela 18 mostra os resultados das correlações entre a questão 2 da ESJ (tempo

gasto em jogo) e as questões correspondentes na TFB e na G-SAS.

Tabela 18: Coeficientes de correlação de Spearman para os escores de tempo gasto em jogo no final de tratamento.

\begin{tabular}{|c|c|c|c|}
\hline & $\begin{array}{l}\text { ESJ } 2^{\text {a }} \text { - tempo } \\
\text { de jogo, últimas } \\
4 \text { semanas }\end{array}$ & $\begin{array}{l}\text { TFB - dias de jogo, } \\
\text { últimos } 30 \text { dias }\end{array}$ & $\begin{array}{l}\text { G-SAS 8- tempo de } \\
\text { jogo, última semana }\end{array}$ \\
\hline $\begin{array}{l}\mathrm{TFB}^{\mathrm{b}} \\
\mathrm{n}=50\end{array}$ & $\begin{array}{l}-0,879 \\
p<0,001\end{array}$ & - & \\
\hline $\begin{array}{l}\text { G-SAS }{ }^{c} \\
n=50\end{array}$ & $\begin{array}{l}-0,682 \\
\mathrm{p}<0,001\end{array}$ & $\begin{array}{l}0,592 \\
\mathrm{p}<0,001\end{array}$ & - \\
\hline
\end{tabular}

A tabela 19 mostra os resultados das correlações entre a questão 3 da ESJ

(dinheiro gasto em jogo) e as questões correspondentes na ASI, na TFB e na EAS.

A tabela 20 mostra os resultados das correlações entre a questão 4 da ESJ

(vontade de jogar) e as questões da G-SAS. 
Tabela 19: Coeficientes de correlação de Spearman para os escores de dinheiro gasto em jogo no final de tratamento.

\begin{tabular}{cccc}
\hline ESJ $3{ }^{a}$ - dinheiro & TFB - dinheiro de & TFB - saldo do & ASI - dinheiro \\
gasto em jogo, & entrada, últimos & dinheiro gasto, gasto, últimos & Situação \\
últimas 4 semanas & 30 dias & últimos 30 dias & 30 dias \\
\hline
\end{tabular}

TFB

$(\text { Dinheiro entrada })^{\mathrm{b}} \quad-0,834$

$\mathrm{n}=50 \quad \mathrm{p}<0,001$

TFB

$\begin{array}{lll}\text { (Saldo }^{\mathrm{c}} & -0,879 & 0,863\end{array}$

$\mathrm{n}=50 \quad \mathrm{p}<0,001 \quad \mathrm{p}<0,001$

$\begin{array}{llll}\text { ASI }^{\mathrm{d}} & -0,844 & 0,992 & 0,863 \\ \mathrm{n}=50 & \mathrm{p}<0,001 & \mathrm{p}<0,001 & \mathrm{p}<0,001\end{array}$

\begin{tabular}{lllll} 
EAS $^{\mathrm{e}}$ & $-0,320$ & 0,174 & 0,252 & 0,148 \\
$\mathrm{n}=50$ & $\mathrm{p}=0,025$ & $\mathrm{p}=0,233$ & $\mathrm{p}=0,081$ & $\mathrm{p}=0,311$ \\
\hline
\end{tabular}

${ }^{a}$ Escala de Seguimento de Jogadores, questão 3

${ }^{\mathrm{b}}$ Timeline Follow-back, (Entrevista Retroativa), dinheiro gasto em jogo na entrada

${ }^{\mathrm{c}}$ Timeline Follow-back (Entrevista Retroativa) saldo do dinheiro gasto em jogo

${ }^{\mathrm{d}}$ Addiction Severity Index (Índice de Gravidade de Dependência), dinheiro gasto

e Escala de Adequação Social, questão 54 
Tabela 20: Coeficientes de correlação de Spearman para os escores de vontade de jogar no final de tratamento.

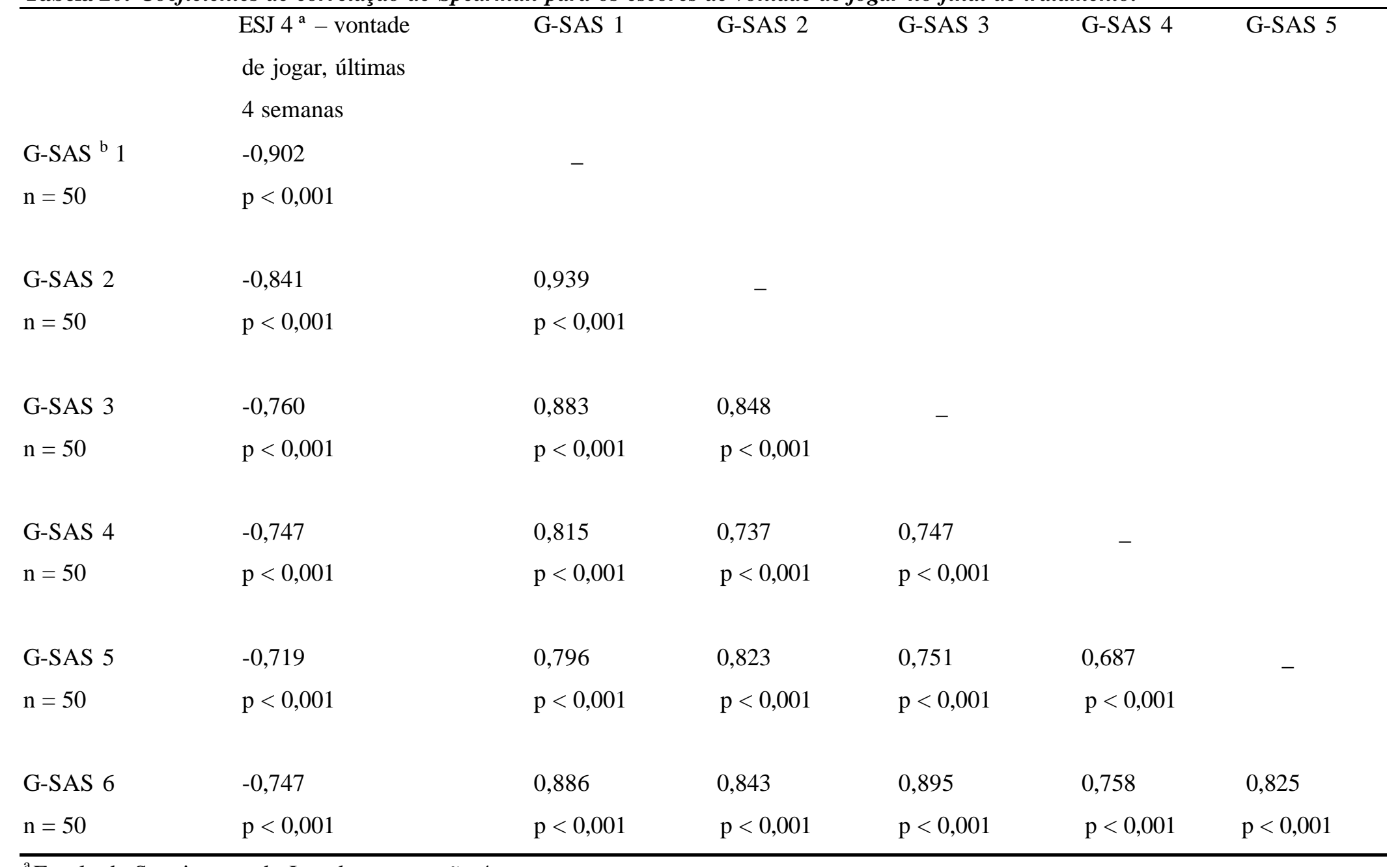

${ }^{\mathrm{a}}$ Escala de Seguimento de Jogadores, questão 4

${ }^{\mathrm{b}}$ Gambling Symptom Assessment Scale 
Tabela 20: Coeficientes de correlação de Spearman para os escores de vontade de jogar no final de tratamento (cont.)

\begin{tabular}{|c|c|c|c|c|c|c|}
\hline & $\begin{array}{l}\text { ESJ } 4^{\text {a }} \text { - vontade } \\
\text { de jogar, últimas } \\
4 \text { semanas }\end{array}$ & G-SAS 6 & G-SAS 7 & G-SAS 8 & G-SAS 9 & G-SAS 10 \\
\hline $\mathrm{G}^{-\mathrm{SAS}^{\mathrm{b}} 7}$ & $-0,763$ & 0,712 & - & & & \\
\hline $\mathrm{n}=50$ & $\mathrm{p}<0,001$ & $\mathrm{p}<0,001$ & & & & \\
\hline G-SAS 8 & $-0,509$ & 0,596 & 0,499 & - & & \\
\hline $\mathrm{n}=50$ & $\mathrm{p}<0,001$ & $\mathrm{p}<0,001$ & $\mathrm{p}<0,001$ & & & \\
\hline G-SAS 9 & $-0,445$ & 0,494 & 0,426 & 0,256 & - & \\
\hline $\mathrm{n}=50$ & $\mathrm{p}=0,001$ & $\mathrm{p}<0,001$ & $\mathrm{p}=0,002$ & $\mathrm{p}=0,076$ & & \\
\hline G-SAS 10 & $-0,445$ & 0,397 & 0,419 & 0,377 & 0,868 & - \\
\hline $\mathrm{n}=50$ & $\mathrm{p}=0,001$ & $\mathrm{p}=0,004$ & $\mathrm{p}=0,002$ & $\mathrm{p}=0,007$ & $\mathrm{p}<0,001$ & \\
\hline G-SAS 11 & $-0,456$ & 0,454 & 0,497 & 0,449 & 0,399 & 0,348 \\
\hline $\mathrm{n}=50$ & $\mathrm{p}=0,001$ & $\mathrm{p}=0,001$ & $\mathrm{p}<0,001$ & $\mathrm{p}=0,001$ & $\mathrm{p}=0,017$ & $\mathrm{p}=0,013$ \\
\hline G-SAS 12 & $-0,386$ & 0,413 & 0,402 & 0,428 & 0,387 & 0,376 \\
\hline $\mathrm{n}=50$ & $\mathrm{p}=0,006$ & $\mathrm{p}=0,003$ & $\mathrm{p}=0,004$ & $\mathrm{p}=0,002$ & $\mathrm{p}=0,006$ & $\mathrm{p}=0,007$ \\
\hline
\end{tabular}

${ }^{\mathrm{a}}$ Escala de Seguimento de Jogadores, questão 4

${ }^{\mathrm{b}}$ Gambling Symptom Assessment Scale 
Tabela 20: Coeficientes de correlação de Spearman para os escores de vontade de jogar no final de tratamento (cont.).

ESJ $4^{\text {a }}$ - vontade

G-SAS 11

G-SAS 12

de jogar, últimas

4 semanas

G-SAS ${ }^{\mathrm{b}}$ Total

$-0,794$

$\mathrm{p}<0,001$

$\mathrm{n}=50$

0,686

$\mathrm{p}<0,001$

0,632

$\mathrm{p}<0,001$

${ }^{\mathrm{a}}$ Escala de Seguimento de Jogadores, questão 4

${ }^{\mathrm{b}}$ Gambling Symptom Assessment Scale 
O coeficiente de correlação de Spearman para os escores sobre dívidas, comparando a questão 5 da ESJ com a questão 54 da EAS (Situação Financeira), no final de tratamento, foi igual a $-0,722$, com $\mathrm{p}<0,001$.

A tabela 21 mostra os resultados das correlações da questão 6 da ESJ (sofrimento emocional) com as questões correspondentes na ASI e G-SAS.

Tabela 21: Coeficientes de correlação de Spearman para os escores de sofrimento emocional no final de tratamento.

\begin{tabular}{|c|c|c|c|}
\hline & $\begin{array}{l}\text { ESJ } 6^{\mathrm{a}} \text { - sofrimento } \\
\text { emocional, últimas } \\
4 \text { semanas }\end{array}$ & $\begin{array}{l}\text { ASI - dias de } \\
\text { problemas devido } \\
\text { a jogo, últimos } 30 \\
\text { dias }\end{array}$ & $\begin{array}{l}\text { G-SAS } 11 \\
\text { sofrimento } \\
\text { emocional, } \\
\text { última semana }\end{array}$ \\
\hline $\mathrm{ASI}^{\mathrm{b}}$ & $-0,560$ & - & \\
\hline $\mathrm{n}=50$ & $\mathrm{p}<0,001$ & & \\
\hline G-SAS $11^{c}$ & $-0,605$ & 0,527 & - \\
\hline $\mathrm{n}=50$ & $\mathrm{p}<0,001$ & $\mathrm{p}<0,001$ & \\
\hline
\end{tabular}

\footnotetext{
${ }^{a}$ Escala de Seguimento de Jogadores, questão 6

${ }^{\mathrm{b}}$ Addiction Severity Index (Índice de Gravidade de Dependência), dias de problemas devido a jogo

${ }^{\mathrm{c}}$ Gambling Symptom Assessment Scale, questão 11

O coeficiente de correlação de Spearman para os escores sobre relacionamentos familiares, comparando-se a questão 7 da ESJ com o escore Família Total da EAS após seis meses, foi igual a $-0,255$, com $\mathrm{p}=0,73$.
} 
A tabela 22 mostra os resultados das correlações da questão 8 da ESJ, sobre autonomia, com as questões correspondentes da EAS.

Tabela 22: Coeficientes de correlação de Spearman para os escores de autonomia no final de tratamento.

\begin{tabular}{|c|c|c|c|}
\hline & $\begin{array}{l}\text { ESJ } 8^{\mathrm{a}}- \\
\text { autonomia, últimas } \\
4 \text { semanas }\end{array}$ & $\begin{array}{l}\text { EAS } \\
\text { Trabalho }\end{array}$ & $\begin{array}{l}\text { EAS } \\
\text { Situação } \\
\text { econômica }\end{array}$ \\
\hline $\begin{array}{l}\text { EAS }{ }^{b} \\
\text { Trabalho } \\
n=50\end{array}$ & $\begin{array}{l}-0,441 \\
p=0,002\end{array}$ & - & \\
\hline $\begin{array}{l}\text { EAS } \\
\text { Situação }\end{array}$ & $\begin{array}{l}-0,510 \\
p<0,001\end{array}$ & $\begin{array}{l}0,314 \\
p=0,032\end{array}$ & - \\
\hline $\begin{array}{l}\text { Econômica } \\
n=50\end{array}$ & & & \\
\hline
\end{tabular}

${ }^{\text {a }}$ Escala de Seguimento de Jogadores, questão 8

${ }^{\mathrm{b}}$ Escala de Adequação Social

A tabela 23 mostra o resultado das correlações dos escores das questões 9 e 10 da ESJ, sobre lazer, com os correspondentes na EAS. 
Tabela 23: Coeficientes de correlação de Spearman para os escores de lazer no final de tratamento.

\begin{tabular}{llll}
\hline & $\begin{array}{l}\text { ESJ 9 }^{\mathrm{a}}- \\
\text { lazer, últimas } \\
4 \text { semanas }\end{array}$ & $\begin{array}{l}\text { ESJ 10- } \\
\text { satisfação, } \\
\text { últimas 4 semanas }\end{array}$ & $\begin{array}{l}\text { EAS } \\
\text { Lazer }\end{array}$ \\
\hline & & & $-0,590$ \\
ESJ $10^{\mathrm{b}}$ & 0,510 & - & $\mathrm{p}<0,001$ \\
$\mathrm{n}=50$ & $\mathrm{p}<0,001$ & & - \\
EAS $^{\mathrm{c}}$ & & $-0,590$ & \\
lazer & $-0,526$ & $\mathrm{p}<0,001$ & \\
$\mathrm{n}=50$ & $\mathrm{p}<0,001$ & & \\
\hline
\end{tabular}

\footnotetext{
${ }^{\text {a }}$ Escala de Seguimento de Jogadores, questão 9

${ }^{\mathrm{b}}$ Escala de Seguimento de Jogadores, questão 10

${ }^{c}$ Escala de Adequação Social
} 


\subsection{Consistência interna}

O Alfa de Cronbach calculado com a ESJ de 120 jogadores patológicos foi de $\mathbf{0 , 8 3}$.

A tabela 24 apresenta os valores das correlações de cada questão com o escore total e o cálculo do Alfa excluindo-se cada uma das questões.

Tabela 24: Análise de confiabilidade das questões da Escala de Seguimento de Jogadores.

\begin{tabular}{lcc}
\hline Questão & $\begin{array}{c}\text { Correlação } \\
\text { item- total }\end{array}$ & $\begin{array}{l}\text { Alfa } \\
\text { excluindo-se } \\
\text { da ESJ }\end{array}$ \\
& & o item \\
\hline ESJ 1 & 0,66 & 0,80 \\
ESJ 2 & 0,65 & 0,80 \\
ESJ 3 & 0,71 & 0,79 \\
ESJ 4 & 0,66 & 0,79 \\
ESJ 5 & 0,56 & 0,81 \\
ESJ 6 & 0,53 & 0,81 \\
ESJ 7 & 0,44 & 0,82 \\
ESJ 8 & 0,09 & 0,85 \\
ESJ 9 & 0,47 & 0,82 \\
ESJ 10 & 0,44 & 0,82 \\
\hline
\end{tabular}

${ }^{a}$ Escala de Seguimento de Jogadores 


\subsection{Análise fatorial}

A análise fatorial das 10 questões da ESJ de 120 jogadores patológicos resultou em 3 fatores, como mostra a tabela 25. Esses fatores explicam 67,4\% da variância das respostas.

Tabela 25: Análise fatorial das questões da Escala de Seguimento de Jogadores.

\begin{tabular}{lrrr}
\hline & \multicolumn{3}{c}{ Componentes } \\
Itens da ESJ & \multicolumn{3}{c}{2} \\
\cline { 2 - 4 } & $\mathbf{0 , 7 4 3}$ & 0,291 & $-0,319$ \\
\hline ESJ 1 & $\mathbf{0 , 6 8 5}$ & 0,382 & $-0,343$ \\
ESJ 2 & $\mathbf{0 , 8 1 7}$ & 0,196 & $6,473 \mathrm{E}-02$ \\
ESJ 3 & $\mathbf{0 , 7 3 4}$ & 0,268 & $-0,130$ \\
ESJ 4 & $\mathbf{0 , 7 3 0}$ & $8,812 \mathrm{E}-02$ & 0,229 \\
ESJ 5 & $\mathbf{0 , 7 2 2}$ & $4,024 \mathrm{E}-02$ & 0,249 \\
ESJ 6 & 0,247 & $\mathbf{0 , 6 2 3}$ & $1,208 \mathrm{E}-03$ \\
ESJ 7 & $7,060 \mathrm{E}-02$ & 0,117 & $\mathbf{0 , 9 0 5}$ \\
ESJ 8 & 0,161 & $\mathbf{0 , 8 1 7}$ & $-7,337 \mathrm{E}-02$ \\
ESJ 9 & 0,110 & $\mathbf{0 , 8 4 0}$ & 0,234 \\
ESJ 10 & & &
\end{tabular}

Método de rotação Varimax 


\subsection{Sensibilidade à mudança no tempo}

A tabela 26 mostra os resultados do teste de Wilcoxon comparando-se os escores, das questões de 1 a 10 da ESJ, do momento inicial e do final de tratamento.

A tabela 27 mostra os resultados do teste de Wilcoxon para os escores da ASI e da TFB, comparando-se o momento inicial e o final de tratamento. 
Tabela 26: Teste de Wilcoxon para as questões de 1 a 10 da ESJ comparando-se os escores iniciais e finais.

\begin{tabular}{|c|c|c|c|c|}
\hline & $\begin{array}{l}\text { mediana } \\
\text { escore } \\
\text { inicial } \\
\end{array}$ & $\begin{array}{l}\text { mediana } \\
\text { escore } \\
\text { final }\end{array}$ & $\mathrm{Z}$ & $\mathrm{p}$ \\
\hline $\begin{array}{l}\mathrm{ESJ}^{\mathrm{a}} 1 \\
\mathrm{n}=50\end{array}$ & 2,5 & 5,0 & $-4,49$ & $<0,001$ \\
\hline $\begin{array}{l}\text { ESJ } 2 \\
n=50\end{array}$ & 3,0 & 5,0 & $-4,12$ & $<0,001$ \\
\hline $\begin{array}{l}\text { ESJ } 3 \\
n=50\end{array}$ & 3,0 & 5,0 & $-3,52$ & $<0,001$ \\
\hline $\begin{array}{l}\text { ESJ } 4 \\
n=50\end{array}$ & 2,0 & 3,5 & $-3,46$ & 0,001 \\
\hline $\begin{array}{l}\text { ESJ } 5 \\
\mathrm{n}=50\end{array}$ & 2,0 & 3,0 & $-3,30$ & 0,001 \\
\hline $\begin{array}{l}\text { ESJ } 6 \\
n=50\end{array}$ & 2,0 & 3,0 & $-4,29$ & $<0,001$ \\
\hline $\begin{array}{l}\text { ESJ } 7 \\
n=50\end{array}$ & 3,5 & 4,0 & $-2,10$ & 0,036 \\
\hline $\begin{array}{l}\text { ESJ } 8 \\
n=50\end{array}$ & 3,0 & 3,0 & $-0,02$ & 0,986 \\
\hline $\begin{array}{l}\text { ESJ } 9 \\
n=50\end{array}$ & 0,83 & 1,04 & $-2,12$ & 0,034 \\
\hline $\begin{array}{l}\text { ESJ } 10 \\
\mathrm{n}=50\end{array}$ & 4,0 & 4,0 & $-2,45$ & 0,014 \\
\hline
\end{tabular}

${ }^{\text {a }}$ Escala de Seguimento de Jogadores 
Tabela 27: Teste de Wilcoxon para as questões da ASI e TFB comparando -se os escores iniciais e finais.

\begin{tabular}{lcll}
$\begin{array}{l}\text { mediana } \\
\text { escore inicial }\end{array}$ & $\begin{array}{c}\text { mediana } \\
\text { escore final }\end{array}$ & $\mathrm{Z}$ & $\mathrm{p}$ \\
\hline 7,5 & 0,0 & $-4,71$
\end{tabular}

$\mathrm{ASI}^{\mathrm{a}}-$ dias de 7,5

0,0

$-4,71$

$<0,001$

jogo, últimos 30 dias

$\mathrm{n}=50$

ASI - dinheiro

700,00

0,00

$-3,51<0,001$

gasto em jogo,

últimos 30 dias

$\mathrm{n}=50$

ASI - dias de

30,0

11,0

$-1,92$

0,055

problemas devido

a jogo, últimos 30 dias

$\mathrm{n}=50$

ASI - grau de

4,0

2,0

$-4,23<0,001$

preocupação devido

a jogo, últimos 30 dias

$\mathrm{n}=50$

$\mathrm{TFB}^{\mathrm{b}}$ - dias de jogo,

6,0

0,0

$-4,33$

$<0,001$

últimos 30 dias

$\mathrm{n}=50$

TFB - horas gastas

9,25

0,0

$-3,72<0,001$

em jogo, últimos 30 dias

$\mathrm{n}=50$

TFB - dinheiro

662,50

0,0

$-3,87<0,001$

gasto em jogo,

últimos 30 dias

$\mathrm{n}=50$

${ }^{\mathrm{a}}$ Addiction Severity Index

b Timeline Follow-back 
A tabela 28 mostra os resultados do teste de Wilcoxon para o número de critérios do DSM-IV e os escores totais da G-SAS nos momentos inicial e final.

A tabela 29 mostra os resultados do teste de Wilcoxon para os escores parciais e total da EAS, comparando-se o momento inicial e o final de tratamento.

Tabela 28: Teste de Wilcoxon para os critérios do DSM-IV e escore da GSAS comparando-se os momentos inicial e final.

$\begin{array}{lll}\text { mediana } & \text { mediana } & \mathrm{Z} \\ \text { escore } & \text { escore } & \\ \text { inicial } & \text { final } & \end{array}$

\begin{tabular}{|c|c|c|c|c|}
\hline Critérios DSM-IV & 8 & 2,5 & 10,33 & $<$ \\
\hline \multicolumn{5}{|l|}{0,001} \\
\hline \multicolumn{5}{|l|}{$\mathrm{n}=50$} \\
\hline G-SAS $S^{b}$ & 30,0 & 17,0 & $-4,74$ & $<0,001$ \\
\hline \multicolumn{5}{|l|}{ escore total } \\
\hline $\mathrm{n}=50$ & & & & \\
\hline
\end{tabular}


Tabela 29: Teste de Wilcoxon para os escores da EAS comparando-se os momentos inicial e final.

\begin{tabular}{|c|c|c|c|c|}
\hline & $\begin{array}{l}\text { mediana } \\
\text { escore } \\
\text { inicial }\end{array}$ & $\begin{array}{l}\text { mediana } \\
\text { escore } \\
\text { final }\end{array}$ & $\mathrm{Z}$ & $\mathrm{p}$ \\
\hline $\begin{array}{l}\text { EAS } S^{a} \text { Trabalho } \\
n=46\end{array}$ & 1,83 & 1,67 & $-1,64$ & 0,100 \\
\hline $\begin{array}{l}\text { EAS - Lazer } \\
\mathrm{n}=49\end{array}$ & 2,78 & 2,27 & $-3,03$ & 0,002 \\
\hline $\begin{array}{l}\text { EAS - Família Total } \\
\mathrm{n}=49\end{array}$ & 2,4 & 2,22 & $-2,67$ & 0,007 \\
\hline $\begin{array}{l}\text { EAS - Econômico } \\
n=49\end{array}$ & 3,0 & 2,0 & $-2,30$ & 0,021 \\
\hline $\begin{array}{l}\text { EAS }- \text { Total } \\
n=49\end{array}$ & 2,58 & 2,17 & $-3,40$ & 0,001 \\
\hline
\end{tabular}

$\frac{\mathrm{n}=49}{{ }^{\mathrm{a}} \text { Escala de ajustamento social }}$ 


\section{FASE 2}

\section{METODOLOGIA}

A questão da ESJ sobre autonomia mostrou problemas quanto à consistência interna da escala. Ela apresentou baixa correlação com o total da escala no cálculo do Alfa de Cronbach e o Alfa total aumentou quando excluída esta questão, mostrando um prejuízo para a consistência interna da escala com sua presença. Além disso, também não mostrou sensibilidade à mudança no tempo. Essa questão foi, então, modificada, substituindo-a pela questão 54 da EAS, sobre vida financeira. Esta troca é justificada pois, em seu construto, a questão da EAS avalia a capacidade do indivíduo em suprir suas necessidades e de sua família, ou seja, autonomia, além de apresent ar altíssima correlação com o item original da ESJ na validade cruzada e sensibilidade à mudança. Os escores dessa questão foram adaptados para o padrão dos escores da ESJ, mantendo-se os cinco itens, porém com ordem invertida. Dessa forma, pontuações maiores indicam melhor ajustamento social.

A ESJ com essa nova estruturação da questão 8, sobre autonomia, foi avaliada nesta fase do estudo e é apresentada a seguir. 


\section{Escala de Seguimento de Jogadores}

As questões abaixo se referem ao jogo, ou outras áreas de sua vida que tenham sido afetadas por ele:

11. Com que freqüência você jogou nas últimas 4 semanas?
1) joguei diariamente
2) joguei em média mais de uma vez por semana
3) joguei em média uma vez por semana
4) joguei ocasionalmente, em média menos de uma vez por semana
5) não joguei

12. Nas últimas 4 semanas, da vez em que jogou por mais tempo, quanto tempo jogou?
1) joguei mais de 12 horas seguidas
2) joguei entre 8 e 12 horas seguidas
3) joguei entre 4 e 8 horas seguidas
4) joguei menos de 4 horas seguidas
5) não joguei

13. Nas últimas 4 semanas, quanto dinheiro você perdeu no jogo em relação à sua renda?

1) joguei sem ter renda própria, OU fiz empréstimos, desfiz-me de bem pessoal, economias, OU roubei (passei cheques sem fundos, falsifiquei cheques) para jogar ou pagar dívidas de jogo

2) possuo renda própria e perdi mais que o equivalente a minha renda

3) possuo renda própria e perdi o equivalente a minha renda ou mais que a metade desse valor

4) possuo renda própria e perdi menos que a metade desse valor

5) não tive perdas

14. Nas últimas 4 semanas, como esteve a sua vontade de jogar?

1) senti uma vontade irresistível de jogar

2) senti uma forte vontade de jogar, algumas vezes resistível, outras não

3) senti uma forte vontade de jogar, porém resistível na maior parte do tempo

4) senti uma leve vontade de jogar

5) não tive vontade de jogar

15. Como você tem se sentido em relação a suas dívidas nas últimas 4 semanas?

1) sinto-me extremamente pressionado, tenho jogado como forma de tentar obter dinheiro para saldar dívidas ou para aliviar as preocupações com elas

2) sinto-me extremamente pressionado, porém não joguei, ou se joguei não foi motivado pelas dívidas

3) tenho dívidas, mas elas não me preocupam no momento

4) não tenho dívidas 
16. Nas últimas 4 semanas, quanto problema emocional o jogo lhe causou (sofrimento, angústia, culpa, vergonha, constrangimento)?
1) extremo
2) muito
3) moderado
4) leve
5) nenhum

17. Nas últimas 4 semanas, como esteve o seu relacionamento familiar (com as pessoas com quem mora ou, se mora sozinho, com familiares com quem tem contato próximo)?

1) não tive contato com minha família

2) minha família me culpa e me critica muito $O U$ estive isolado a maior parte do tempo

3) minha família ainda desconfia de mim, mas às vezes sinto afeto e encorajamento por parte deles

4) sinto afeto e encorajamento por parte de minha família, mas às vezes eles ainda me criticam

5) sinto muito encorajamento por parte de minha família, eles agora confiam em mim e passamos bons momentos juntos

18. Nas últimas 4 semanasvocê teve dinheiro suficiente para suprir as suas necessidades e as de sua família?

1) tive sérias dificuldades

2) no geral não tive dinheiro suficiente e precisei pedir dinheiro emprestado

3) cerca de metade do tempo tive dificuldades financeiras, porém não precisei pedir dinheiro emprestado

4) no geral tive dinheiro suficiente, porém com pequenas dificuldades

5) tive dinheiro suficiente para as necessidades básicas 
19. Como você tem ocupado seu tempo livre nas últimas 4 semanas? Utilize os números abaixo para marcar o número de vezes que realizou cada uma das atividades descritas.

número de vezes

$\begin{aligned} & \text { A tividades Esportivas } \\ & \text { em academias ou clubes } \\ & \mathbf{4} \text { ou + }\end{aligned}$
$\begin{aligned} & \text { em ambiente externo, como corridas ou } \\ & \text { caminhadas }\end{aligned}$
$\begin{aligned} & \text { joguei futebol ou outros esportes coletivos } \\ & \text { outras. Especifique: }\end{aligned}$

20. Qual foi a sua satisfação em realizar as atividades acima?
1) Nenhuma, ou não fiz nada
2) Muito pouca satisfação
3) Pouca satisfação
4) Razoável satisfação
5) Muita satisfação 


\subsection{Consistência interna}

Foram utilizados os dados dos 120 pacientes que procuraram tratamento no AMJO. Novo Alfa de Cronbach foi calculado.

\subsection{Análise fatorial}

Foi feita nova análise fatorial utilizando-se rotação Varimax para examinar os itens nos fatores encontrados.

\subsection{Comparação entre gêneros}

Foi feita comparação entre gêneros com as questões da ESJ, nos momentos inicial e final, utilizando o Mann-Whitney (teste não paramétrico para comparação de duas amostras, semelhante ao teste t). 


\section{RESULTADOS}

\subsection{Consistência interna}

O alfa de Cronbach calculado com a substituição da questão sobre autonomia foi 0,86 .

A tabela 30 apresenta o valor da correlação de cada questão com o escore total e o Alfa excluindo-se cada questão.

Tabela 30: Análise de confiabilidade das questões da Escala de Seguimento de Jogadores após reestruturação.

\begin{tabular}{lcc}
\hline Questão & $\begin{array}{c}\text { Correlação } \\
\text { item- total }\end{array}$ & $\begin{array}{c}\text { Alfa excluindo-se } \\
\text { da ESJ }{ }^{\text {a }}\end{array}$ \\
\hline ESJ 1 & 0,67 & 0,83 \\
ESJ 2 & 0,69 & 0,83 \\
ESJ 3 & 0,71 & 0,83 \\
ESJ 4 & 0,65 & 0,83 \\
ESJ 5 & 0,59 & 0,84 \\
ESJ 6 & 0,55 & 0,84 \\
ESJ 7 & 0,43 & 0,85 \\
ESJ 8 & 0,49 & 0,85 \\
ESJ 9 & 0,42 & 0,85 \\
ESJ 10 & 0,49 & 0,85 \\
\hline
\end{tabular}

${ }^{a}$ Escala de Seguimento de Jogadores 


\subsection{Análise fatorial}

A análise fatorial das 10 questões da ESJ de 120 jogadores patológicos resultou em 3 fatores, como mostra a tabela 31. Esses fatores explicam $68,2 \%$ da variância das respostas.

Tabela 31: Análise fatorial das questões da Escala de Seguimento de Jogadores após reestruturação.

\begin{tabular}{lrrr}
\hline Itens da & \multicolumn{3}{c}{ Componentes } \\
\cline { 2 - 4 } ESJ & \multicolumn{1}{c}{1} & \multicolumn{1}{c}{3} \\
ESJ 1 & $\mathbf{0 , 8 6 8}$ & 0,132 & 0,178 \\
ESJ 2 & $\mathbf{0 , 7 4 3}$ & 0,232 & 0,291 \\
ESJ 3 & $\mathbf{0 , 7 0 4}$ & 0,447 & 0.119 \\
ESJ 4 & $\mathbf{0 , 7 6 3}$ & 0,230 & 0,183 \\
ESJ 5 & 0,319 & $\mathbf{0 , 7 7 1}$ & $9,125 \mathrm{E}-02$ \\
ESJ 6 & 0,387 & $\mathbf{0 , 6 4 6}$ & $3,774 \mathrm{E}-02$ \\
ESJ 7 & 0,344 & $1,501 \mathrm{E}-02$ & $\mathbf{0 , 5 9 4}$ \\
ESJ 8 & $5,576 \mathrm{E}-02$ & $\mathbf{0 , 8 3 7}$ & 0,228 \\
ESJ 9 & 0,145 & 0,189 & $\mathbf{0 , 8 1 2}$ \\
ESJ 10 & 0,103 & 0,128 & $\mathbf{0 , 8 4 4}$ \\
\hline
\end{tabular}

Método de rotação Varimax 


\subsection{Comparação entre gêneros}

Não foram encontradas diferenças entre gêneros com as questões da ESJ nos dois momentos analisados. 


\section{DISCUSSÃO}

\subsection{Perfil sócio-demográfico, características clínicas e comparação entre gêneros}

As características sócio-demográficas encontradas nesse estudo são semelhantes a amostras de estudos prévios realizados no AMJO (Tavares et al, 2003; Fuentes, 2004; Martins et al, 2004). Esses pesquisadores encontraram dados muito próximos dos achados neste estudo: idade média ao redor de 40 anos, maioria caucasianos (mais de 80\%), maioria casados e empregados, tempo médio de educação formal acima de 11 anos. Essas semelhanças mostram um perfil estável ao longo do tempo da população de pacientes que procura tratamento no AMJO.

Foram encontradas diferenças significativas quanto à idade de início de jogo, intervalo de jogo social e intervalo total entre a idade de início de jogo e a idade de procura de tratamento. As mulheres apresentaram início de jogo mais tardio e progressão mais rápida para jogo problema, uma ação específica da variável gênero que se observou em Jogo Patológico e algumas dependências químicas (álcool e derivados de ópio - Tavares et al, 2003), fenômeno denominado telescoping effect.

As mulheres mostraram maior dificuldade em se manter abstinentes após a progressão para jogo problema, como mostrado pela diferença significativa entre as médias dos períodos máximos de abstinência $(\mathrm{p}=0,004)$.

A grande maioria dos jogadores aposta em jogos eletrônicos (90\%), sem diferença entre os gêneros, confirmando a preferência dessa população por esse tipo 
de jogo de azar considerado de maior risco para desenvolvimento de jogo patológico. Isto se explica pelo curto intervalo de tempo entre a aposta e o resultado e a característica intermitente e aleatória das premiações como fortes reforçadores desse comportamento (Tavares et al, 2003).

As jogadoras apostam mais do que os homens em bingo de cartela (diferença com $p=0,044$ ) e os jogadores são mais prevalentes entre os apostadores de jogos tradicionais como baralho, cartas, loteria e jogo do bicho (diferença com $\mathrm{p}<$ 0,001). Essas diferenças podem ser explicadas pelo contexto social desses jogos no Brasil. Os chamados jogos tradicionais estão presentes a mais tempo em nosso país e vêm de uma época em que não havia boa aceitação de mulheres nesses ambientes, sendo comportamento restrito aos homens. A partir da década de 90, com a legalização e grande expansão das casas de bingo no Brasil, essa modalidade de jogo tornou-se muito difundida como forma de lazer e passou a ser freqüentada por homens e mulheres. As casas de bingo tornaram-se locais de encontro social e divertimento aceitos pela sociedade. O jogo de bingo em cartela é mais preferido por mulheres que freqüentam as casas de bingo como forma de socialização, pois tem intervalo mais longo entre a aposta e o resultado, possibilitando maior tempo de jogo.

Foi encontrada diferença entre gêneros quanto aos comportamentos de risco. Tentativa de suicídio prévia foi mais freqüente entre mulheres $(42 \%)$ do que entre os homens (4\%), com $\mathrm{p}=0,005$. As taxas de prevalência desses comportamentos de risco e taxa de tentativa de suicídio significativamente maior entre mulheres jogadoras encontradas neste estudo confirmam os achados do estudo de Martins e colaboradores, sobre Jogo Patológico, gênero e comportamentos de risco, realizado nesta mesma população (Martins et al, 2004). 


\subsection{Confiabilidade da ESJ}

As questões avaliadas para confiabilidade inter-juízes sobre frequiência de jogo, tempo gasto em jogo, dinheiro gasto em jogo, autonomia e freqüência de lazer apresentaram índices de Kappa variando entre considerável e moderado (0,214 e 0,486) com boa significância estatística em todas as questões (valores de $\mathrm{p}<\mathrm{ou}=$ 0,001). A questão sobre relacionamentos familiares apresentou confiabilidade superficial ( Kappa $=0,170 \mathrm{com} \mathrm{p}=0,039)$, mostrando uma fragilidade desta questão. A boa confiabilidade da escala no formato entrevista da primeira versão foi mantida na segunda versão com formato de auto-preenchimento.

\subsection{Validação cruzada da ESJ}

As questões da ESJ de 1 a 5, sobre atividade de jogo (frequiência de jogo, tempo gasto em jogo, dinheiro gasto, avidez e dívidas) correlacionaram-se muito bem com todas as escalas de referência. As questões da ASI-Jogo mostraram alta correlação com a TFB ( $\mathrm{p}<0,001)$, compatível com os achados de Petry em seu estudo psicométrico sobre a ASI-Jogo (Petry, 2003), sugerindo que a consistência psicométrica dos originais foi mantida nas versões em português. Essas três escalas tiveram alta correlação entre si (todas com $\mathrm{p}<0,001$ ), mostrando a validade da ESJ, no formato de auto-preenchimento, comparando-a com duas entrevistas já validadas e reconhecidas para jogadores patológicos.

A questão sobre avidez correlacionou-se muito bem com o escore total da GSAS e individualmente com cada questão, exceto com as questões 11 e 12. Essas duas 
questões não abordam avidez, mas sofrimento emocional e problemas causados por jogo, explicando a baixa correlação.

As questões de 1 a 3 da escala para informante colateral (freqüência de jogo, tempo gasto em jogo e dinheiro gasto) também mostraram correlações significativas (todas com $\mathrm{p}<0,05$ ) coma ESJ, com a ASI-Jogo, com a TFB e com a EAS no subitem Situação Econômica. As boas correlações mostram a validade da escala para informante colateral nesses itens e a validade das informações prestadas pelos jogadores.

A questão 6, sobre sofrimento emocional, mostrou alta correlação com a questão da ASI-jogo sobre dias de preocupação com jogo e com a .questão 11 da GSAS na qual foi inspirada $(\mathrm{p}<0,001)$.

A questão sobre relacionamentos familiares da ESJ mostrou correlação significativa com o escore Família Total da EAS no início de tratamento, mas não manteve correlação significativa no segundo momento, ao final de tratamento. No estudo anterior sobre a primeira versão da ESJ no formato de entrevista semiestruturada, o item Relações Familiares também apresentou controvérsias. O mesmo foi criticado pelos especialistas consultados por abordar conceitos díspares como: agressão, relacionamentos inter-pessoais, isolamento e apoio. A segunda versão do mesmo quesito para o formato de auto-preenchimento foi conceitualmente simplificada. As opções de resposta representam um continuum que oscila entre ausência de encorajamento e atitudes punitivas, até muito encorajamento e nenhuma punição. Embora as apresentações desse quesito, na primeira e na segunda versão da ESJ, apresentem boa correlação com os demais itens da escala, a validade externa do item foi apenas parcialmente confirmada na validação cruzada investigada para o formato de auto-preenchimento. Nossa impressão é que relações familiares talvez 
sejam por demais complexas para serem corretamente apreendidas por apenas uma questão e que talvez encorajamento e punição sejam duas funções familiares independentes que coexistam em família de jogadores. Com efeito, há inúmeros relatos das atitudes ambíguas dessas famílias em relação ao problema do familiar afetado. Talvez uma solução seja o desmembramento desse quesito em duas, ou mais perguntas que avaliem separadamente as atitudes positivas e negativas da família em relação ao jogador.

Os escores sobre autonomia da questão 8 da ESJ correlacionaram-se significativamente com os escores da EAS dos sub-itens Trabalho e Situação Econômica. A correlação mais forte com o sub-item Situação Econômica pode ser explicado pela maior semelhança semântica entre essas questões, abordando o quesito autonomia. A escala correspondente para informante colateral correlacionou-se muito bem com a ESJ $(p<0,001)$, teve boa correlação com a EAS Trabalho $(p=0,038)$, mas não mostrou correlação com a EAS Situação Econômica.

As questões sobre lazer (freqüência de lazer e satisfação) correlacionaram-se muito bem com a EAS Lazer e entre si $(\mathrm{p}<0,001)$. Os dados dos informantes colaterais sobre frequiência de atividade de lazer também se correlacionaram bem com a ESJ $(p=0,001)$ e tiveram boa correlação com a EAS $(p=.0,047)$.

A ESJ mostrou excelente validade cruzada quando comparada às escalas de referência, à exceção do quesito família que apresentou controvérsia. Nova reformulação dessa questão deverá ser feita com novo estudo psicométrico. 


\subsection{Consistência interna da ESJ}

A ESJ mostrou boa consistência interna com Alfa de Cronbach de 0,83. Porém, a questão 8, sobre autonomia, apresentou uma baixa correlação item vs. escala total $(0,09)$. Foi, também, a única questão cuja exclusão para o cálculo final resulta em aumento no Alfa $(0,85)$, comprometendo, portanto, a consistência interna da escala. Desde a primeira versão da ESJ o indicador Ocupação também não apresentou boa correlação com os demais itens da escala. Por esses motivos, o indicador autonomia foi substituído pela questão de referência para validação cruzada: a questão sobre vida financeira da EAS. A escolha desta questão foi baseada na similaridade do conceito avaliado e na alta correlação encontrada no cálculo da validade cruzada entre elas.

A questão da EAS é construída de forma mais simples baseando-se no conceito de autonomia como a capacidade do indivíduo em suprir suas necessidades básicas e de seus familiares. A questão da ESJ abrange, além desse conceito, a existência ou não de fonte de renda própria e a satisfação com o trabalho realizado. A presença de vários conceitos em uma mesma questão torna-a mais complexa e pode ser obstáculo para a compreensão desta pelo paciente, além de torná-la menos específica para o que se deseja avaliar. Falha em manter a simplicidade e objetividade da questão. Com efeito, após a substituição, o Alfa total aumentou para 0,86, a correlação deste item com o Alfa total foi semelhante aos demais itens da escala e sua exclusão não acarretou aumento do Alfa total. Esses resultados mostram uma melhor participação dessa questão no conjunto total da escala, melhorando a consistência interna. 


\subsection{Análise Fatorial}

A análise fatorial da estrutura inicial da ESJ determinou três fatores bem definidos. Após a reformulação da questão sobre autonomia, manteve-se a estrutura com três fatores, mas com modificação da participação das questões sobre dívidas e sofrimento emocional nos fatores. Um fator foi composto por todas as questões específicas sobre jogo (questões de um a quatro). Assim como na sua correspondente ASI-Jogo, todas as questões específicas sobre jogo (freqüência, tempo, dinheiro, e avidez) encontram-se em um único fator que envolve comportamentos e sintomas diretamente relacionados a jogo.

As questões sobre dívidas, sofrimento emocional e autonomia constituem um segundo fator. Elas se inter-relacionam pelo estresse emocional subjacente, gerado pela incapacidade financeira de suprir suas necessidades e de seus familiares e pela pressão sentida devido à presença de dívidas, que permeia essas três questões.

As duas questões sobre lazer encontram-se no mesmo fator, juntamente com a questão sobre família (questões sete, nove e dez), comportando-se como um único fator pela característica de socialização existente nelas.

Podemos nomear os fatores: (1) Fator Jogo, envolvendo os comportamentos específicos da patologia; (2) Fator de Auto-relacionamento, que inclui o relacionamento do indivíduo com suas dificuldades subjetivas; e (3) Fator de Socialização, abrangendo a relação do indivíduo com o meio social

Assim, os fatores formados são coerentes com os conceitos abordados nas questões. 


\subsection{Sensibilidade à mudança no tempo}

A ESJ apresentou diferenças significativas nos escores de suas questões quando comparados num período de seis meses, antes e após intervenção terapêutica (p variando de 0,034 a $<0,001$ ), mostrando-se sensível para detectar mudanças no tempo.

Os itens sobre comportamentos específicos de jogo (freqüência, tempo e dinheiro gasto) avaliados pela ASI-jogo e pela TFB também mostraram mudança significativa nesse intervalo de tempo, confirmando a propriedade psicométrica da versão em português da ASI e as diferenças significativas encontradas nos itens da ESJ (questões 1, 2 e 3). A diferença encontrada no número de critérios diagnósticos do DSM -IV no intervalo de seis meses $(\mathrm{p}<0,001)$ reforça a sensibilidade à mudança encontrada na ESJ, mostrando mudança no comportamento de jogo.

Assim como a questão sobre avidez da ESJ, o escore total da GSAS também mostrou diferença significativa no tempo $(\mathrm{p}<0,001)$.

Os escores parciais da EAS sobre Família, Lazer e Situação econômica mostraram diferenças significativas no tempo (valores de $\mathrm{p}=0,005 ; 0,023 ; 0,002 \mathrm{e}$ 0,021, respectivamente). $\mathrm{O}$ escore total da EAS também mostrou diferença significativa no tempo $(\mathrm{p}=0,001)$.

Todas as escalas mostraram mudanças no tempo na mesma direção, apresentando um resultado coerente.

A ESJ mostrou-se uma escala confiável, com boa consistência interna, excelente validade cruzada com escalas de referência já reconhecidas, sensível à mudança no tempo, e suas questões se apresentam como fatores bem definidos de 
acordo com suas características. Além dessas excelentes propriedades psicométricas, também presentes na ASI-jogo, a ESJ possui vantagens em relação às escalas para jogadores já existentes. Ela abrange não apenas sintomas específicos de jogo, mas também áreas de funcionamento impactadas por ele. A pressão pelas dívidas, as características dos relacionamentos familiares, a autonomia financeira e as ações de socialização e de entretenimento obtidas com o lazer podem interferir no comportamento de jogo. Estudos futuros realizados com a ESJ podem ajudar a esclarecer o papel deles no seu relacionamento com o comportamento de jogo.

A ESJ também é uma escala rápida e de auto-preenchimento, portanto dispensa entrevistador e treinamento para sua aplicação, poupando tempo e investimento para os serviços de saúde e profissionais, e evita o desgaste do paciente que não precisa se submeter a entrevistas que se alongam no tempo. Isto facilita seu uso com maior frequiência e a aplicação em número maior de indivíduos. Também poderia ser realizada como entrevista por telefone possibilitando a avaliação à distância. Pela sua praticidade, pode ser facilmente conjugada com outras medidas de avaliação mais específicas para tipos de tratamento diferentes para jogadores, sem onerar o conjunto total da avaliação e ainda fornecendo uma medida geral sobre jogo e sintomas associados.

A ESJ encontra-se pronta para uso clínico. Contudo, ela pode ainda ser aprimorada. A questão sobre relacionamentos familiares mostrou certa fragilidade pois teve validade cruzada com a EAS, sua escala de referência, parcialmente confirmada e apresentou fraca confiabilidade. Ainda assim, decidiu-se por mantê-la na escala, pois sua participação na consistência interna e na formação dos fatores da ESJ mostraram um bom relacionamento com as demais questões, mantendo a harmonia do conjunto. Entretanto, devem-se rever os conceitos envolvidos no seu 
construto e a possibilidade de desdobrá-la em duas ou mais questões. Talvez atitudes de punição, crítica e apoio, presentes na questão atual, não sejam as únicas envolvidas nos relacionamentos familiares que tenham importância para o comportamento do jogador. Talvez a capacidade de comunicação entre os indivíduos da família, a clareza das regras de funcionamento entre eles e o sentir-se amado pelos seus familiares também possam contribuir para o desenvolvimento e manutenção desse comportamento. As características do funcionamento de famílias de jogadores é tema de estudo em andamento realizado por profissional da equipe do AMJO e seus resultados poderão contribuir para a melhor compreensão dessas relações tão complexas (Mazzoleni, 2006). O trabalho de reestruturação da questão sobre relacionamentos familiares encontra-se em andamento e resultados de novas avaliações poderão ser vistos em breve. 


\section{CONCLUSÃO}

Frente aos resultados obtidos e à discussão anterior, as principais conclusões desse estudo são:

- A ESJ mostrou boa confiabilidade, boa consistência interna e suas questões bem definidas em três fatores: Fator Jogo, Fator de Auto-relacionamento e Fator Socialização.

- Em sua versão de auto-preenchimento, a ESJ apresentou boa correlação com as escalas de referência, mostrando sua validade cruzada.

- A ESJ mostrou-se sensível à mudança no tempo, seguindo seu propósito de avaliar jogadores em tratamento.

- A questão sobre relacionamentos familiares apresentou-se frágil, pois teve sua validade cruzada parcialmente confirmada e fraca confiabilidade. Foi mantida na escala por contribuir com a harmonia do conjunto nas demais testagens psicométricas realizadas.

- A ESJ encontra-se pronta para uso clínico. 
ANEXO - Escala de Seguimento de Jogadores - $1^{\text {a }}$ versão

AMJO - AMBULATÓRIO DO JOGO PATOLÓGICO E OUTROS TRANSTORNOS DO IMPULSO

INSTITUTO DE PSIQUIATRIA - HOSPITAL DAS CLÍNICAS - FMUSP

ESCALA DE SEGUIMENTO DE JOGADORES PATOLÓGICOS

\begin{tabular}{|c|c|c|c|c|c|}
\hline $\begin{array}{l}\mathbf{N} \\
\mathbf{O}\end{array}$ & $\begin{array}{l}\text { ATIVIDADE } \\
\text { JOGO }\end{array}$ & OCUPAÇÃO & $\begin{array}{c}\text { RELAÇÕES } \\
\text { FAMILIARES }\end{array}$ & LAZER & J.A. \\
\hline $\mathbf{T}$ & $\begin{array}{l}\text { O Sr. (a) jogou nas últim as } 4 \\
\text { semanas? }\end{array}$ & $\begin{array}{l}\text { Como está o seu trabalho, } \\
\text { emprego? }\end{array}$ & $\begin{array}{l}\text { Com quem você mora? } \\
\text { (últimas } 4 \text { semanas) }\end{array}$ & $\begin{array}{l}\text { Como você ocupa seu tempo livre? } \\
\text { (últimas } 4 \text { semanas) }\end{array}$ & Esta freqüentando o J.A.? \\
\hline $\mathbf{1}$ & $\begin{array}{l}\text { Jogou diariamente ou nos dias } \\
\text { que jogou, jogou por mais de } 12 \\
\text { horas }\end{array}$ & $\begin{array}{l}\text { Não está trabalhando, } \\
\text { abandonou as atividades } \\
\text { profissionais ou perdeu o } \\
\text { emprego }\end{array}$ & Não tem moradia & O passatempo principal é o jogo & $\begin{array}{l}\text { Não conhece e nunca foi ao } \\
\text { J.A. }\end{array}$ \\
\hline 2 & $\begin{array}{l}\text { Joga em média mais que } 1 \mathrm{x} \text { por } \\
\text { semana ou quando jogou, jogou } \\
\text { em média de } 8 \text { a } 12 \text { horas por } \\
\text { vez }\end{array}$ & $\begin{array}{l}\text { As atividades e/ou sustento } \\
\text { passaram para a } \\
\text { responsabilidade de outra } \\
\text { pessoa da família }\end{array}$ & $\begin{array}{l}\text { Mora com os familiares, com } \\
\text { agressões físicas }\end{array}$ & $\begin{array}{l}\text { Atividades de lazer somente quando é } \\
\text { estimulado(a) pelos outros }\end{array}$ & $\begin{array}{l}\text { Compareceu a pelo menos } 1 \\
\text { reunião do J.A. }\end{array}$ \\
\hline 3 & $\begin{array}{l}\text { Jogou em média } 1 \text { vez por } \\
\text { semana ou quando jogou, jogou } \\
\text { em média mais que } 4 \text { horas por } \\
\text { vez }\end{array}$ & Atividade irregular & $\begin{array}{l}\text { Mora com os familiares, mas em } \\
\text { situação de isolamento }\end{array}$ & Atividades de rotina & $\begin{array}{l}\text { Compareceu a mais de } 1 \\
\text { reunião, porém não esta } \\
\text { freqüentando regularmente }\end{array}$ \\
\hline 4 & $\begin{array}{l}\text { Jogou ocasionalmente, em } \\
\text { média menos que } 1 \text { vez por } \\
\text { semana e quando jogou, jogou } \\
\text { em média menos que } 4 \text { horas }\end{array}$ & $\begin{array}{l}\text { Atividade regular, porém com } \\
\text { dificuldade para a realização } \\
\text { das mesmas }\end{array}$ & $\begin{array}{l}\text { Mora com os familiares, com } \\
\text { agressões verbais }\end{array}$ & Atividade gratificante esporádica & $\begin{array}{l}\text { Frequenta regularmente } 1 \mathrm{x} \\
\text { por semana }\end{array}$ \\
\hline 5 & Abstinência & Trabalho estável & Situação familiar estável & Atividade gratificante regular & $\begin{array}{l}\text { Frequenta é membro ativo e } \\
\text { participa da organização das } \\
\text { atividades do J.A. }\end{array}$ \\
\hline
\end{tabular}




\section{Referências Bibliográficas}

Almeida Filho N, Santana VS, Mari JJ. Princípios de epidemiologia para profissionais de saúde mental. Brasília, Centro de Documentação do Ministério da Saúde, 1989.

American Psychiatric Association. Diagnostic and statistical manual of mental disorders, Third edition. Washington, DC; 1980.

American Psuchiatric Association. Diagnostic and statistical manual of mental disorders. Third edition Revised. Washington, DC; 1987.

American Psychiatric Association. Diagnostic and Statistical Manual of Mental Disorders, Fourth edition. Washington, DC; 1994.

Andrade AG, Bernik MA, Brunfentriker P, Negro Jr. Dados de confiabilidade sobre uma entrevista semi-estruturada para avaliação de tratamento: Escala de Severidade de Alcoolismo (ESA). Revista da Associação Brasileira de Psiquiatria - Asociación de La América Latina. 1988; Vol. 10, pp 1-4.

Armstrong BK, White E, Saracci R. Principles of exposure measurement in epidemiology. New York, Tokio, Oxford University Press, Oxford, 1994. 
Bartko JJ. The intraclass correlation coefficient as a measure of reliability. Psychol Rep 1966; 19:3-11.

Beconia E. Prevalence surveys of problem and pathological gambling in Europe: The cases of Germany, Holland and Spain. J Gamb Studies. 1996; 12:179-192.

Blanco C, Moreyra P, Nunes EV, Sáiz-Ruiz J, Ibáñes A. Pathological gambling: addiction or compulsion? Seminars in Clinical Neuropsychiatry. 2001; 6(3):167-176.

Bush AB. Validity, reliability and other key concepts in outcome assessment and services research. In: IsHak WW, Burt T, Sederer LI (Eds.). Outcome measurement in psychiatry: a critical review, first edition, American Psychiatric Publishing, New York, 2002; pp. 3555.

Castro V, Fuentes D, Tavares H. The Gambling Follow-up Scale: Development and reliability testing of a scale for pathological gamblers under treatment. Can J Psychiatry. $2005 ; 50(2): 167-172$.

Classificação Internacional de Doenças. Classificação dos Transtornos Mentais e de Comportamento: Descrições Clínicas e Diretrizes Diagnósticas. Coord Organização Mundial da Saúde, trad. Dorgival Caetano, Porto Alegre, Artes Médicas, 1993. 
Cohen JA. A coefficient of agreement for nominal scales. Ed Psychol Meas 1960; 20:3746.

Cooper, P, Osborn M, Gath D, Feggetter G. Evaluation of a modified self-report measure of social adjustment. Br J Psychiatry. 1982. 141:68-75.

DeCaria CM, Hollander E, Grossman R, Wong CM, Mosovich AS, Cherkasky S. Diagnosis, neurobiology and treatment of pathological gambling. J Clin Psychiatry. 1996; 57 (suppl 8):80-84.

DeCaria C. M., Hollander E., Grossman R., Wong C. M., Mosovich A. S., Cherkasky S. Diagnosis, neurobiology and treatment of pathological gambling. J Clin Psychiatry. 1996; 57 (suppl 8), 80-84.

DeCaria CM, Hollander E, Begaz T, Schmeidler J, Wong C, Cartwright C, and others. Reliability and validity of a pathological gambling modification of the Yale-Brown Obsessive-Compulsive Scale (PG-YBOCS): preliminary findings. Paper presented at the Third International Obsessive-Compulsive Disorders Conference; 1998; Madeira (Portugal)

Dostoiéviski F. Um jogador: apontamentos de um homem moço. Trad. Boris Schnaiderman - São Paulo: Ed. 34, 2004. 
Dube SR, Anda RF, Felitti VJ, Chapman DP, Williamson DF, Giles WH. Childhood abuse, household dysfunction, and the risk of attempted suicide throughout the life span: findings from the adverse childhood experiences studies. J Am Med Assoc. 2001; 286 (24), 3089-3096.

Echebúria E, Báez C, Fernández-Montalvo J. Comparative effectiveness of three therapeutic modalities in the psychological treatment of pathological gambling: long-term outcome. Behavioral and Cognitive Psychotherapy. 1996; 24:51-72.

Ellis BB, Minsel B, Becker P. Evaluation of attitude survey translations: an investigation using item response theory. Intern J Psychol. 1989; 24:665-84.

Flaherty JÁ, Gaviria FM, Pathack D, Mithell T, Wintrob R, Richman JA, Birz S. Development instruments for cross cultural psychiatry research. J Nerv Ment Dis. 1988; 176:257-63.

Fuentes D. Jogo Patológico: análise por neuroimagem, neuropsicológica e de personalidade. Tese de Doutorado apresentada ao Departamento de Psiquiatria da Faculdade de Medicina da Universidade de São Paulo. 2004.

Gorenstein C, Moreno RA, Bernik MA, Carvalho SC, Nicastri S, Cordas T, Camargo APP, Artes R, Andrade L. Validation of the Portuguese Version of the Social Adjustment Scale on Brazilian samples. J Affect Dis. 2002; 69(167-175). 
Grant JE, Kim SW, Potenza MN, Blanco C, Ibanez A, Stevens L, Hektner JM, Zaninelli R. Paroxetine treatment of pathological gambling: a multi-centre randomized controlled trial. Intern Clin Psychopharm. 2003; 18:243-249.

Grayson SN. Role of outcome measurement in Psychiatry. In: IsHak WW, Burt T, Sederer LI (Eds.). Outcome measurement in psychiatry: a critical review, first edition, American Psychiatric Publishing, New York, 2002; pp. 3-13.

Guy W. ECDEU Assessment Manual for psychopharmacology. US Department of Health, Education and Welfare publication (ADM) 76-338. Rockville, MD: National Institute of Mental Health. 1976; pp. 218-222.

Hodgins DC, el-Guebaly N, Armstrong S. Critcal dimensions of relapse in pathological gambling. Final Report. National Center for Responsible Gaming. 2001.

Hodgins DC, el-Guebaly $\mathrm{N}$ Retrospective and prospective reports of precipitants to relapse in pathological gambling. J Consult Clin Psychol. 2004; 72:72-80.

Hodgins DC, Currie S, El-Guebaly N, Peden N. Brief Motivational Treatment for Pathological Gambling: a 24-month follow-up. Psycology of Additive Behaviors. Setember 2004; 18(3):293-296. 
Hodgins DC. Implications of a brief intervention trial for problem gambling for future outcome research. J Gamb Studies. 2005 Spring;21(1):13-9.

Jacques C, Ladouceur R, Ferland F. Impact of availability on gambling: A longitudinal study. Can J Psychiatry. 2000; 45:810-815.

Kelsey JL, Whittemore AS, Evans AS, Thompson WD. Methods in observational epidemiology. New York, Oxford, Oxford University Press, 1996.

Kim SW, Grant JE, Adson DE, Shin YC. Double-blind Naltrexone and placebo comparison study in the treatment of pathological gambling. Biol Psychiatry. 2001; 49:914-921.

Kim SW, Grant JE, Adson DE, Shin YC, Zaninelli R. A double-blind placebo controlledstudy of the efficacy and safety of paroxetine in the treatment of pathological gambling. $J$ Clin Psychiatry. 2002; 63:501-507.

Ladouceur R. The prevalence of pathological gambling in Canadá. J Gamb Studies. 1996; 12:129-142.

Ladouceur R, Walker M. A cognitive perspective on gambling. In PM Salkovskis (Ed.), Trends in cognitive and behavioural therapies. New York: Wiley; 1996; pp 89-120. 
Ladouceur R, Sylvain C, Boutin C, Lachance S, Doucet C, Leblond J, and other. Cognitive treatment of pathological gambling. J Men Nerv Dis. 2001; 189:774-80.

Lesieur HR, Blume SB. The South Oaks gambling screen (SOGS): a new instrument for the identification of pathological gamblers. Am J Psychiatry. 1987; 144(9):1184-1188.

Lesieur HR, Blume SB. Evaluation of patients treated for pathological gambling in a combined alcohol, substance abuse and pathological gambling treatment unit using the Addiction Severity Index. Br J Addict. 1991; 86:1017 - 1028.

Lesieur HR, Blume SB. Modifying the Addiction Severity Index for use with pathological gamblers. Am J Addict. 1992; 1:240 - 247.

Lesieur HR, Blume SB. Revising the South Oaks Gambling Screen in different settings. J Gamb Behav . 1992; 9(3):213-219.

Martins SS, Tavares H, da Silva Lobo DS, Galetti AM, Gentil V. Pathological gambling, gender and risk taking behaviors. Addictive Behav . 2004; 29(6):1231-5.

Mazzoleni MHB. Medidas de estrutura e função de famílias de jogadores patológicos. Dissertação de mestrado em desenvolvimento pelo Departamento de Psiquiatria da Faculdade de Medicina da Universidade de São Paulo. 2006. 
McConaghy N, Blaszczynski A, Frankova A. Comparison of imaginal desensitization with other behavioural treatment of pathological gambling. A two-to-nine-year followup. Br J Psychiatry.

McDowell I, Newell C. Measuring health: a guide to rating scales and questionnaires. Second ed. New York, Oxford University Press, 1996.

McElroy SL, Hudson JI, Pope H Jr, Keck PE Jr, Aisley HG. The DSM-III impulse control disorders not elsewhere classified: clinical characteristics and relationship to other psychiatric disorders. Am J Psychiatric. 1992, Mar; 149(3):318-27.

McLellan AT, Luborsky L, Cacciola J, Griffith J, Evans F, Barr HL, O’Brian CP. New data from the Addiction Severity Index: Reliability and validity in three centers. $J$ Nerv Ment Dis. 1985; 173:412 - 423.

McLellan AT, Kushner H, Metzger D, Peters R, Smith L, Grissom G, Pettinati H, Argeriou M. The fifth edition of the addiction severity index. J Subst Abuse Treatment . 1992; 9:199-213.

Menezes PR, Nascimento AF. Validade e confiabilidade das escalas de avaliação em psiquiatria. In: In: Gorenstein C, Andrade LHSG, Zuarde AW (Eds). Escalas de avaliação clínica em psiquiatria e psicofarmacologia. São Paulo, Lemos-Editorial, 2000; pp 23-28. 
Nevo B. Face validity revisited. J Ed Meas, 1985; 22: 287-93.

Nunnaly J, Bernstein I. Psychometric Theory. New York, McGraw-Hill, 1994.

Oakley-Browne MA, Adams P, Mobberley PM. Intervensions for pathological gambling. Cochrane Database Syst Rev.2000; 2:CD001521.

Oliveira MPMT. Jogo Patológico: um estudo sobre jogadores de bingo, videopoker e jockey club. Dissertação de mestrado apresentada ao Instituto de Psicologia da Universidade de São Paulo. 1997.

Oliveira MPMT, Silva MT. Pathological and nonpathological gamblers: a survey in gambling settings. Substance use \& misuse. 2000; 35(11):1573-83.

Oliveira MPMT, Silva MT. A comparison of horse-race, bingo, and video poker gamb lers in brazilian gambling settings. Journal of Gambling Studies. 2001; 17(2):137148.

Pasquali L. Princípios de elaboração de escalas psicológicas. In: Gorenstein C, Andrade LHSG, Zuarde AW (Eds). Escalas de avaliação clínica em psiquiatria e psicofarmacologia. São Paulo, Lemos-Editorial, 2000; pp15-21. 
Peck DF, Dean C. Measurement in psychiatry. In: Kendell RE, Zealleu AK (Eds.) Companion to psychiatry studies, third edition. Churchill Livingston, New York. 1983.

Petry NM, Armentano C. Prevalence, assessment and treatment of pathological gambling: A review. Psychiatry services. 1999; 50:1021-1027.

Petry NM. Gambling problems in substance abusers are associated with increased sexual risk behaviour. Addiction. 2000; 95(7): 1089-1110.

Petry NM. Substance abuse, pathological gambling and impulsiveness. Drug and Alcohol Dependence. 2001; 63:29-38.

Petry NM. Validity of a gambling scale for the Addiction Severity Index. J Nerv Ment Dis. 2003; 191:399-407.

Petry N. Stages of change in treatment-seeking pathological gamblers. J Consult Clin Psychol. 2005; 73(2):312-322

Potenza MN, Steinberg MA, McLaughlin SD, Wu R, Rounsaville BJ, O`Malley SS. Illegal behaviours in problem gambling: analysis of data from a gambling helpline. Journal of American Academy Psychiatry Law. 2000; 28(4):389-403.

Proimos J, DuRant RH, Pierce JD, Goodman E. Gambling and other risk behaviours among 8th to 12th grade students. Pediatrics. 1998; 102(2):e23. 
Shaffer HJ, Korn DA. Gambling and related mental disorders: a public health analysis. Annuals Rev Public Health. 2002; 23:171-212.

Sobell LC, Sobell MB. Timeline Follow-back: a technique for assessing self-report alcohol consumption. In R Litten, J Allen (Eds), Measuring alcohol consumption, Totowa, WJ: Humana Press. 1992; pp41-71.

Steel Z. \& Blaszczynski A. Impulsivity, personality disorders and pathological gambling severity. Addiction. 1998; 93 (6), 895-905.

Stinchfield R. Reliability, validity and classification accuracy of the South Oaks Gambling Screen (SOGS). Additive Behaviors. 2002, 27(1):1-19.

Sylvain C, Ladouceur R, Boisvert JM. Cognitive and behavioral treatment of pathological gambling: a controlled study. J Consult Clin Psychol. 1997: 65:727-32.

Tabachnick BG, Fidell LS. Using Multivariate Statistics. Third edition. Harper Collin College Publishers, Northridge, pp.132-134, 1996.

Tavares H., Zilberman M. L., Beites F. \& Gentil V. Gender differences in treatmentseeking gamblers. J Gamb Studies. 2001; 17 (2), 151-159. 
Tavares H, Zilberman ML, el-Guebaly N. Are there cognitive and behavioural approaches specific to the treatment of pathological gambling? Can J Psychiatric. 2003, Feb;48(1):22-7.

Tavares H, Martins SS, Lobo DS, Silveira CM, Gentil V, Hodgins DC. Factors at play in faster progression for female pathological gamblers: an exploratory analysis. J Clin Psychiatry. 2003; 64(4): 433-8.

Volberg RA. The prevalence and demographics of pathological gamblers: implications for public health. Am J Pub Health. 1994; 84:237-241.

Volberg RA. Prevalence studies in problem gambling in the United States. J Gamb Studies. 1996; 12:111-128.

Weinstock J, Whelan JP, \& Meyers AW. Behavioral assessment of gambling: an application of the Timeline Follow-back method. Psychological Assessment, 2004; 16, $72-80$.

Weissman MM, Bothwell S. Assessment of social adjustment by pacient self-report. Arch Gen Psychiatry. 1976; 33:1111-5. 
Weissman MM, Paykel ES, Siegel R, Klerman GL. Disocial role performance of depressed women: compariosons with a normal group. Am J Orthopsychiatry. 1971; $41: 390-405$

Weissman MM, Prusoff BA, Thompson WD, Haring PS, Myers JK. Social adjustment by self-report in a comunity sample and in psychiatric outpacients. J Nerv Ment Dis. 1978; $166: 317-26$.

Westphal JR, Johnson LJ, Stodghill S, Stevens L. Gambling in the South: implications for physicians. South Med J. 2000; 93(9):850-00.

Zimmerman M, Breen RB, Posternak MA. An open-label study of the citalopram in teh treatment of pathological gambling. J Clin Psychiatry. 2002; 63:44-8. 